Final Report

\title{
Advanced Biocatalytic Processing of Heterogeneous Lignocellulosic Feedstocks to a Platform Chemical Intermediate (Lactic acid Ester)
}

\author{
Award Number \\ DE-FC02-99CH11007 \\ Submitted by \\ Dr. Sharon Shoemaker, Principal Investigator \\ University of California, Davis \\ One Shields Ave. \\ Davis, CA 95616
}

\section{Project Team}

University of California Davis

Professor David Mills, Professor David Block, and Dr. Sharon Shoemaker (PI)

Mr. Jae-Han Kim, Dr. Hanshu Ding, Mr. Oliver de la Salle, and Dr. Elena Vlasenko

Argonne National Laboratory

Dr. Seth Snyder, Dr. James Frank (co-PI's)

Dr. Mark Donnelly, Dr. Ed St. Martin, and Dr. Rathin Datta

Industrial Partners

Vertec Biosolvents

BC International

TSS Consultants

Illinois Department of Commerce and Community Affairs 


\section{Table of Contents}

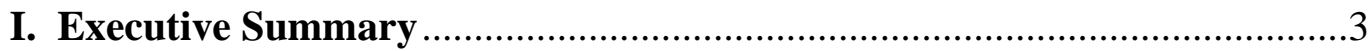

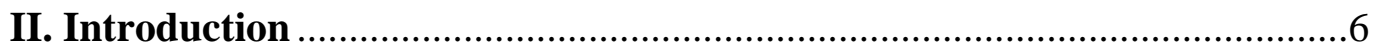

III. Project Goals, Tasks and Milestones ................................................

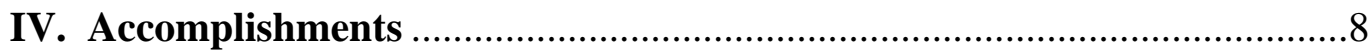

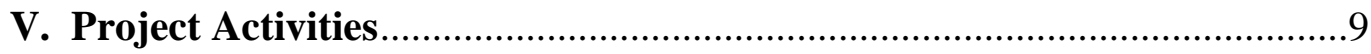

VI. Technology Transfer Activities..........................................................65

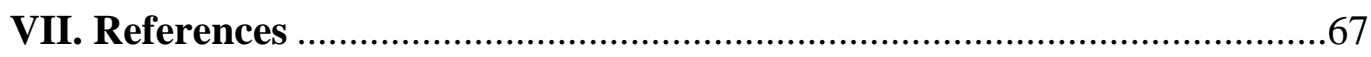

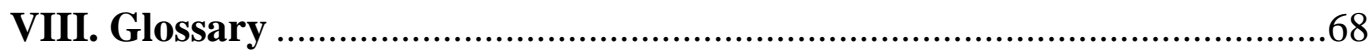

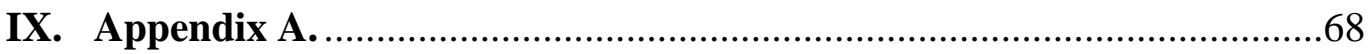




\section{Executive Summary}

The development of commercial bio-based processes and products derived from agricultural waste biomass has the potential for significant impact on the economy and security of our nation. Adding value, rather than disposing of the waste of agriculture, can solve an environmental problem and reduce our dependence on foreign sources of fossil fuel for production of chemicals, materials and fuels. This three-year multidisciplinary project focused on developing new microorganisms and a body of data to support a commercial bioprocess that utilizes waste biomass, such as rice straw, for the production of a higher value platform chemical intermediate, lactic acid ester. The overall process was divided into three steps: Feedstock bioconversion to mixed sugars, microbial fermentation to lactic acid, and purification and chemical conversion to a lactic ester.

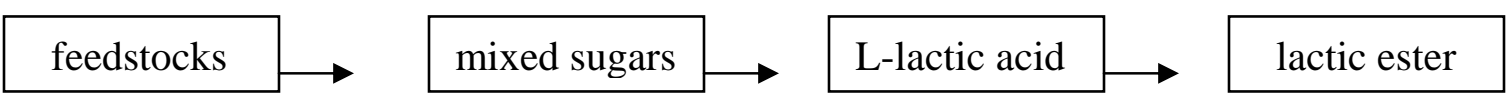

The project built upon a small existing commercial process that used a corn-derived single sugar (glucose) fermentation process to produce lactic acid, which was followed by a three-step conversion/separation process to produce lactic esters, such as ethyl lactic acid. Vertec Biosolvents (formerly called NTEC) joined our project to further its commercialization of lactic ester-based solvent blends.

The new features of this project were:

- Utilizing a complex biomass (lignocellulosic) feedstock;

- Developing microorganisms that can completely and simultaneously use the mixed sugars (both hexoses and pentoses);

- Developing a cost-effective fermentation process to produce primarily lactic acid from mixed sugars; and

- Improving the economics of the subsequent separation, derivatization and purification steps.

Rice straw was found to be of particular interest as a feedstock because it has the potential of being a low-cost source of sugars for fermentation, and because of a need to support the rice industry by finding new uses for straw. Furthermore, the availability and abundance of straw in concentrated areas, such as in northern California, where about 1.5 million tons are produced annually, and the demonstration that treatment of rice straw with mild acid followed by cellulase hydrolyzes its sugar-polymers to soluble sugars, supported its use as a low-cost sugar feedstock.

In addition, a focused parallel effort by DOE in partnership with commercial enzyme companies, resulted in reducing the cost of cellulases ten-fold, a necessary but insufficient achievement to bio-based commercialization of lignocellulosic feedstocks.

Three new microorganisms with the desired properties were isolated and developed in this project; a wild-type strain of Lactobacillus brevis (Lb. brevis), a naturally isolated carboncatabolite derepressed strain of Lactobacillus pentosus (Lb. pentosus); and a recombinant strain of Escherichia coli (E. coli). 
The two lactobacilli strains were found to simultaneously and completely utilize both hexoses (glucose) and pentoses (xylose and arabinose) to give L-lactic acid in high yield (1 to $2 \mathrm{mM}$ lactic acid from 1mM glucose). E. coli strain CSM5, a stable recombinant strain derived from CSM1, was able to convert a dilute mixture of hexoses and pentoses.

The following desired properties were found with the $L b$. strains:

- Natural lactic acid producing microorganisms;

- Simultaneous and complete utilization of mixed sugars without carbon catabolite repression;

- No inhibition by known inhibitors in the rice straw hydrolysate;

- Compatible in the presence of cellulases in a simultaneous saccharification mixed sugar fermentation (SSMSF); and

- Supports several modes of bio-processing (Batch, Fed-batch, SSMSF).

Demonstration and optimization of fermentation processes was achieved using fed-batch fermentation of rice straw. Using fed-batch SSMSF, the enzyme dosage and operational time was reduced in two ways: First, by removing feedback inhibition from cellobiose and glucose; and second, by not requiring additional enzyme with subsequent additions of rice straw. The elimination of acetate as a co-product from hexose was achieved with $L b$. pentosus, and a low cost culture medium containing corn steep liquor was demonstrated. The limiting factors influencing the yield of L-lactic was a low allowable maximum concentration of sugars due to insolubility of rice straw and the presence of silica in the fermentor. During the course of this project an older fermentor system was retrofitted with modern web-based process controls.

The feasibility of chemically converting the L-lactic acid to ethyl lactic acid was demonstrated in the two-step process developed by the project team at Argonne National Laboratory. Specifically, the lactic acid salt is concentrated by electrodialysis. If the lactic acid is present as an alkali salt, it is converted to the acid by water-splitting electrodialysis. The acid is esterified by an alcohol (typically bioethanol). This equilibrium is driven by water removal by pervaporation. In the more advanced technology, the fermentation is neutralized with ammonia to produce ammonium lactic acid. After concentration, the ammonium salt is converted directly to the lactic acid ester by “direct esterification”. In direct esterification, the ammonium salt is thermally cracked in the presence of the alcohol (typically bioethanol). The reactions are driven by efficient removal of both the water and the freed ammonia with pervaporation.

An overall economic, environmental and energy (3 E’s) evaluation was performed in collaboration with TSS Consultants. A comparison of corn, rice straw and fossil fuel feedstocks showed that rice straw had a neutral to positive impact in the $3 \mathrm{E}$ 's over the life cycle of a proposed process.

This project demonstrated the feasibility of a process for production of lactic esters from rice straw, a lignocellulosic feedstock, but commercialization requires further investment in process at commercial scale, and cellulase cost compatible with process needs. Microorganisms with desired properties were isolated and characterized for this purpose and Lactobaccilus pentosus is recommended as the microorganism of choice. Commercialization of lactic esters from dextrose 
derived from corn is being advanced by Vertec Biosolvents and Argonne National Laboratory in relationship with the Arthur Daniels Midland Company (Decatur, IL). Three students received their research training for their Ph.D. degree during the course of this project. Several events, publications, and oral and poster presentations resulted from this project. 


\section{Introduction}

The work under this subcontract builds upon the novel membrane-based technologies that enable the low-cost synthesis of ethyl lactic acid and other lactic acid esters from carbohydrate feedstocks being developed by the team at Argonne National Laboratory (ANL) and the feedstock and enzyme expertise being developed by the team at UC Davis.

\section{The Opportunity: \\ The lactic acid ester production technology would gain significant value if it could be integrated with utilization of low cost agricultural waste from California.}

Lactic acid esters have excellent solvent properties, are nontoxic (approved for food use), and are completely degradable. Thus, they have the potential to be a major "green" solvent to replace many of the toxic chlorinated solvents that are currently in use. They would have widespread use in industrial, commercial, and consumer applications. With the conventional technology, lactic acid esters could not be manufactured at a cost that would be competitive with petrochemically-derived solvents, but this major economic hurdle can now be overcome with the ANL technology. This innovative technology has won several major awards, which include The Presidential Green Chemistry Challenge Award, 1998 (sponsored by the EPA), and the Discover Technology Innovation Award, 1998 (for Environmental Technology). The technology has been patented by Argonne and licensed to Vertec Biosolvents (Downers Grove IL), which has collaborated with pilot-scale development. Partnering with Archer Daniels Midland, the team is evaluating installation of a commercial demonstration plant with a capacity of 2 million lb/yr. The goal is to develop large-scale, commercial plants of 100 million lb/yr capacity.

A lactic acid ester, such as ethyl lactic acid, is also a very versatile building-block molecule that can be used to derive a wide variety of chemical products. Using certain basic chemical and catalytic conversion processes on the lactic acid ester molecule can yield such products as degradable plastic polymers; three-carbon oxygenated chemicals, such as propylene glycol, acrylates, and propylene oxide; and specialty product derivatives. The aggregate volume and value of the platform of products that are derivable exceeds 7 billion lb/yr and $\$ 5$ billion, respectively, in the United States alone. The world market is estimated to be two-fold larger.

During the last seven years, the California Institute of Food and Agricultural Research (CIFAR) has been working closely with the California agricultural community and post-harvest companies to develop and transfer technologies that make them more competitive. In this regard, CIFAR has coordinated UC Davis faculty expertise in an attempt to solve environmental problems facing the industry, such as treating wastewater to reduce disposal costs, water use and energy consumption, finding new uses for rice straw to replace open-field burning, and in determining what, where, when and how waste is generated in the state. It is clear that the underutilized biomass and carbohydrate in California is highly concentrated so as to make it a meaningful, inexpensive feedstock for fermentation processing. CIFAR has developed processing capabilities, methods and a collection of strains and enzymes for use in the conversion of lignocellulosic biomass to yield inexpensive sugars.

The research team at Argonne National Laboratory (ANL) has developed novel membrane-based technologies that enable the low-cost synthesis of ethyl lactic acid and other lactic acid esters 
from carbohydrate feedstock. The innovative technologies overcame major technical hurdles of "cation" elimination, yield, conversion, and product purity. The new process, based on these technologies, will use approximately one-tenth of the energy of the conventional process, eliminate the production of waste salt, and will enable the industry to lower the future manufacturing costs of ethyl lactic acid in large-scale plants to the 30-35\$/lb range.

\section{Project Goals, Tasks and Milestones}

The overall goal is to develop the technology and data to support a commercial bioprocess utilizing waste agricultural feedstocks (mixed wood waste, rice straw, waste sugar streams, waste lactose) for the production of a higher value platform chemical intermediate, lactic acid ester.

A dual approach was taken in order to accomplish the goals and objectives; namely,

- To design feedstock mixtures based on available biomass and optimize for the current platform chemical intermediate, lactic acid ester, and

- To develop an organism that can utilize both glucose and xylose.

Project organization was through tasks and milestones. During the course of this three-year project some of the tasks and milestones stated below were modified from the initial statements, after discussions and approval by the DOE program director, Dr. Mark Paster.

Task 1. Selection, acquisition and characterization of biomass feedstocks.

\section{Milestone 1. Selected biomass feedstocks characterized.}

Task 2. Pretreatment and hydrolysis of biomass.

2.1 Pretreatment of biomass feedstocks

Milestone 2. Selected biomass feedstocks pretreated.

2.2 Develop advanced enzyme plan.

2.3 Acquire advanced cellulase-producing organisms

2.4 Develop enzyme production at bench-scale.

Milestone 3. Enzyme production at bench-scale developed.

Task 3. Microorganism development.

3.1 Selection, screening and mutagenesis of lactic acid-producing microorganisms on hydrolysates.

3.2 Screening and construction of robust strains.

Milestone 4. Lactic acid producing microorganisms developed.

Task 4. Fermentation process development.

Milestone 5. Lactic acid fermentation process developed.

Task 5. Technical interface with project teams \& protocol definition for analytical testing. 
Task 6. Develop new applications for ethyl lactic acid across all industrial sectors.

Task 7. Purification and esterification process development and validation.

\section{Milestone 6. Purification and esterification process to obtain ethyl lactic acid developed.}

Task 8. Process integration from biomass to ethyl lactic acid.

\section{Milestone 7: One kilogram of purified ethyl lactic acid produced using an integrated biomass-to-ethyl lactic acid process.}

Task 9. Process design and economic evaluations

Milestone 8. Process design and economic development evaluation.

Task 10. Assist in attaining the value of heterogeneous lignocellulosic feedstocks

\section{Accomplishments}

The overall goals stated above were accomplished. The primary feedstock selected for this project was rice straw. The microorganisms that were isolated and developed were shown to utilize simultaneously and completely both the hexoses (glucose) and pentoses (xylose, arabinose) present in rice straw and a several other biomass feedstocks. No inhibition was found with the selected microorganisms with acid-pretreated (unwashed) rice straw hydroysate. It is significant that the acid-treated rice straw did not have to be washed before use. The cellulase enzyme mixture was found to be stable in the presence of both the acid-pretreated rice straw hydroysate and the candidate strains.

The tasks and milestones were mostly accomplished with the following exceptions.

Milestone 5. Lactic acid fermentation process developed at a 3-4 L scale due to lack of larger fermentors. This changed to smaller scale demonstration as approved by Dr. Mark Paster.

Milestone 6. Purification and esterification process to obtain ethyl lactic acid developed. This was validated with using electrodialysis at small scale since sufficient equipment and funds were not available. More funds than predicted were spent on labor for microorganism development and contracting for the life-cycle assessment. This was approved by Dr. Mark Paster.

Milestone 7: One kilogram of purified ethyl lactic acid produced using an integrated biomass-toethyl lactic acid process. Similar reasons as stated for Milestone 6. The integrated process was validated at small scale as approved by Dr. Mark Paster. 


\section{Project Activities}

\section{Task 1. Selection, acquisition and characterization of biomass feedstocks.}

Four potential biomass feedstocks were considered for this project based on amount and yearround availability; namely, rice straw; wood waste (forest slash and thinnings); municipal solid waste (MSW); and pulp mill waste. Each feedstock was characterized and evaluated. Rice straw and wood waste were given special attention because they were selected as the feedstocks for other California Biomass projects (Gridley and Collins Pine projects). Rice straw was later chosen as the prime feedstock for this project, because it made sense with its abundance in concentrated regions of northern California, and because we could have large quantities of acidpretreated straw provided to us by BC International.

Approximately 20\% of the U.S. rice crop is produced in northern California giving an annual yield of 1.5 million tons of rice and a concomitant amount of straw. Traditionally the straw has been removed from the field by burning, but a law banning this practice was enacted in 2000 so that new uses for straw were being intensely pursued. In parallel with our studies, California rice growers are developing an infrastructure for collecting and storing straw and are supporting many research projects to find value-added use. Since rice straw consists of about $60 \%$ carbohydrate (by weight), it offered potential as a viable feedstock for fermentation.

The project team decided to select rice straw as the feedstock to pursue given the partnership with BC International where we could take advantage of their offer to supply us with acidpretreated rice straw, and involve us in their information on their partnerships with rice growers for supply.

\section{Task 2. Pretreatment and hydrolysis of biomass.}

\subsection{Pretreatment of biomass feedstocks.}

Rice straw was pretreated by BC International (BCI) using dilute sulfuric acid. About ten gallons of unwashed pretreated material containing 35\% solids was shipped to UC Davis in November 1999. Two other dilute-acid pretreated materials available at UC Davis include rice straw and MSW, both pretreated at NREL (Table 2.1).

It was shown, that the steam exploded- and the acid-pretreatments effectively removed hemicellulose from rice straw, providing high yields of fermentable sugars. The AFEXpretreatment was distinctly different from other pretreatments in that it did not significantly solubilize hemicellulose. All three pretreatment procedures substantially increased enzymatic digestibility of rice straw. Three commercial Trichoderma reesei-derived enzyme preparations: Cellulase 100L (Iogen), Spezyme CP (Genencor), and A1 (Fermtech) were more active on pretreated rice straw compared to others tested.

Conditions for hydrolysis of rice straw using Cellulase 100L were evaluated in more detail. The supplementation of this enzyme preparation with cellobiase (Novozyme 188) significantly improved the parameters of hydrolysis for the Swan- and the acid-pretreated materials, but did not affect the hydrolysis of the fiber-exploded, pretreated rice straw. 
Table 2.1. Pretreated lignocellulosic materials at UC Davis

\begin{tabular}{cccccc}
\hline Material & Glucan (\%) & $\begin{array}{c}\text { Non-glucose } \\
\text { polysaccharide } \\
(\%)\end{array}$ & $\begin{array}{c}\text { Amount } \\
\text { (gallons) }\end{array}$ & Solids (\%) & Received \\
\hline Rice straw* & & & 10 & 35 & $11 / 99$ \\
Rice & 45.1 & 1.5 & 3 & 30 & $08 / 95$ \\
straw** & 54.5 & 1.0 & 10 & 24 & $06 / 97$ \\
\hline MSW*** & 5.5 & &
\end{tabular}

* $\quad$ Pretreated at BCI using dilute sulfuric acid

** Pretreated at NREL in a high-solids, pilot scale (100-L) reactor. Conditions: Solids $10 \%$, sulfuric acid 0.8 $\mathrm{wt} \%, 160^{\circ} \mathrm{C}, 10 \mathrm{~min}$

*** Prepared at NREL by blending five different feedstocks, fir (35\% of dry weight), almond tree pruning (20\%), wheat straw (20\%), office waste paper (12.5\%), and newsprint (12.5\%), followed by hydrolysis with dilute sulfuric acid.

In addition to dilute-acid pretreatment, other processes are also being considered for pretreatment of rice straw. They include acid-catalyzed steam explosion and ammonia fiber explosion. Table 2.2 shows carbohydrate composition of pretreated rice straw samples that have been evaluated as a source of fermentable carbohydrate using hydrolysis with prescreened commercial enzyme preparations, products of Genencor International (USA), Novo (Denmark), Iogen (Canada) and Fermtech (Russia). Table 2.3 shows specific activities and protein content of the cellulases.

Table 2.2. Carbohydrate compositions of crude and pretreated rice straws (dry weight basis)

\begin{tabular}{ccccc}
\hline Component & Crude & $\begin{array}{c}\text { Steam } \\
\text { explosion } \\
\text { (SWAN) }\end{array}$ & $\begin{array}{c}\text { Acid } \\
\text { (NREL) }\end{array}$ & $\begin{array}{c}\text { AFEX } \\
\text { (Texas A\&M) }\end{array}$ \\
\hline Cellulose & 37.2 & 39.3 & 43.2 & 48.7 \\
Pectin & 3.1 & 1.7 & 1.1 & 2.0 \\
Hemicellulose & 26.1 & 9.5 & 3.4 & 23.3 \\
\hline $\begin{array}{c}\text { Total } \\
\text { carbohydrate }\end{array}$ & 66.4 & 49.5 & 47.8 & 74.0 \\
\hline SWAN, a company in Naperville, IL & & &
\end{tabular}

SWAN, a company in Naperville, IL 
Table 2.3. Specific activities and protein content of commercial cellulases*

\begin{tabular}{cccccc}
\hline Cellulase & $\begin{array}{c}\text { Filter } \\
\text { Protein } \\
\text { preparation }\end{array}$ & $\begin{array}{c}\text { paper } \\
\text { activity } \\
\text { (FPU/mg }\end{array}$ & $\begin{array}{c}\text { Viscometric } \\
\text { activity } \\
\text { (cP/min/mg) }\end{array}$ & $\begin{array}{c}\text { CMC-ase } \\
\text { activity } \\
\text { (IU/mg) }\end{array}$ & $\begin{array}{c}\text { Cellobiase } \\
\text { activity } \\
\text { (CBU/mg) }\end{array}$ \\
\hline Spezyme CP & 146 & 0.79 & 18420 & 11.6 & 0.11 \\
Celluclast 1.5L & 191 & 0.49 & 7929 & 4.99 & 0.02 \\
Novozyme 188 & 143 & 0.01 & 217.2 & 0.06 & 3.84 \\
Cellulase 100L & 147 & 0.89 & 20440 & 16.6 & 0.15 \\
T. reesei A1 & 168 & 0.59 & 13230 & 6.75 & 0.03 \\
T. reesei A1 (solid) & 45 & 0.55 & 9798 & 6.55 & 0.15 \\
Penicillium sp. B1 & 45 & 0.44 & 10210 & 7.25 & 0.33 \\
(solid) & 45 (\%) & & & & \\
\hline
\end{tabular}

The three pretreatment techniques were compared on a basis of a total yield and distribution of fermentable carbohydrates released by enzymatic hydrolysis (the highest possible substrate concentrations were used, $150 \mathrm{~g} / \mathrm{l}$ for the Swan- and the acid-, and $100 \mathrm{~g} / \mathrm{l}$ for the AFEXpretreated straw; enzyme loading of 6.7 Filter Paper Units (FPU) and 6.7 Cellobiase Units (CBU) per gram of dry straw was the same for all pretreated materials). A combined yield of monosaccharides produced by a pretreatment step and by enzymatic hydrolysis was found to be 46, 42, and $37 \mathrm{~g} / \mathrm{l}$ for the Swan-, the acid-, and the AFEX-pretreated rice straw, respectively (Table 2.4).

Table 2.4 Comparison of pretreatments on the basis of the combined yield of fermentable sugars produced by pretreatment and by 72-h enzymatic hydrolysis using combined enzyme preparation of Cellulase 100L and Novozyme 188

\begin{tabular}{cccc}
\hline & $\begin{array}{c}\text { Steam explosion } \\
\text { (Swan) }\end{array}$ & $\begin{array}{c}\text { Acid } \\
(\text { NREL })\end{array}$ & $\begin{array}{c}\text { AFEX (Texas } \\
\text { A\&M) }\end{array}$ \\
\hline Rice straw (g/L) & 150 & 150 & 100 \\
Enzyme loading (FPU/g + & $6.7+6.7$ & $6.7+6.7$ & $6.7+6.7$ \\
CBU/g) & 46 & 42 & 37 \\
Fermentable CHO (g/L) & 56 & 53 & 45 \\
CHO conversion (\%) & 5 & & \\
\hline
\end{tabular}




\subsection{Develop advanced enzyme plan.}

A plan was prepared for identifying, selecting and testing cellulase strains. Subtask 2.2 and 2.3 were carried out based on the plan.

Fungal strains/preparations were sought with the following properties:

- Contains complete cellulase system of CBH, EG, and BG

- Hyperproducing strains

- Expression is catabolite derepressed

- High $\beta$-glucosidase activity

- Produces cellulase on appropriate carbon source (solid and liquid)

The NREL cost sensitivity analysis data (Table 2.5) was used for the parameter for the economical cellulose-producing strain selection.

Table 2.5. Cost sensitive analysis for cellulase producing strains

\begin{tabular}{c|c}
\hline Parameter & NREL data \\
\hline Productivity & $75 \mathrm{FPU} / \mathrm{L}-\mathrm{hr}$ \\
Yield & 200 FPU/g cellulose \\
Loading & $15 \mathrm{FPU} / \mathrm{g}$ cellulose \\
Specific activity & $600 \mathrm{FPU} / \mathrm{g}$ protein \\
\hline
\end{tabular}

\subsection{Acquire advanced cellulase-producing organisms.}

Over 15 cellulase preparations and strains have been obtained, not including strain L27, a strain that was developed by Dr. S. Shoemaker while at Cetus Corporation. Best attempts will be made to acquire this strain. Cellulase strains at UC Davis are shown in Table 2.6.

Table 2.6. Cellulase strains at UC Davis

\begin{tabular}{cc}
\hline Trichoderma reesei & QM 6a \\
& QM 9414 \\
& Rut C30 \\
& TW1 \\
& Schwuan, China strain \\
\hline Penicillium sp. & B4 \\
\hline Myroconium thermophilum & 43-MT \\
\hline
\end{tabular}




\subsection{Develop enzyme production at bench-scale.}

Cellulase organisms was screened and validated for their ability to produce large quantities of cellulase using a low cost fermentation culture medium. The most promising organisms selected Trichoderma reesei Rut C30 and T. reesei TW1 and the optimum cellulase production conditions are given in Table 2.7.

\section{Table 2.7. Optimum environmental conditions for cellulase production}

\begin{tabular}{ccc}
\hline Parameter & TW1 & Rut C30 \\
\hline Temperature $\left({ }^{\circ} \mathrm{C}\right)$ & 32 & 28 \\
pH & 5.6 & 4.2 \\
DO level (\% & \multicolumn{2}{c}{$20-40 \%$} \\
saturation) & \multicolumn{2}{c}{0.56} \\
Aeration (vvm) & \multicolumn{2}{c}{$300-500$} \\
Agitation (rpm) & Avicel & Glc/Lac \\
Carbon feed & \multicolumn{2}{c}{}
\end{tabular}

T. reesei Rut C30 and T. reesei TW-1 which were selected for the industrial cellulose producing strains were evaluated in a fed-batch $14 \mathrm{~L}$ fermentation under its optimal conditions which were determined in previous year. Considering the economical values of media, different composition, which described in the Table 2.8 were used for the maximum cellulose production by each strains.

Table 2.8. Media composition for cellulose production

\begin{tabular}{|c|c|c|}
\hline & T. reesei Rut C30 & T. reesei TW-1 \\
\hline \multirow{2}{*}{ Carbon source } & 25g/L glucose & 1.0g/L Glucose \\
\hline & 5.0g/L Avicel & 25g/L Solka Floc \\
\hline \multirow{3}{*}{ Nitrogen source } & $3.5 \mathrm{~g} / \mathrm{L}\left(\mathrm{NH}_{4}\right)_{2} \mathrm{SO}_{2}$ & $4.6 \mathrm{~g} / \mathrm{L}\left(\mathrm{NH}_{4}\right)_{2} \mathrm{SO}_{2}$ \\
\hline & 0.75g/L Urea & 30g/L Corn steep liquor \\
\hline & $2.5 \mathrm{~g} / \mathrm{L}$ Protease pepton & \\
\hline \multirow{8}{*}{ Mineral } & $5 \mathrm{~g} / \mathrm{L} \mathrm{KH}{ }_{2} \mathrm{PO}_{4}$ & $3 \mathrm{~g} / \mathrm{L} \mathrm{KH}{ }_{2} \mathrm{PO}_{4}$ \\
\hline & $0.75 \mathrm{~g} / \mathrm{L} \mathrm{MgSO}_{4} * 7 \mathrm{H}_{2} \mathrm{O}$ & $0.4 \mathrm{~g} / \mathrm{L} \mathrm{MgSO}_{4} * 7 \mathrm{H}_{2} \mathrm{O}$ \\
\hline & $1 \mathrm{~g} / \mathrm{L} \mathrm{CaCl} 2 * 2 \mathrm{H}_{2} \mathrm{O}$ & $0.4 \mathrm{~g} / \mathrm{L} \mathrm{CaCl} 2 * 2 \mathrm{H}_{2} \mathrm{O}$ \\
\hline & $0.0125 \mathrm{~g} / \mathrm{L} \mathrm{FeSO}_{4} * 7 \mathrm{H}_{2} \mathrm{O}$ & $0.02 \mathrm{~g} / \mathrm{L} \mathrm{FeSO}_{4} * 7 \mathrm{H}_{2} \mathrm{O}$ \\
\hline & $0.004 \mathrm{~g} / \mathrm{L} \mathrm{MnSO}_{4} * 4 \mathrm{H}_{2} \mathrm{O}$ & $0.02 \mathrm{~g} / \mathrm{L} \mathrm{MnSO}_{4} * 4 \mathrm{H}_{2} \mathrm{O}$ \\
\hline & $0.0035 \mathrm{~g} / \mathrm{L} \mathrm{ZnSO}_{4} * 7 \mathrm{H}_{2} \mathrm{O}$ & $0.02 \mathrm{~g} / \mathrm{L} \mathrm{ZnSO}_{4} * 7 \mathrm{H}_{2} \mathrm{O}$ \\
\hline & $0.005 \mathrm{~g} / \mathrm{L} \mathrm{CoCl}{ }_{2} * 6 \mathrm{H}_{2} \mathrm{O}$ & \\
\hline & 0.5 mL/L Tween 80 & \\
\hline
\end{tabular}


The fermentation was started by addition of $0.7 \mathrm{~L}$ of the inoculum to $6.3 \mathrm{~L}$ of sterile fermentation medium, and was carried out in two consecutive stages - batch and fed-batch. The first stage was carried out with the aim to increase the concentration of fungal biomass, while the second stage was necessary for protein (cellulase) production. For the T. reesi TW-1 fermentation, cell growth was carried out for 20 hours then cellulose was added but $T$. reesi Rut 30, cellulose was fed at 40 hours. The productivity of cellulase production based on the activity were summarized in the Table 2.9. The maximum productivity of $T$. reesi TW-1 and T. reesi Rut30 were obtained at the 141 hours and 95 hours respectively. This was 77 hours after induction and addition of cellulose.

Table 2.9. Cellulase production by Rut C30 fermentation

\begin{tabular}{cccccc}
\hline Strains & $\begin{array}{c}\text { Fermentation } \\
\text { time (hour) }\end{array}$ & $\begin{array}{c}\text { Protein } \\
(\mathrm{mg} / \mathrm{mL})\end{array}$ & $\begin{array}{c}\text { FP } \\
\text { activity } \\
\text { (FPU/mL) }\end{array}$ & $\begin{array}{c}\text { Specific } \\
\text { FP activity } \\
\text { (FPU mg) }\end{array}$ & $\begin{array}{c}\text { Productivit } \\
\text { (FPU/L- } \\
\text { hr) }\end{array}$ \\
\hline \hline $\begin{array}{c}\text { T.reesei } \\
\text { TW-1 }\end{array}$ & 95 & 36.4 & 26.6 & 0.73 & 279 \\
$\begin{array}{c}\text { T. reesei } \\
\text { Rut C30 }\end{array}$ & 69 & 5.5 & 3.14 & 0.57 & 45.5 \\
\hline
\end{tabular}

With the \$15MM efforts at both Genencor International and Novozymes Biotech to improve the production and performance of cellulase in order to reduce its cost by 10-fold, we decided not to continue a separate approach and to use the developed commercial enzyme for design of the lactic acid process.

\section{Task 3. Microorganism development.}

Microorganism development was the central task of the project and our work yielded significant new information and strains for use in biomass (mixed sugar) fermentations. The following sections describe the reason we chose Lactobacillus brevis, isolation and development of new and improved $L b$. brevis strains (higher yield from glucose) and development of a new recombinant strain of Escherichia coli.

\subsection{Selection of non-carbon catabolite repressed Lactobacillus strains.}

Initial screens sought to identify lactobacilli strains that ferment both five and six carbon sugars homofermentatively; that is, strains that produce lactic acid as a sole end product. To date, homofermentation of five carbon sugars has been confirmed in a single lactobacillus species, Lactobacillus MONT4. This strain is being developed at NREL for both ethanol and lactic acid production. Reports of other lactobacilli that homofermentatively ferment five carbon sugars have not been substantiated or, in one case, the strains were not maintained.

Given the dearth of published reports on lactobacilli that ferment five carbon sugars homofermentatively, we have focused our efforts on promising heterofermentative strains. Many heterofermentative strains ferment various five carbon sugars including xylose and arabinose, both constituents in rice straw lignocellulose. Therefore such heterofermentative strains would require little or no engineering to transport and metabolize five carbon sugars. By 
definition, heterofermentation results in a range of end-products, chiefly lactic and acetic acids. To be compatible with the patented ANL membrane-based technology for synthesis of lactic acid esters (a downstream processing element inherent in this proposal) it is critical that the fermentative production of acetic acid (and other organic acids) be minimized. In all heterofermentative strains, ethanol can be produced in the place of acetic acid in a process dependent on the cellular requirement for cofactor $\left(\mathrm{NAD}^{+}\right)$regeneration.

We have analyzed several heterofermentative strains for metabolism of various five and six carbon sugars. In addition, we have performed preliminary inhibition studies of rice straw hydrolysate on microbial growth. Strains analyzed to date are listed in Table 3.1.

Table 3.1. Heterofermentative lactobacilli strains at UC Davis

\begin{tabular}{ll}
\hline Facultatively Heterofermentative & Obligately Heterofermentative \\
\hline Lactobacillus pentosus ATCC 8041 & Lactobacillus brevis IFO3960 \\
Lactobacillus plantarum (V\&E isolate) & Lactobacillus brevis NRRL B-4527 \\
Lactobacillus MONT4 & Lactobacillus brevis NRRL B-11837 \\
Lactobacillus sake ATCC 15578 & Lactobacillus brevis NRRL B-1834 \\
& Lactobacillus suebicus DSM 5007 \\
& Lactobacillus suebicus DSM 5008 \\
\hline
\end{tabular}

V\&E: Viticulture and Enology Department, UC Davis

Of these strains none were significantly inhibited by addition of up to $300 \mathrm{~g} / \mathrm{L}$ hydrolyzed rice straw. In general the obligately heterofermentative strains produced more acetic acid during growth on a mixture of glucose $(50 \mathrm{~g} / \mathrm{L})$, xylose $(30 \mathrm{~g} / \mathrm{L})$, galactose $(20 \mathrm{~g} / \mathrm{L})$, arabinose $(15 \mathrm{~g} / \mathrm{L})$ and cellobiose $(10 \mathrm{~g} / \mathrm{L})$ than did the facultatively heterofermentative strains, as expected. Interestingly, $L b$. suebicus strains consumed arabinose (a five carbon sugar) prior to consumption of glucose suggesting an interesting, atypical, regulation of sugar metabolism in this strain. In addition, Lactobacillus brevis IFO3960 consumed both arabinose and glucose simultaneously with no apparent catabolite repression. Preliminary results indicate that, unlike arabinose, xylose is metabolized by $L b$. brevis after exhaustion of glucose.

Since $L b$. brevis exhibited co-metabolism of glucose and arabinose, we have chosen to examine this strain further. Others have shown that $L b$. brevis possesses an atypical metabolic capacity producing enzyme activities characteristic of the Embden-Meyerhof-Parnas pathway (homofermentative pathway) when grown anaerobically on fructose. This suggests that homofermentative metabolism can be induced in this $L b$. brevis.

Previous work at ANL resulted in five lactobacilli strains optimized for production of lactic acid from potato starch hydrolysate and corn steep liquor. Of those five strains only two, both $L b$. casei strains, are facultatively heterofermentative and therefore can metabolize five carbon sugars. In addition to the metabolic analysis on $L b$. brevis, we characterized the two ANL $L b$. casei strains for endproduct formation as well as inhibition by rice straw hydrolysate.

3.1.a. Metabolic flux engineering for enhancement of the lactic acid yield in $\mathbf{L b}$. brevis. The NAD/NADH ratio is key control factor of acetate and ethanol production. As shown in Table 
3.2, upon addition of xylose carbon flux changes from ethanol to acetate. No ethanol production is observed in the xylose media. This is likely due to the increased need to regenerate NAD(P)+ as a result of heterofermentative glucose metabolism as compared to xylose metabolism, thus the ethanol formation pathway has function of balancing the NAD+/NADH ratio of cell.

Table 3.2. Lactic acid yield in $L b$. brevis

\begin{tabular}{|c|c|c|c|}
\hline & \multicolumn{3}{|c|}{ Yield } \\
\hline & Lactate & Acetate & Ethanol \\
\hline 200mM GLC + 100mM XYL & 1.20 & 0.20 & 1.21 \\
\hline 150mM GLC + 150mM XYL & 0.84 & 0.56 & 0.21 \\
\hline 100mM GLC + 200mM XYL & 0.94 & 0.62 & 0.12 \\
\hline 300mM XYL & 0.99 & 0.69 & 0.30 \\
\hline \multicolumn{2}{|c|}{} & 1.06 & 0.02 \\
\hline Yield : mM product / mM total substrate used & \\
\hline
\end{tabular}

3.1.b. Lb. brevis genome sequencing project. Future work to optimize production of bioproducts using Lactobacillus brevis will be assisted by access to the complete genome sequence. Recently, Co-PI David Mills co-lead a project to sequence nine lactic acid bacteria including $L b$. brevis (Mills, 2004). Access to the $L b$. brevis genome sequence has/will enable both fundamental and applied studies of the regulation of sugar utilization in Lb. brevis. Moreover genome sequence is the starting point for future metabolic engineering approaches. (Mills, D. A. 2004. The lactic acid bacteria genome project. Journal of Food Science, 69 FMS2830.)

3.1.c. Catabolite repression in Lactobacillus casei. Preliminary sugar utilization studies were carried out on the two $L b$. casei strains obtained from ANL. As indicated in Figure 1, both strains possess the typical sequential utilization of xylose (or arabinose). This (expected) result suggests that catabolite repression is active in $L b$. casei.

3.1.d. Strain comparison between Lactobacillus casei and Lactobacillus brevis. Lactic acid production from $L b$. brevis and $L b$. casei were analyzed in lab-scale flask fermentations performed under semi-aerobic conditions at $30^{\circ} \mathrm{C}$. The medium $\mathrm{pH}$ was set at 6.0 initially but not controlled during fermentation.

There is no apparent difference of lactic acid production in control MRS media between two $L b$. casei strains and $L b$. brevis NRRL 1836 during exponential phase. For 24 hours, both Lb. brevis and $L b$.casei strains consumed glucose completely but after $L b$. casei cannot utilize xylose and arabinose at all. However, $L b$. brevis can up take the xylose and arabinose with glucose and continued utilization after depletion of glucose. $L b$. casei did not produce the acetic acid and ethanol but $L b$. brevis did. Fermentation profiles are described in the Figure 3.1.

3.1.e. Justification for selection of Lactobacillus brevis strains. Lb. brevis is a natural lactic acid producing strain and does not have carbon catabolite repression which allows simultaneous mixed sugar utilization. Because lignocellulosic feedstocks are the focus of this project, simultaneous and complete utilization of mixed sugars (hexoses and pentoses) are critical parameters in overall process design. Even though $L b$. brevis produces 2-carbon co-product in 
addition to the 3-carbon lactic acid, ethanol may be useful in the production of ethyl lactic acid and the other, acetate, may be eliminated by further research.

Figure 3.1 Mixed sugar utilization of A: Lb Lb. casei 1449 and B : Lb. brevis NRRL1836.

A : Lb.casei 1449

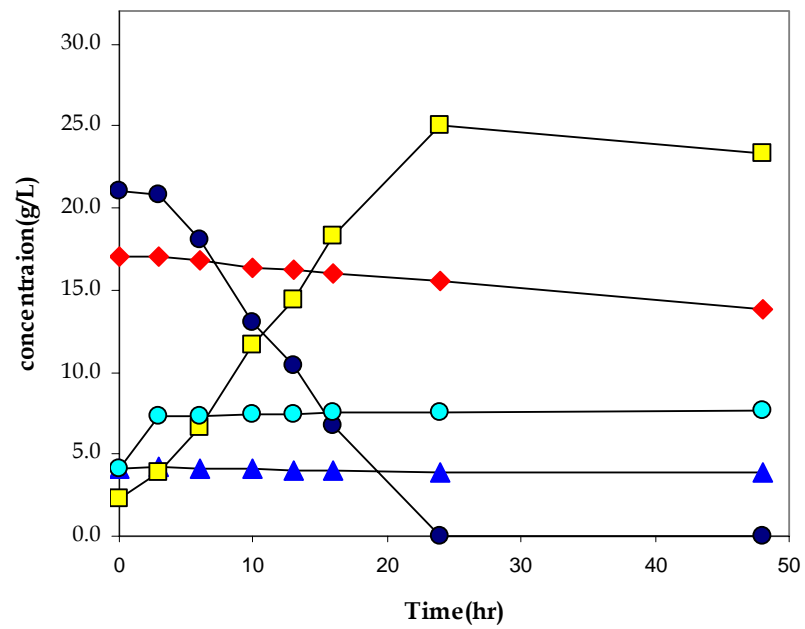

B : Lb.brevis NRRL 1836

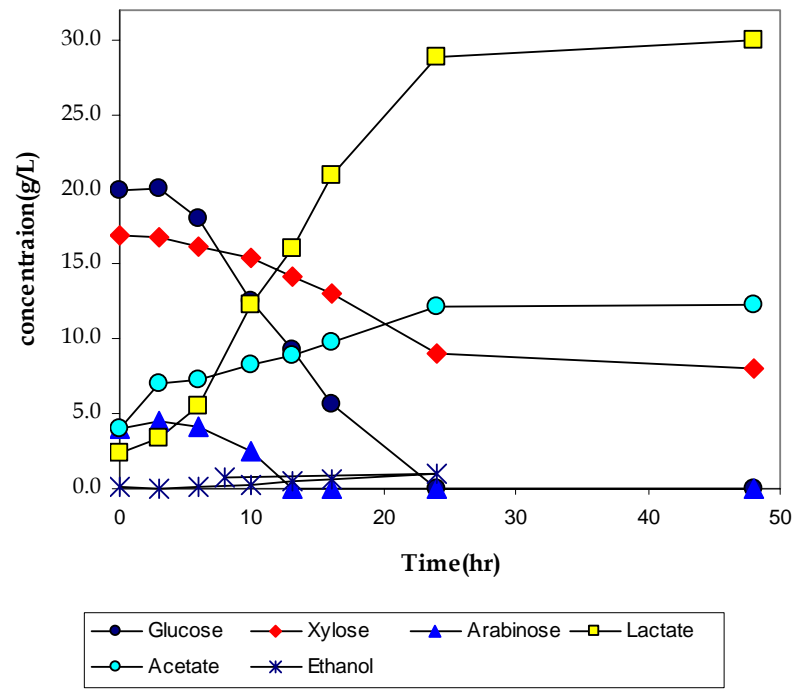

Figure 3.1 illustrates simultaneous carbohydrate utilization by Lb. brevis in contrast to the utilization pattern of $L b$. casei, which did not use xylose and arabinose. It should be noted that the high initial acetate concentration is derived from the acetate buffer used in enzyme hydrolysis reaction. 


\subsection{Isolation of new non-catabolite repressed facultative heterofermentative strains: Lactobacillus pentosus.}

The strategy of using simultaneous carbohydrate fermentation added flexibility in the process design for utilizing a mixed carbon source (mixed carbohydrate) that is normally not possible with current industrial strains. Moreover, the recent availability of whole genome sequence for these strains adds the feasibility of potential genetic manipulation. Having such a strong advantages as industrial microorganisms, $L b$. brevis has only one weak point in industrial scale lactic acid production. Because $L b$. brevis is an obligate heterofermentative lactobacilli, the maximum lactic acid yield from hexose is $1.0(\mathrm{mM} / \mathrm{mM})$. Lb. brevis fermentation of hexoses results in one carbon lost as carbon dioxide and the resulting pentose phosphate split into three carbon and two carbon products. Therefore, the maximum product yields for heterofermentative fermenters is $1.0(\mathrm{mM} / \mathrm{mM})$ of lactic acid and $1.0(\mathrm{mM} / \mathrm{mM})$ of acetic acid/ethanol. Compared to homofermentative lactobacilli which ferment hexoses solely to lactic acid (maximum yield 2.0 $(\mathrm{mM} / \mathrm{mM})$ )lactic acid production by $L b$. brevis wastes carbon by producing an unwanted two carbon by-product, especially acetic acid. Acetic acid production also decreases the separation efficiency in downstream processing and thus further increases the lactic acid production cost.

To overcome the disadvantages and maintain the advantages, new facultative heterofermentative strains, having both homofermentative and heterofermentative pathway, have been sought through a microbial screening program. Here our goal is to isolate facultative heterofermentative lactobacilli that are able to ferment most of industrial waste carbon sources (mixed sugars) without carbon catabolite repression.

3.2.a. Origin. The origin of the wild type strain is as a contaminant of Lactobacillus brevis NRRL 4527 culture stock obtained from the stock collection at USDA. Cultivation of Lb. brevis NRRL 4527, the lactic acid yield was greater than $1.0(\mathrm{mM} / \mathrm{mM})$ from glucose, which was unusual for $L b$. brevis since it is classified as obligated heterofermentative lactobacilli. Therefore, the $L b$. brevis NRRL 4527 stock culture had suspected to be contaminated with another homofermentative lactic acid bacteria. Furthermore, with the 2-deoxyglucose, a nonmetabolizable glucose analogue, the contaminated $L b$. brevis NRRL 4527 showed simultaneous glucose and sucrose or lactose utilization which normally could not used by $L b$. brevis type strain. Therefore, potential contaminant possibly could have homofermentative pathway and use lactose, sucrose without carbon catabolite repression.

3.2.b. Lactobacillus sp. JH1 JH15. Thirteen different colonies (suspected contaminants from the $L b$. brevis NRRL 4527 culture) were isolated from an MRS-agar plate culture. The candidate strains were able to utilize glucose and xylose both aerobically and anaerobically. Unlike $L b$. brevis, these strains did not show simultaneous carbohydrate utilization. The final product from glucose was only lactic acid and the yields of lactic acid were between $1.7 \sim 1.8(\mathrm{mM} / \mathrm{mM})$. The isolated contaminants were catalase negative rods believed to be facultative heterofermentative lactobacilli, termed Lactobacillus sp. JH1 to JH10. Partial 16S RNA sequencing of the JH1 strain revealed it to be $L b$. pentosus.

Lactobacillus sp. JH1 JH10 were cultivated in the MRS media at $30^{\circ} \mathrm{C}$. Based on the cell growth rate, Lactobacillus sp. JH1 and JH5 was selected for further experiments. The product yields from glucose and xylose by Lactobacillus sp. JH1 and JH5 and their comparison with various 
lactobacillus strains are summarized in Table 3.3. Different from theoretical product, significant amount of ethanol was produced from glucose, especially by Lactobacillus sp. JH1.

3.2.c. Lactobacillus sp. JHX1 and Lactobacillus sp. JHX5. In order to select high cell growth strains in the xylose media, two host strains, Lactobacillus sp. JH1 and Lactobacillus sp. JH5 was enriched three times in the modified MRS media which contained $15 \mathrm{~g} / \mathrm{L}$ of bactopeptone, $5.0 \mathrm{~g} / \mathrm{L}$ of yeast extract, $2.0 \mathrm{~g} / \mathrm{L}$ of ammonium citrate, $5.0 \mathrm{~g} / \mathrm{L}$ of sodium acetate, $0.1 \mathrm{~g} / \mathrm{L}$ of magnesium sulfate, $0.5 \mathrm{~g} / \mathrm{L}$ of manganese sulfate, $2.0 \mathrm{~g} / \mathrm{L}$ of di-potassium phosphate and $20 \mathrm{~g} / \mathrm{L}$ of xylose as carbon source.

The enriched culture broth was inoculated in the modified MRS media with 20g/L of xylose and $5.0 \mathrm{~g} / \mathrm{L}$ of 2-deoxyglucose for the selection of carbon catabolite de-repressed mutant. After three consecutive enrichments of carbon catabolite de-repressed mutant, each selected mutant was named Lactobacillus sp. JHX1 and Lactobacillus sp. JHX5.

Similar to Lactobacillus brevis, Lactobacillus sp. JHX1 and JHX5 utilize both glucose and xylose simultaneously, a trait not observed in the parental strain (Figures 3.2 and 3.3). Parental strains JH1 and JH5 exhibited a slight xylose utilization during the glucose fermenting phase, however, the xylose consumption was small and the utilization rate was reduced after glucose completion. In contrast, mutant strains, JHX1 and JHX5 showed simultaneous glucose and xylose utilization and complete consumption of carbon source with similar xylose and glucose utilization rates (Figure 3.4).

3.2.d. Stability. The novel mutant strains showed simultaneous glucose and xylose utilization. To test the stability of the co-utilization phenotype, simultaneous glucose and xylose consumption was tested by sequential fermentations. Modified MRS media with $10 \mathrm{~g} / \mathrm{L}$ of glucose and $10 \mathrm{~g} / \mathrm{L}$ of xylose was used as in the previous experiments. $5 \%(\mathrm{v} / \mathrm{v})$ of previous culture broth was used to seed a sequential fermentation. As described in the Figure 3.5 and 3.6, five consecutive fermentations exhibited stable and reproducible fermentation behaviors. A total $20 \mathrm{~g} / \mathrm{L}$ of sugars was consumed with in 24 hours and both glucose and xylose were utilized simultaneously.

3.2.e. Carbohydrate utilization pattern with mutant strains. The carbohydrate utilization pattern and consumption pattern in the presence of glucose were observed in order to investigate the existence of apparent carbon catabolite repression. Glucose, galactose, mannose, fructose (hexose), xylose ribose, arabinose (pentose), maltose, lactose, sucrose, cellobiose (hexose dimer) were prepared separately. Precultured Lactobacillus sp. JH1XP5 in the MRS media was inoculated in the $100 \mathrm{~mL}$ of modified MRS media with $20 \mathrm{~g} / \mathrm{L}$ of each carbohydrate. Fermentation conditions were as described previously. Lactobacillus sp. JH1XP5 was not able to utilize mannose, lactose, sucrose and cellobiose (Table 3.4). Fructose was converted to lactic acid, acetate and mannitol as well. From galactose and maltose utilization, high amount of ethanol was produced which suggested the necessity of NADH oxidation during fermentation of those particular sugars.

The JHXP strains were further for carbohydrate consumption patterns in the presence of glucose. For this study, $10 \mathrm{~g} / \mathrm{L}$ of glucose and $10 \mathrm{~g} / \mathrm{L}$ of a second carbohydrate were added on the modified 
MRS media and the mixture cultivated under same conditions as in previous experiments.

Product formation and substrate utilization were monitored every 4 hours for 24 hours. Similar to Lactobacillus brevis, Lactobacillus JHXP consumed xylose, arabinose, ribose, galactose, fructose and maltose simultaneously with glucose without apparent carbon catabolite repression. Fructose also converted to acetate and mannitol most likely due to mannitol dehydrogenase activity. Galactose and maltose produced significant quantities of ethanol (Table 3.5). Surprisingly, the pentose sugars arabinose and ribose were preferred to glucose by JH1XP5. 
Figure 3.2. Fermentation profiles of host strains in the modified MRS media with glucose and xylose. Fermentations were carried out at $30^{\circ} \mathrm{C}$ aerobic condition with gentle shaking. $\mathrm{pH}$ was set at 6 initially but did not controlled during fermentation. A: Lactobacillus pentosus JH1, B: Lactobacillus sp.

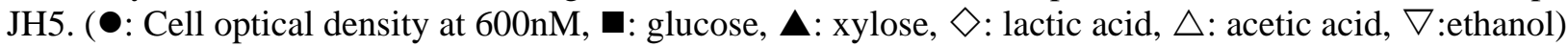

\section{A. Lactobacillus pentosus JH 1}

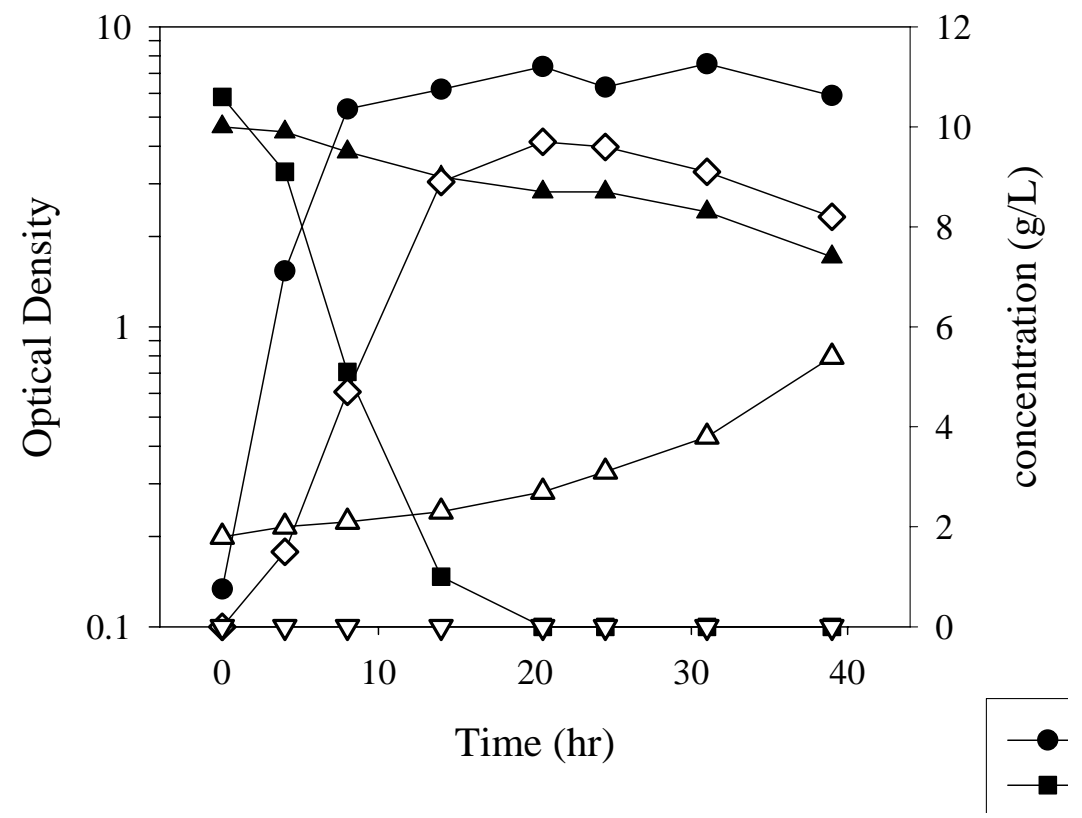

B. Lactobacillus sp. JH 5

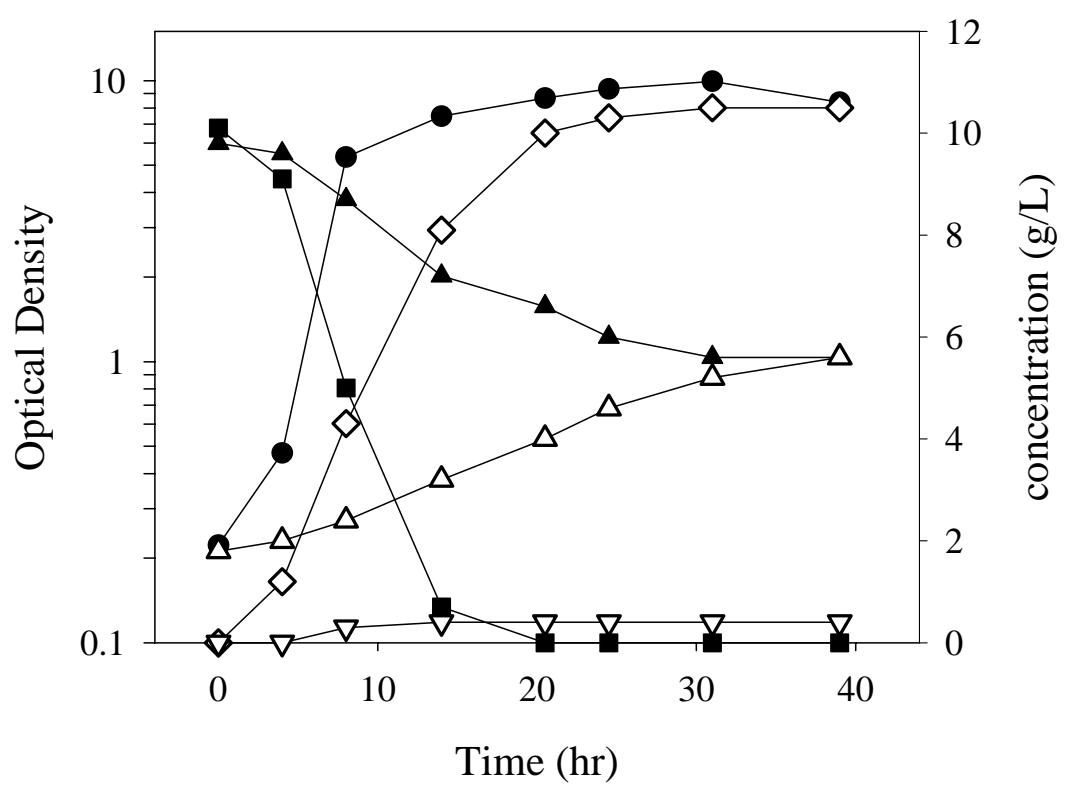


Figure 3.3. Fermentation profiles of $L b$. pentosus JHX1 and JHX5 in the modified MRS media with glucose and xylose. Fermentations were carried out at $30^{\circ} \mathrm{C}$ aerobic condition with gentle shaking. pH was set at 6 initially but did not controlled during fermentation. A: Lactobacillus pentosus

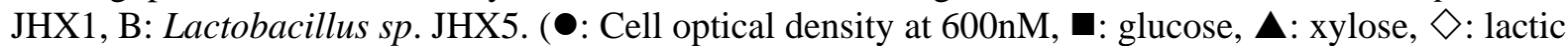
acid, $\triangle$ : acetic acid, $\nabla$ :ethanol)

\section{A. Lactobacillus pentosus JHX1}

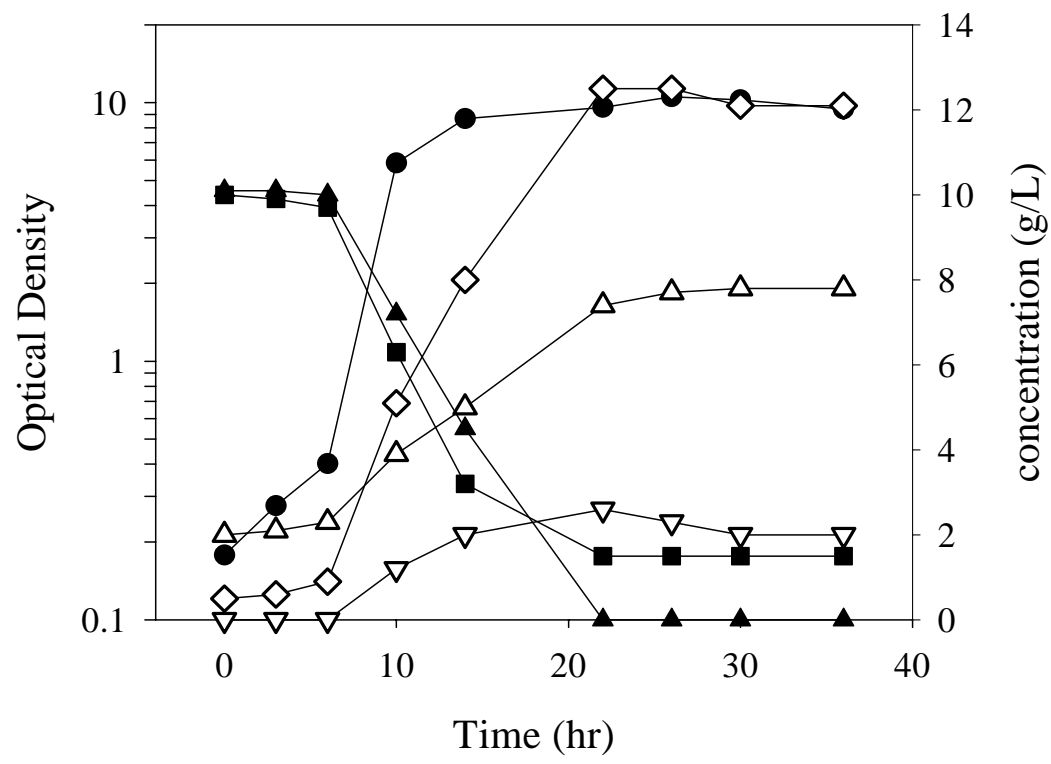

B. Lactobacillus sp.JHX5

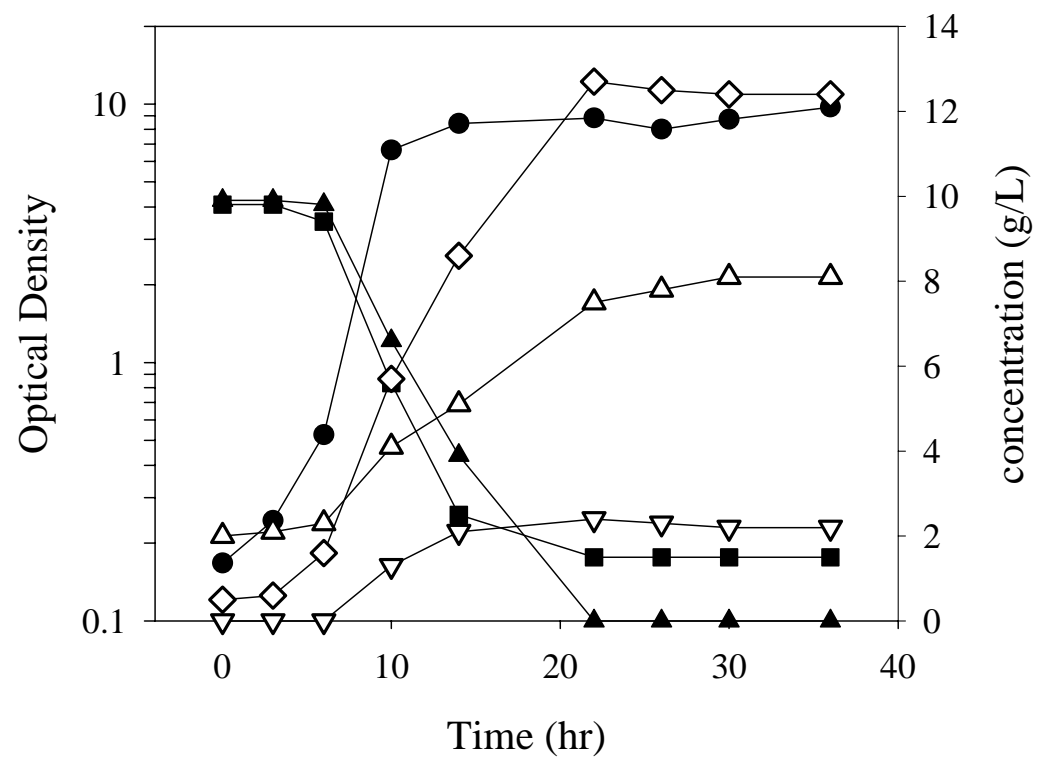


Figure 3.4. Fermentation profiles of $L b$. pentosus JH1XP5 and JH5XP5 in the modified MRS media with glucose and xylose. Fermentations conditions were the same as in Figure 1. A: Lactobacillus pentosus JH1XP5, B: Lactobacillus sp. JH5XP5. (•: Cell optical density at 600nM, $\mathbf{\square}$ : glucose, $\mathbf{\Lambda}$ : xylose, $\diamond$ : lactic acid, $\triangle$ : acetic acid, $\nabla$ :ethanol)

A. Lactobacillus pentosus JH1-XP5

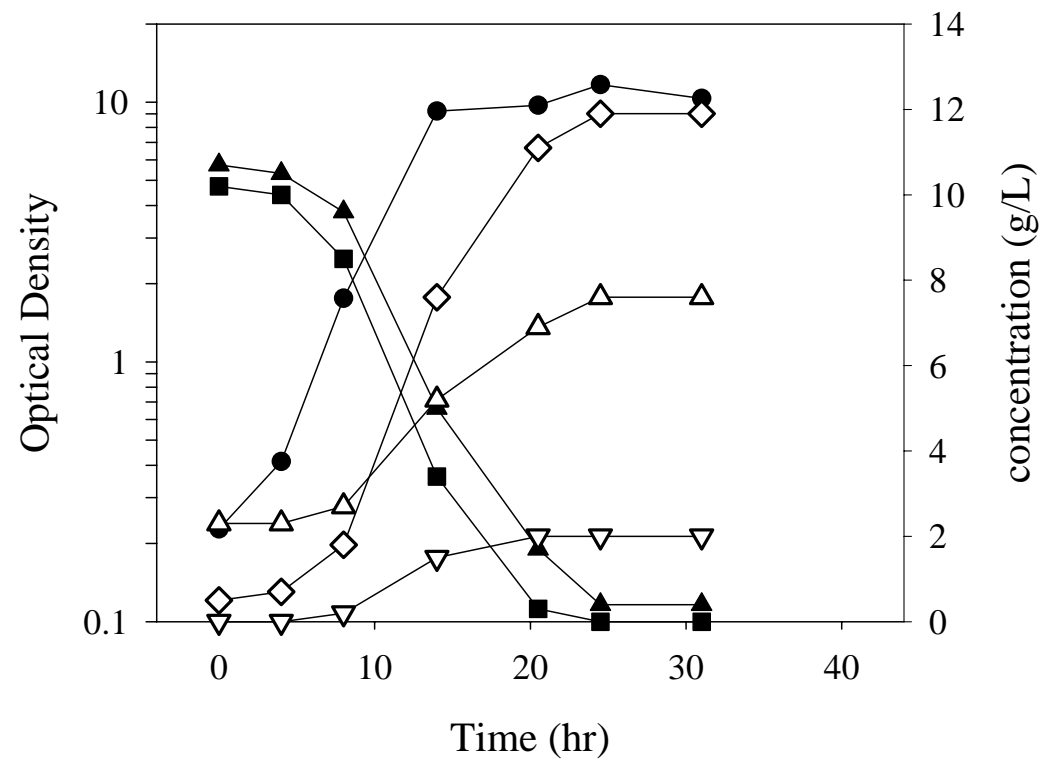

B. Lactobacillus sp.JH5XP5

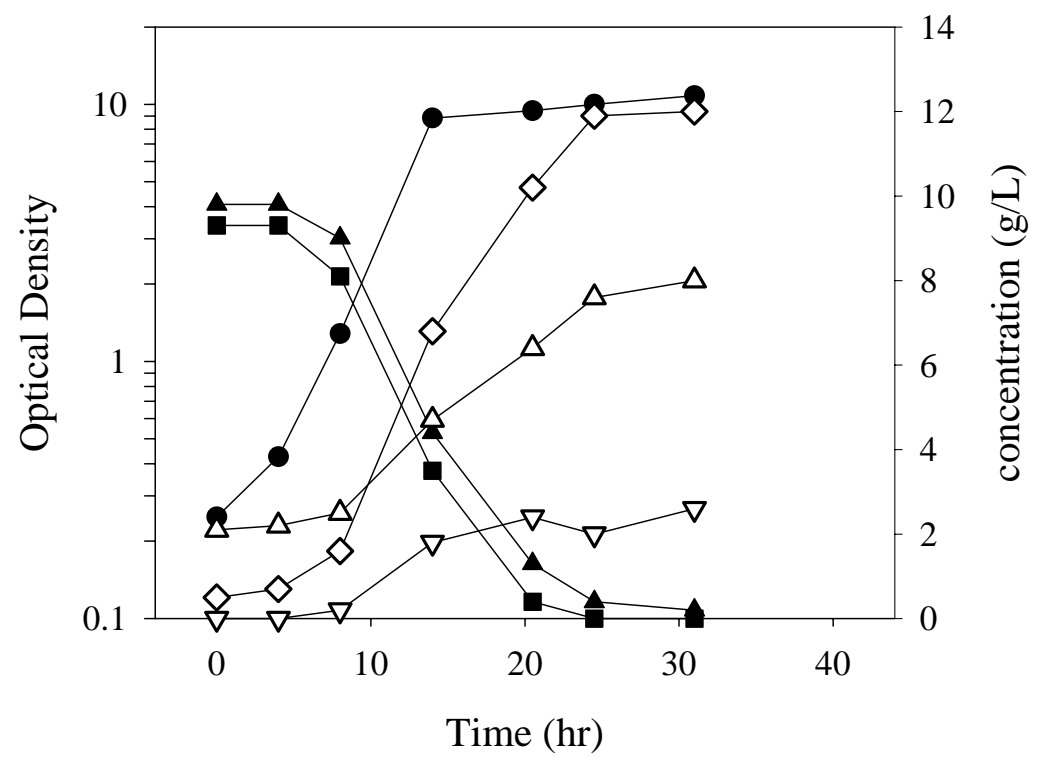



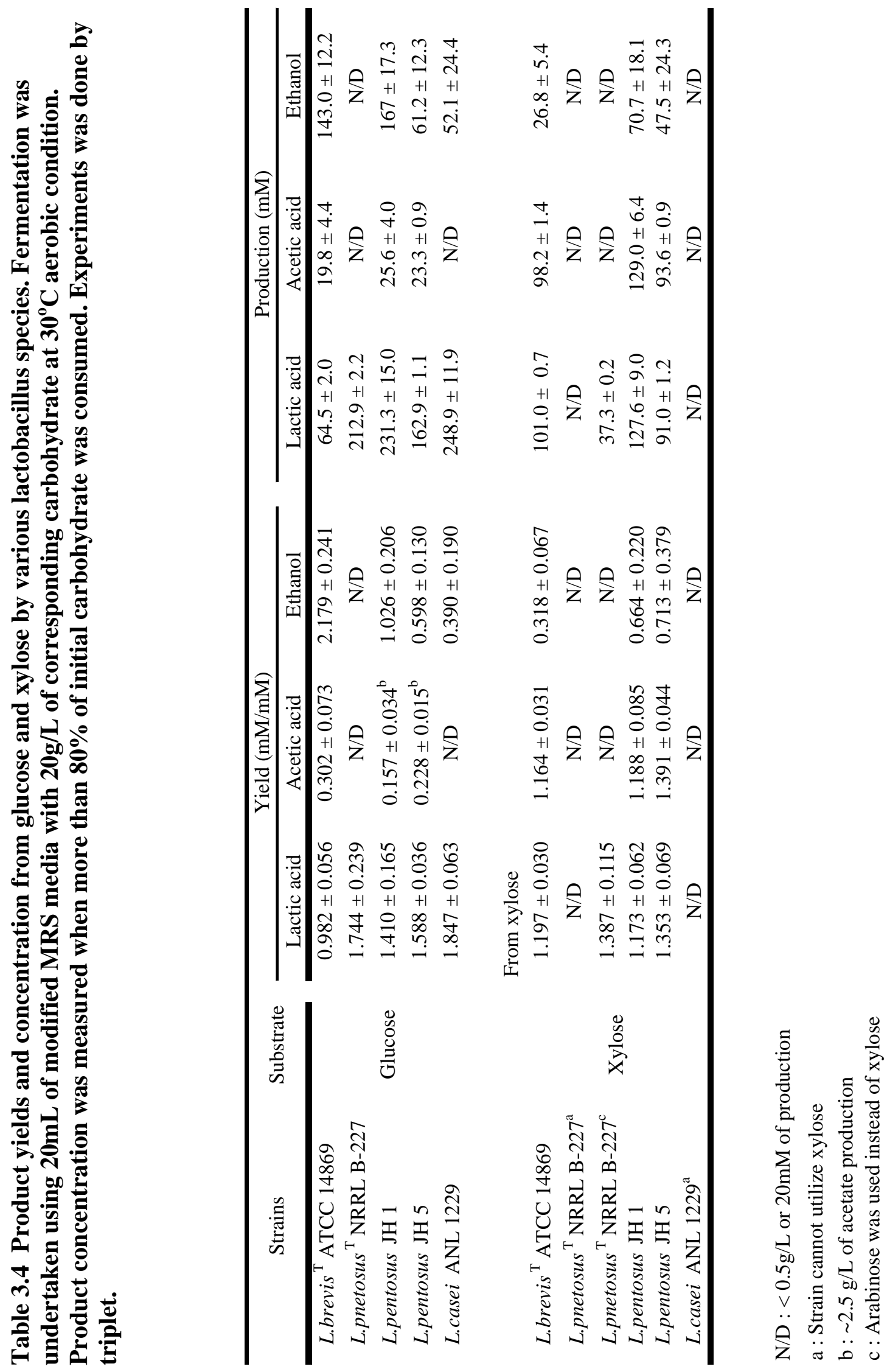


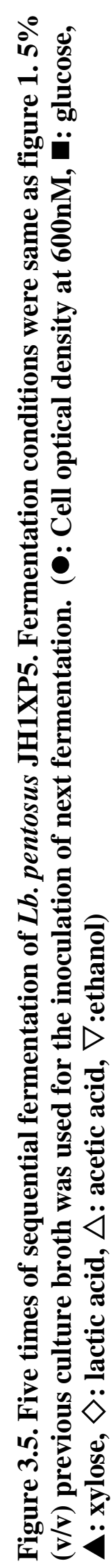

离

( Т/8) บо!̣อ.пนววนоว

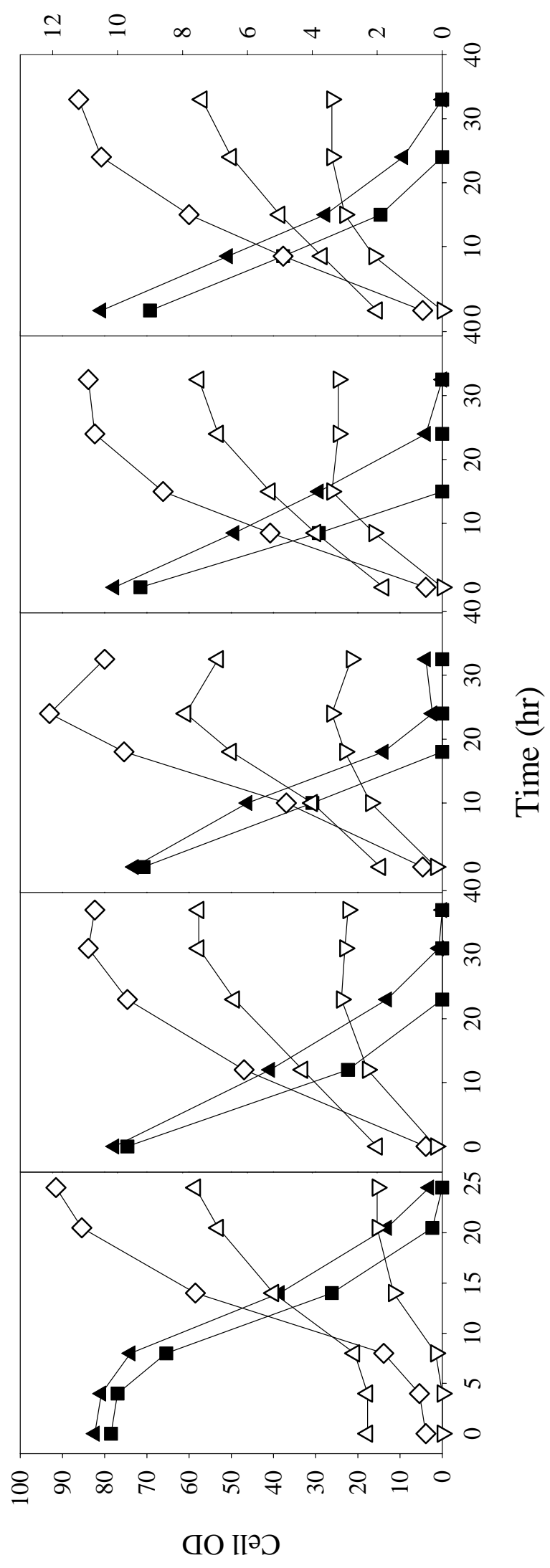




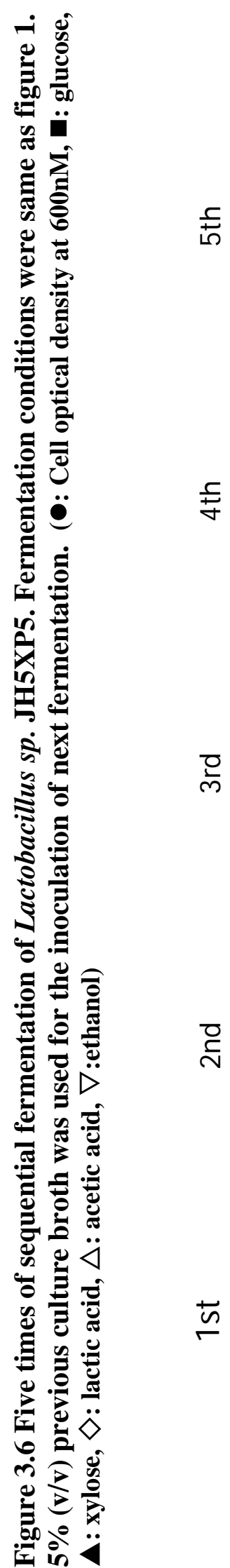

(т/8) чоп̣епиววนоว

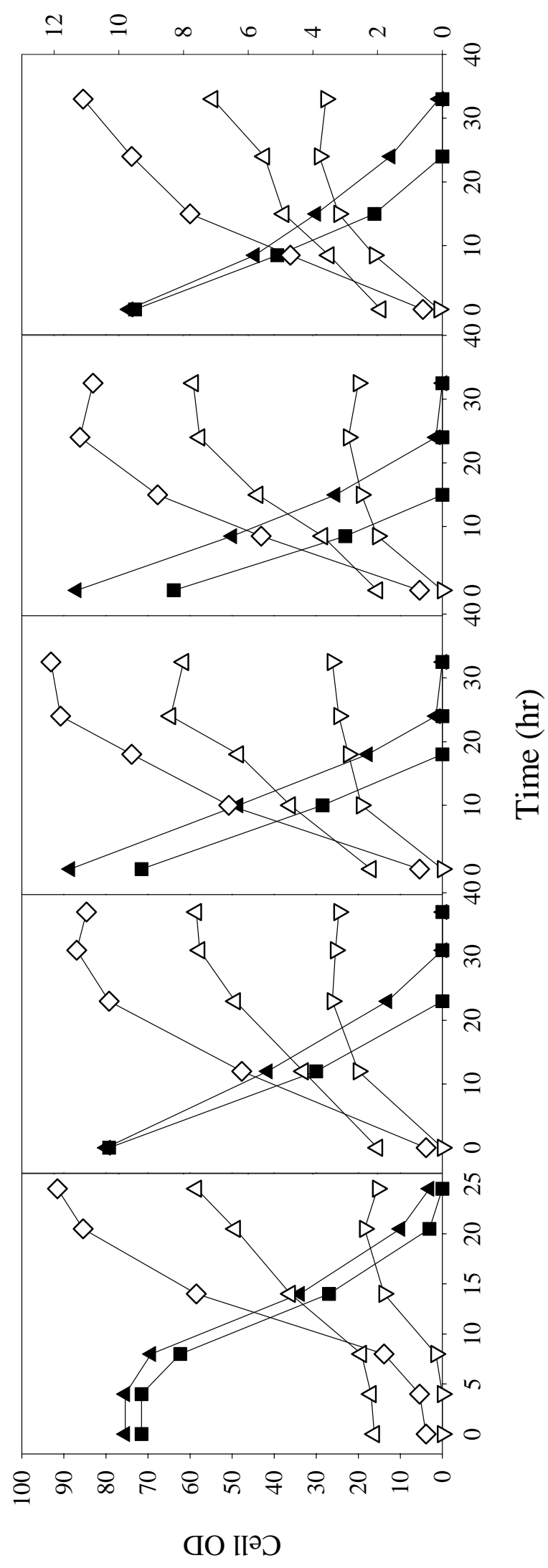




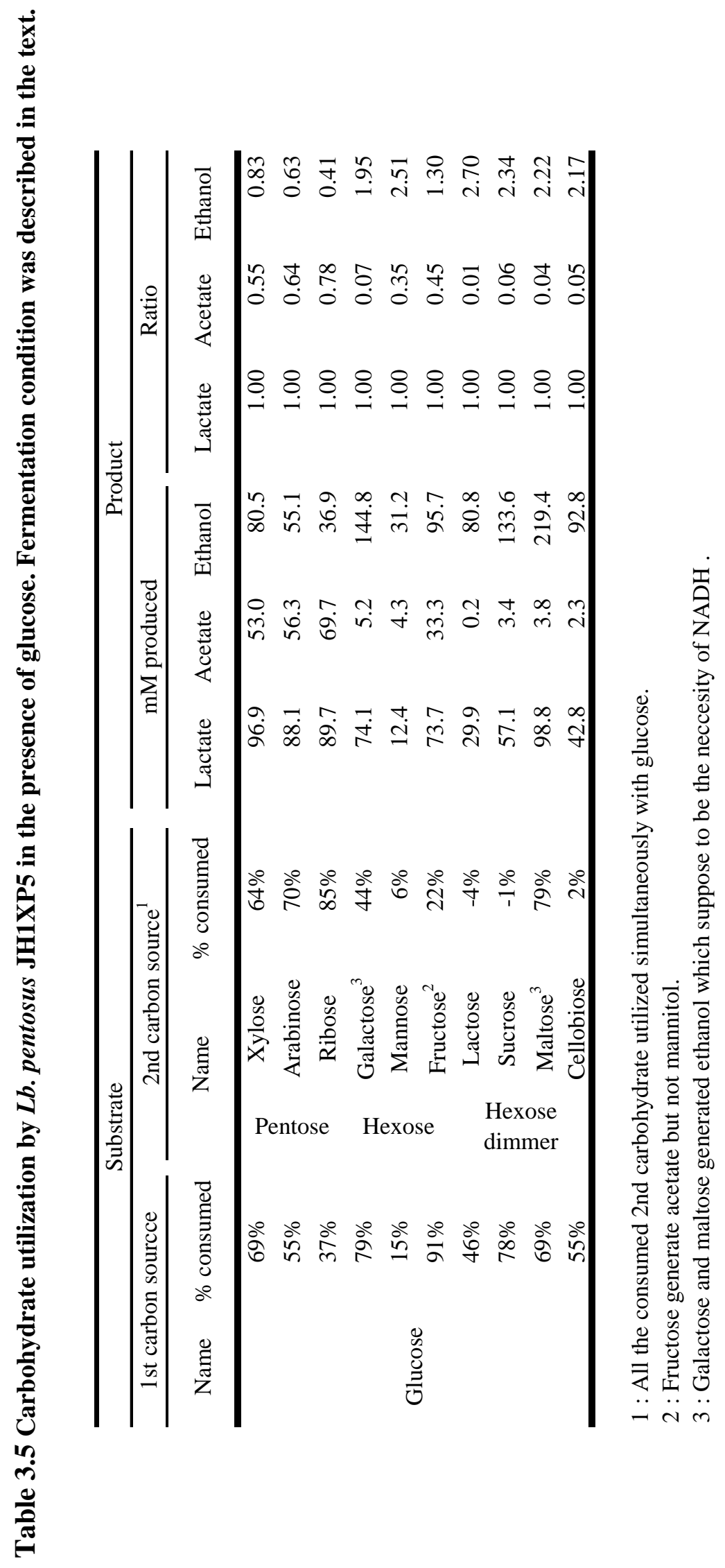




\subsection{Sucrose and lactose utilizing strains.}

Lactose and sucrose are abundant in nature as well as industrial waste such as cheese whey and sugar cane. Selection of the new catabolite de-repressed mutants able to utilize lactose and sucrose would enhance the value of isolated strains and enlarge the waste substrate options to produce platform chemical intermediates as well as traditional fermentation process.

Two previously selected xylose and glucose co-utilizing strains, Lactobacillus. JH1XP5 and JH5XP5 were not able to utilize lactose and sucrose as single carbon source. However, previous experiments suggested that the parental strains showed cell growth and lactic acid production from lactose and sucrose.

3.3.a. Lactose consumption by strains Lactobacillus sp. JHL1 and Lactobacillus sp. JHL5. Lactobacillus sp. JH1 and JH5 was enriched sequentially in the modified MRS media with 20g/L of lactose. After four consecutive enrichments, $5 \%$ of culture broth was inoculated on the modified MRS media with $20 \mathrm{~g} / \mathrm{L}$ of lactose and $5 \mathrm{~g} / \mathrm{L}$ of 2-deoxyglucose. Selection in the presence of 2-deoxyglucose was done twice. The new strains, named Lactobacillus sp. JHL1 and JHL5, could utilize glucose and lactose simultaneously (Figure 3.7). Most of lactose was converted to lactic acid and accumulation of galactose or glucose was not observed.

3.3.b. Sucrose consumption by strains Lactobacillus sp. JHS1 and Lactobacillus sp. JHS5. Sucrose utilizing catabolite de-repressed strains, Lactobacillus sp. JHS1 and Lactobacillus sp. JHS5, were isolated from JH1 and JH5 respectively by same method as described for lactose utilization above. The major end product from sucrose fermentation was lactic acid (Figure 3.8). Minimal acetic acid and surprisingly, no mannitol was produced. 
Figure 3.7. Fermentation profiles of $L b$. pentosus JHL1 and JHL5 in the modified MRS media with glucose and lactose. Fermentations were carried out at $30^{\circ} \mathrm{C}$ aerobic condition with gentle shaking. pH was set at 6 initially but did not controlled during fermentation. A: Lactobacillus pentosus JHL1, B: Lactobacillus sp. JHL5. (•: Cell optical density at $600 \mathrm{nM}, \mathbf{\square}$ : glucose, $\boldsymbol{\nabla}$ : lactose, $\diamond$ : lactic acid, $\triangle$ : acetic acid, $\nabla$ :ethanol)

\section{A. Lactobacillus pentosus JHL 1}

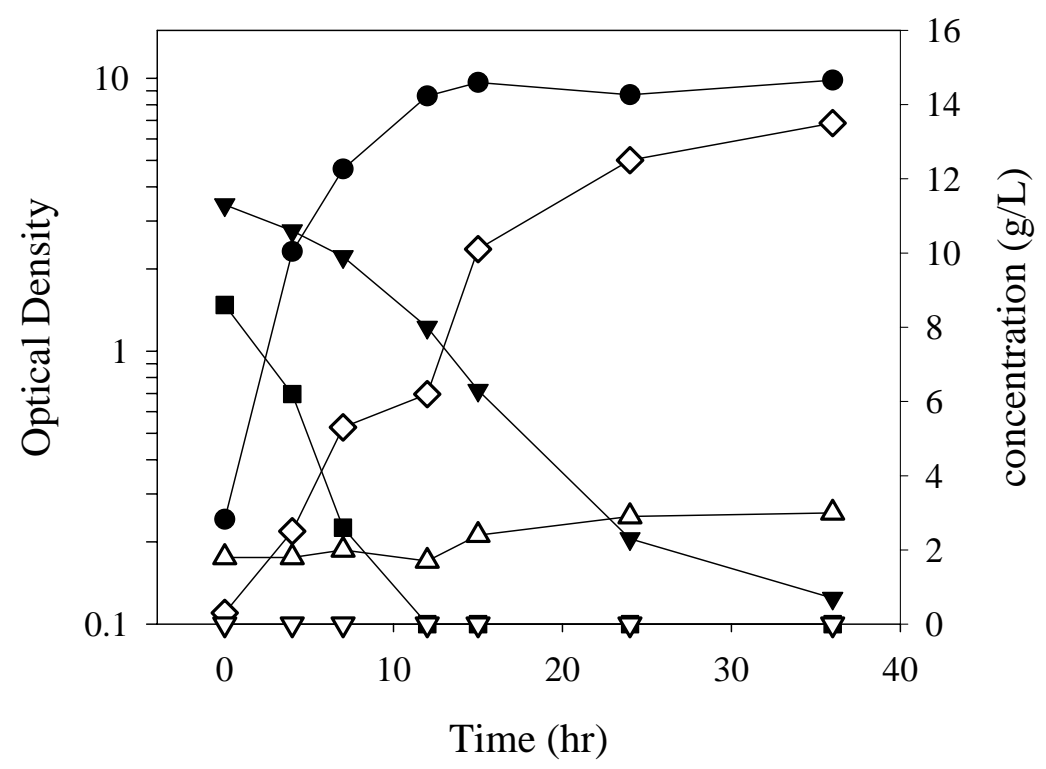

B. Lactobacillus pentosus JH 5

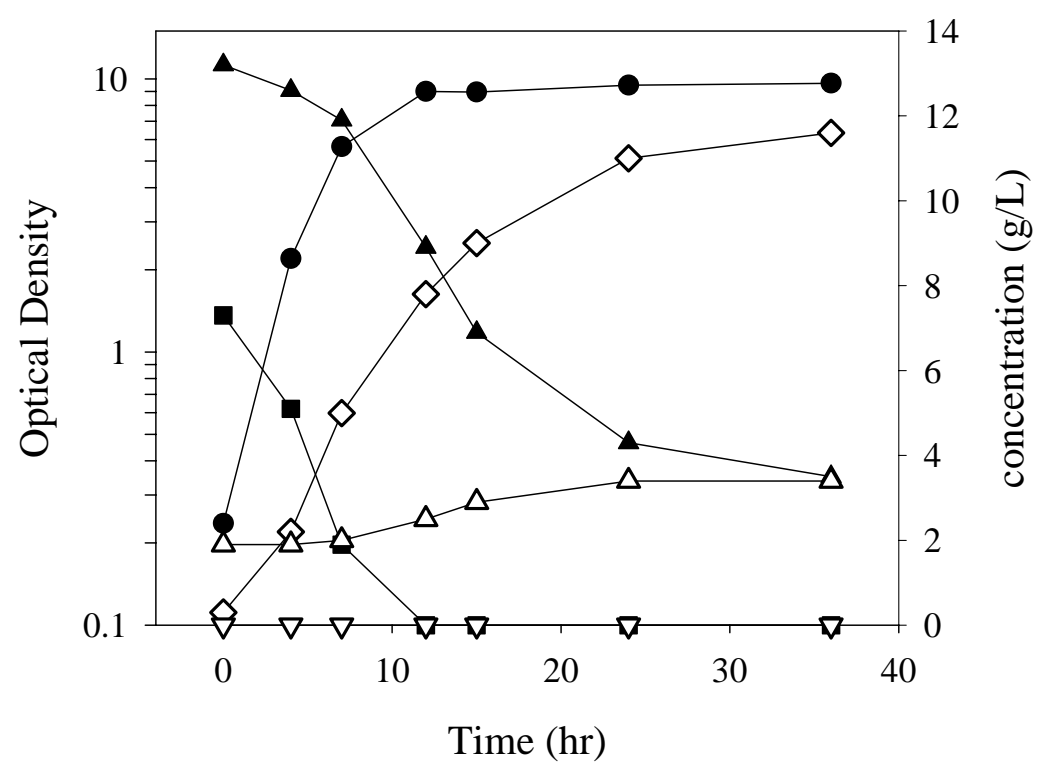


Figure 3.8. Fermentation profiles of $L b$. pentosus JHS1 and JHS5 in the modified MRS media with glucose and lactose. Fermentations were carried out at $30^{\circ} \mathrm{C}$ aerobic condition with gentle shaking. pH was set at 6 initially but did not controlled during fermentation. A: Lactobacillus pentosus JHS1, B: Lactobacillus sp. JHS5. ( $\bullet$ : Cell optical density at $600 \mathrm{~nm}, \boldsymbol{\square}$ : glucose, $\boldsymbol{\nabla}$ : sucrose, $\diamond$ : lactic acid, $\triangle$ : acetic acid, $\nabla$ :ethanol)

\section{A. Lactobacillsu pentosus JHS 1}

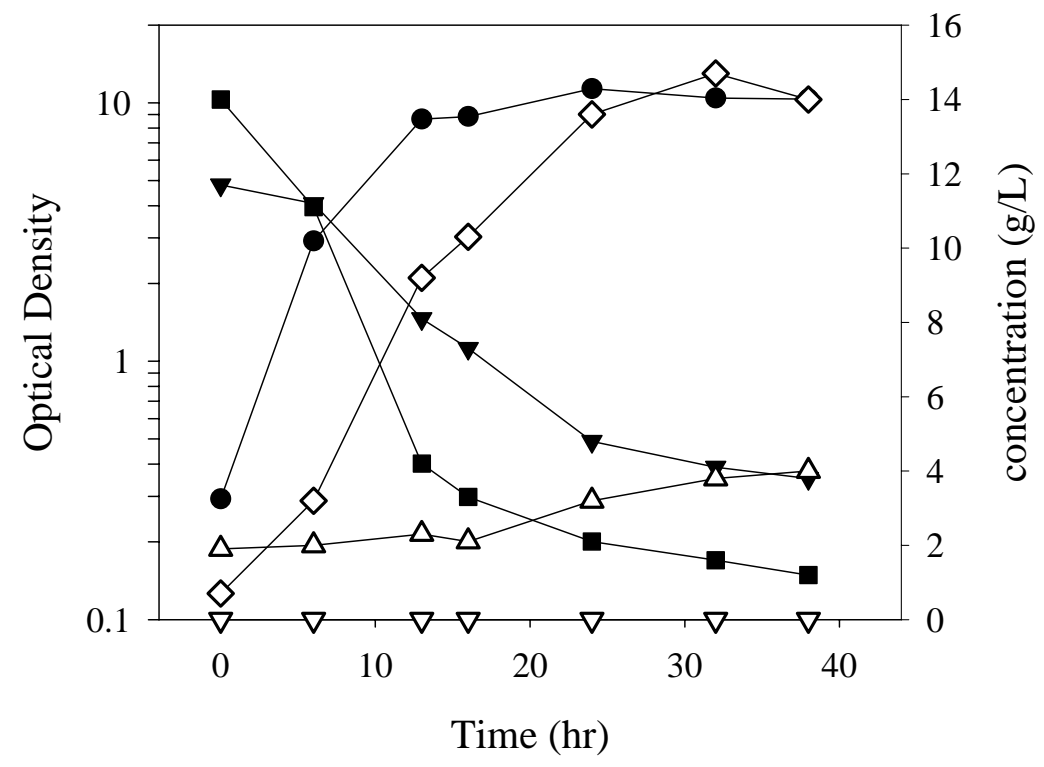

B. Lactobacillus sp.JHS 5

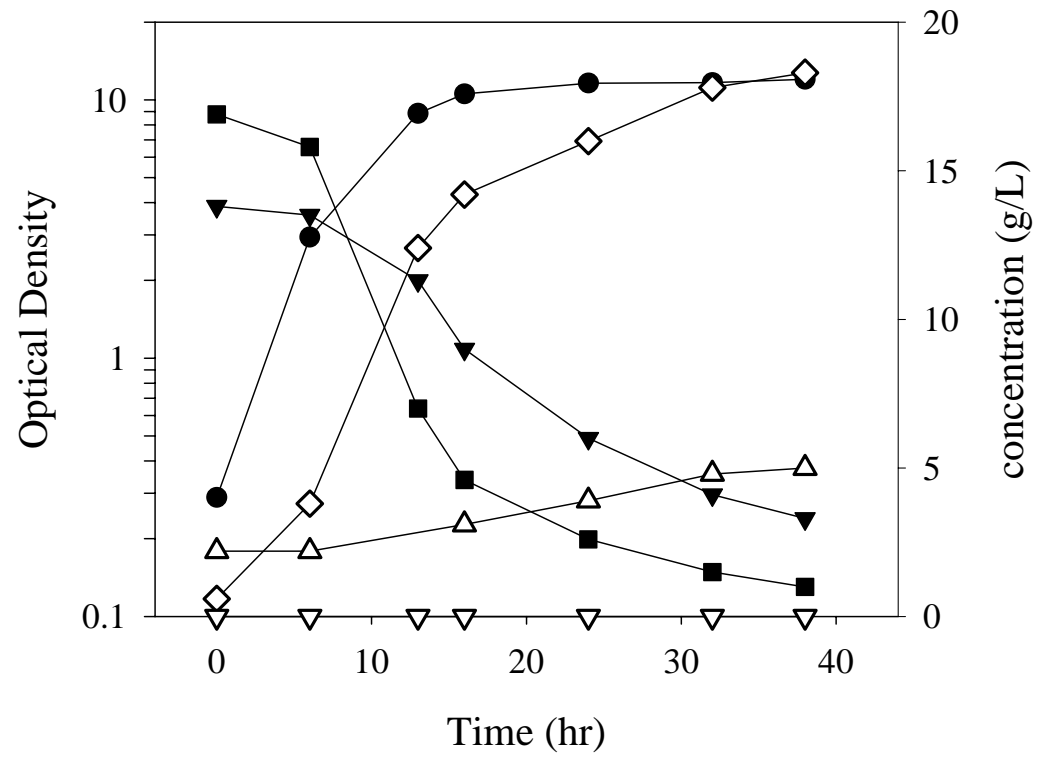




\section{Lactic acid production in E. coli.}

Construction of lactic acid producing E. coli. Inactivation of pyruvate:formate lyase (Fig. 3.9) in a vigorously growing strain of $E$. coli generated the strain CSM1, which rapidly produces high concentrations of lactic acid from glucose in high yield. We have now shown that CSM1, unlike many E. coli strains, can metabolize xylose, the most common pentose in lignocellulosic hydrolysates. However, like many bacteria, metabolism of xylose is inhibited in the presence of glucose by genetic regulatory mechanisms involving the glucose phosphotransferase system. We have bypassed these mechanisms by inactivation of the $p t s G$ gene, which encodes the glucose transporter of the system. This mutation allows simultaneous consumption of glucose and xylose, but results in the production of succinate and acetate (Table 3.6). Inactivation of the frd genes, that encode fumarate reductase, the enzyme that makes succinate, eliminates succinate and acetate formation.

Figure 3.9. Genes involved in construction of the xylose utilizing derivative of CSM1

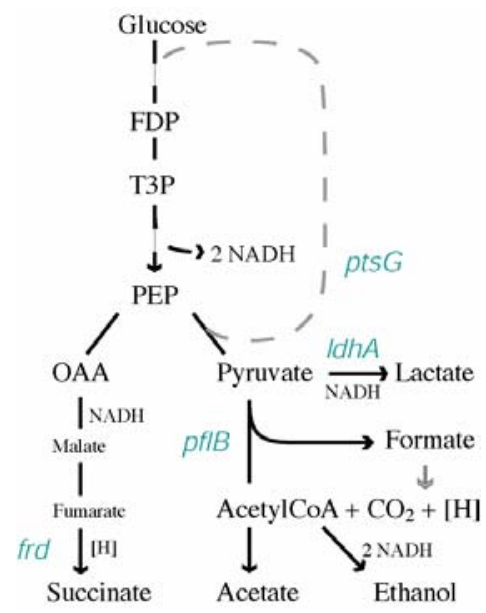

$$
\begin{aligned}
& \checkmark \text { ptsG - glucose permease } \\
& \text { of the PTS } \\
& \text { V IdhA - lactic acid } \\
& \text { dehydrogenase } \\
& \text { V pflB - pyruvate:formate } \\
& \text { lyase enzyme } \\
& V \text { frd - fumarate reductase }
\end{aligned}
$$

Table 3.6. Metabolism of glucose by CSM1 and its derivatives.

\begin{tabular}{lcccc} 
& \multicolumn{3}{c}{ Yields (molar) } \\
Strain & $\underline{\text { Lactic }}$ & $\underline{\text { Succinic }}$ & $\underline{\text { Acetic }}$ & Ethanol \\
CSM1 & 1.96 & 0.08 & 0.02 & 0 \\
$+\quad p t s G$ & 0.20 & 1.12 & 0.66 & 0.10 \\
$+\quad$ frd & 1.54 & 0.06 & 0.32 & 0.31
\end{tabular}


Washed and unwashed rice straw hydrolysate samples were neutralized with $1 \mathrm{M}$ dibasic sodium phosphate and supplemented with tryptone, yeast extract and sodium chloride to final concentrations of 50, 25, and $10 \mathrm{~g} / \mathrm{L}$, respectively. These components provided nitrogen containing nutrients for growth of the cells. In an industrial fermentation, corn steep liquor often provides these nutrients. In preliminary tests, the media was sanitized in four ways, by autoclaving, autoclaving under an atmosphere of nitrogen, filtration and pasteurization. Samples, taken periodically, showed that all procedures except pasteurization completely eliminated growth by microbes present in the hydrolysate, which was not sterile. Autoclaving destroyed over half of the glucose present, even under nitrogen. Filtration gave totally sterile, undamaged medium but was very slow and is the least suited for industrial scale fermentations.

Pasteurization at $65^{\circ}$ for 30 min prevented growth of indigenous lactic acid bacteria for over 24 $\mathrm{hr}$. But after that, glucose was metabolized to lactic acid. Pasteurization at $68^{\circ} \mathrm{C}$ for $45 \mathrm{~min}$ destroyed enough of the bacteria that samples incubated for 2 days at $37^{\circ}$ were not metabolized. Less than $10 \%$ of the sugars were destroyed by this protocol, and it was used for subsequent experiments.

Sugars were metabolized efficiently in both washed and unwashed hydrolysates. After $68 \mathrm{hr}$, all the glucose, most of the xylose, and half the arabinose were consumed. The remaining arabinose most likely is not arabinose but rather another component in the hydrolysate that co-elutes with arabinose.

Note that significant succinate was formed in the previous experiment; at $44 \mathrm{hr} 6.3 \mathrm{~g} / \mathrm{L}$ of succinate and $32.5 \mathrm{~g} / \mathrm{L}$ of lactic acid were formed. Strain 418 is CSM1 with the gene encoding fumarate reductase, the enzyme that makes succinate, deleted. When grown under the same conditions, 418 produced $4.1 \mathrm{~g} / \mathrm{L}$ succinate and $30.0 \mathrm{~g} / \mathrm{L}$ lactic acid in $44 \mathrm{hr}$, indicating the deletion helps reduce but does not eliminate succinate formation. Some of the succinate may be formed from amino acids in the medium.

E. coli strain CSM1 rapidly produces high concentrations of lactic acid from glucose in high yield in rich media. We have modified this strain to allow efficient use of mixtures of sugars derived from lignocellulosic hydrolysates. Previously, we reported the conversion of true hydrolysates (received from UC Davis) by the strains to lactic acid. We evaluated conversion of a new preparation of rice straw hydrolysate that contained higher concentrations of sugars. Also, we reconstructed the mutants of CSM1 to generate a more stable strain, CSM5, that is able to convert mixtures of sugars to lactic acid. We observed that the more highly concentrated hydrolysate was somewhat toxic to the strains, resulting in incomplete conversion. If the hydrolysate was diluted two-fold, it was rapidly converted to lactic acid. 
Strain CSM5 was constructed by serially introducing knockout mutations that eliminated the activity of the $p t s G$ and frdABCD genes. The first gene encodes a glucose transporter that also is involved in regulation. This loss of regulation allows the resulting strain to convert mixtures of glucose and other sugars simultaneously, but the strain produced considerable amounts of succinic acid as well as lactic acid. The second mutation eliminated activity of the enzyme that makes succinic acid, and the resulting strain, CSM5, converted sugars exclusively to lactic acid. Both strains were subjected to extensive purification and selection to assure that no reversion of the introduced traits occurred.

Rice straw hydrolysate samples were neutralized with $1 \mathrm{M}$ dibasic sodium phosphate and supplemented with tryptone, yeast extract as described previously. Analysis of the hydrolysates by HPLC indicated the presence of approximately $39 \mathrm{~g} / \mathrm{L}$ glucose, $15 \mathrm{~g} / \mathrm{L}$ xylose, and $32 \mathrm{~g} / \mathrm{L}$ arabinose. However, the peak identified as arabinose certainly is mostly due to some other compound that coelutes with arabinose, possibly a product of partially hydrolysis. Arabinose is well known to be a minor component of hydrolysates, never a major component. Cells were cultured in $\mathrm{LB}$ overnight, diluted and grown aerobically to an $\mathrm{OD}_{600}=1$, then $1 \mathrm{ml}$ was added to $10 \mathrm{ml}$ of anaerobic medium in tubes containing $1 \mathrm{~g} \mathrm{MgCO}_{3}$ to maintain $\mathrm{pH}$.

Sugars in diluted hydrolysates were rapidly metabolized to lactic acid, but metabolism of undiluted hydrolysates was slower (Figure 3.10). In the diluted sample, sugars were nearly completely consumed in 24 hours, and $26 \mathrm{~g} / \mathrm{L}$ of lactic acid had accumulated, giving a productivity of greater than $1 \mathrm{~g} / \mathrm{Lh}$ for the entire conversion. The large amount of "arabinose" remaining was not metabolized further, consistent with our evaluation that it was not truly arabinose. The decrease of arabinose observed, approximately $4 \mathrm{~g} / \mathrm{L}$, is consistent with the amount of arabinose expected from hydrolyzed rice straw. Using that value, the initial composition of the hydrolysate would be: glucose, $29 \mathrm{~g} / \mathrm{L}$; xylose $15 \mathrm{~g} / \mathrm{L}$; arabinose $4 \mathrm{~g} / \mathrm{L}$, consistent with expectations and with our analysis of the first hydrolysate received from UC Davis. A small amount of other products were formed, approximately $1 \mathrm{~g} / \mathrm{L}$ each of succinate, acetate and ethanol.

The undiluted hydrolysate was converted more slowly; only19 g/L lactic acid was formed in 24 hours, and even after 140 hours some xylose remained unconverted. The final lactic acid concentration was $49.5 \mathrm{~g} / \mathrm{L}$, with $4 \mathrm{~g} / \mathrm{L}$ xylose remaining. The amounts of other products formed were: succinate, $1 \mathrm{~g} / \mathrm{L}$, acetate, $2 \mathrm{~g} / \mathrm{L}$ and ethanol, $3 \mathrm{~g} / \mathrm{L}$. The slower conversion in undiluted hydrolysate very likely reflects toxicity of materials present in the hydrolysate that are less detrimental when diluted. In defined media, the strain is very able to tolerate higher concentrations of sugars and lactic acid than were present in these experiments. It is possible that the material that co-migrates with arabinose contributes to this toxicity, and that altered hydrolysis conditions might reduce the toxicity. 


\section{Figure 3.10. Strain CSM1 fermentation}

A) Diluted hydrolysate

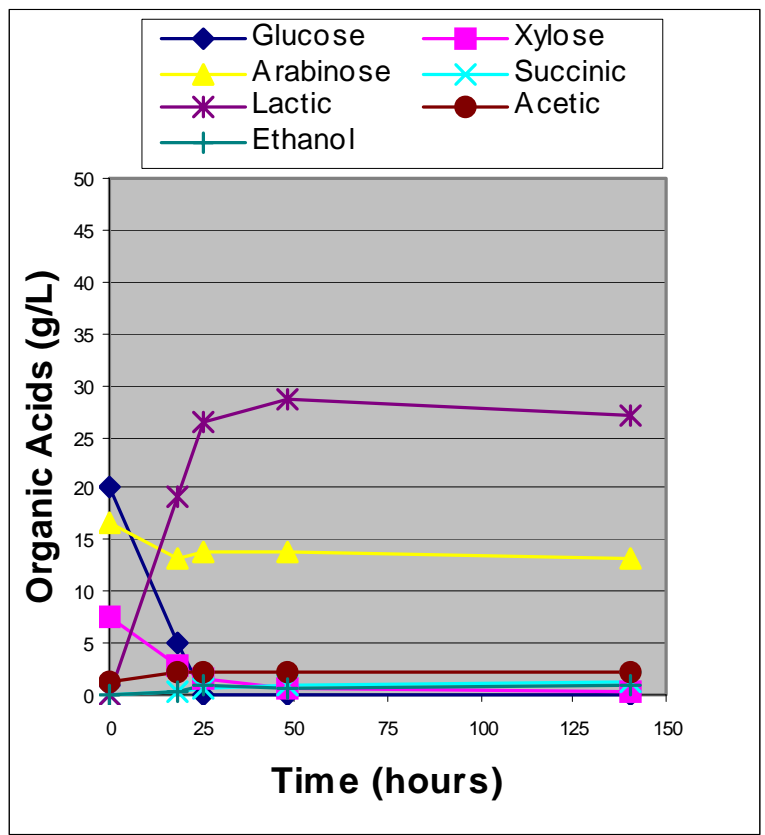

B) Undiluted hydrolysate

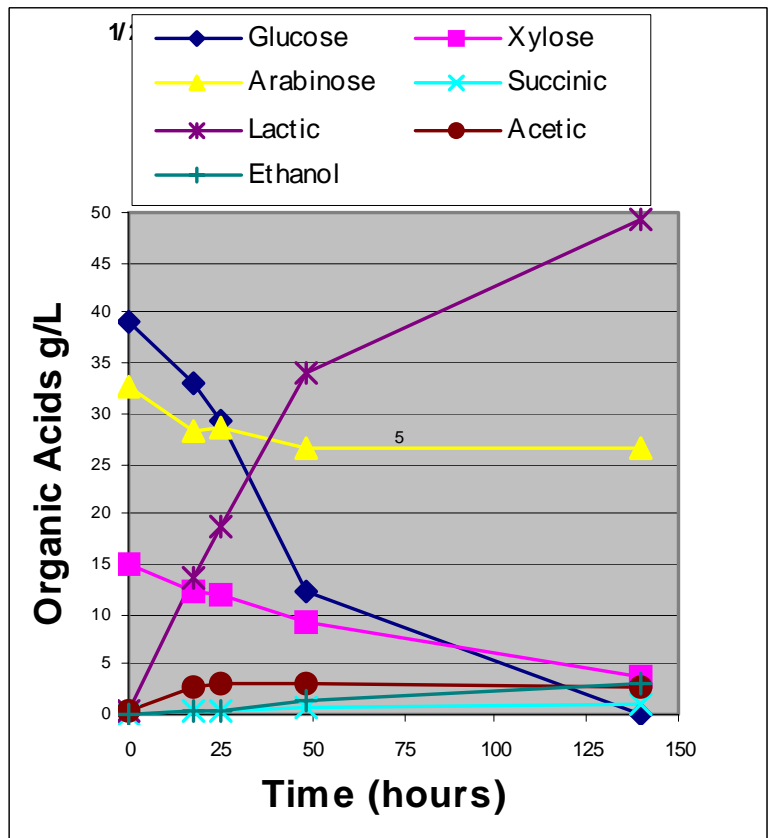

E. coli strain CSM1 rapidly produces high concentrations of lactic acid from glucose in high yield in rich media and its derivative, CSM5, produces lactic acid effectively from the mixtures of sugars found in lignocellulosic hydrolysates. We evaluated the ability of another derivative, CSM2, to produce lactic acid in a strict minimal medium. CSM2 contains mutations in the genes encoding pyruvate:formate lyase (which channels metabolism to lactic acid) and in fumarate reductase (which eliminates the side product, succinate). Advanced separations technologies under development at Argonne use electrochemical, membrane-based separation of organic acids from streams containing the salts of the acids. While potentially useful under many conditions, these approaches perform best when the fermentation broth processed contains fewer contaminating materials. One approach to reducing the concentration of contaminants is to use a simple mineral salts medium to culture the production organism and carry out the bioconversion.

The CSM lineage of E.coli grows well in a strict, mineral salts medium (Table 3.7). The improved growth under these conditions is illustrated by comparison of CSM1 to another lactic acid producing strain from the published literature, FMJ123. Both strains produce lactic acid and succinate under these conditions, but FMJ123 requires addition of amino acids for growth. Even when these are added, it grows significantly more slowly than CSM1 (Figure 3.11). Inactivation of the fumarate reductase gene in CSM1 gave CSM2, which converts glucose exclusively to succinate in minimal medium (Figure 3.12, Table 3.8). Titers of over $100 \mathrm{~g} / \mathrm{L}$ lactic acid can be generated in less than $40 \mathrm{hrs}$, and only small amounts of organic acids contaminate the final broth. Because no nutrient supplements are required, the broth is also free of the amino acids, vitamins and other poorly defined supplements commonly added to fermentation media. 
Because E. coli naturally makes D-lactic acid, it is possible for CSM2 to generate pure D-lactic acid in minimal medium. This result cannot be achieved in rich medium because the supplements added contain some L-lactic acid. Thus, lactic acid purified from the broths generated by CSM2 in minimal medium allow production of pure poly-D-lactic acid. Fibers of this polymer can be added to fibers of pure poly-L-lactic acid (the current commercial product) to modulate the properties of the resulting polymers while retaining the environmentally desirable characteristics of the polymers.

Table 3.7 . Strict mineral salts medium used for growth and lactic acid production by CSM2

\begin{tabular}{|c|c|}
\hline $\mathrm{K}_{2} \mathrm{HPO}_{4}$ & $20 \mathrm{mM}$ \\
\hline $\mathrm{KH}_{2} \mathrm{PO}_{4}$ & $50 \mathrm{mM}$ \\
\hline$\left(\mathrm{NH}_{4}\right)_{2} \mathrm{SO}_{4}$ & $70 \mathrm{mM}$ \\
\hline $\mathrm{MgSO}_{4}$ & $32 \mathrm{mM}$ \\
\hline
\end{tabular}

Figure 3.11. Growth of CSM1 and FMJ123 in minimal medium + amino acids

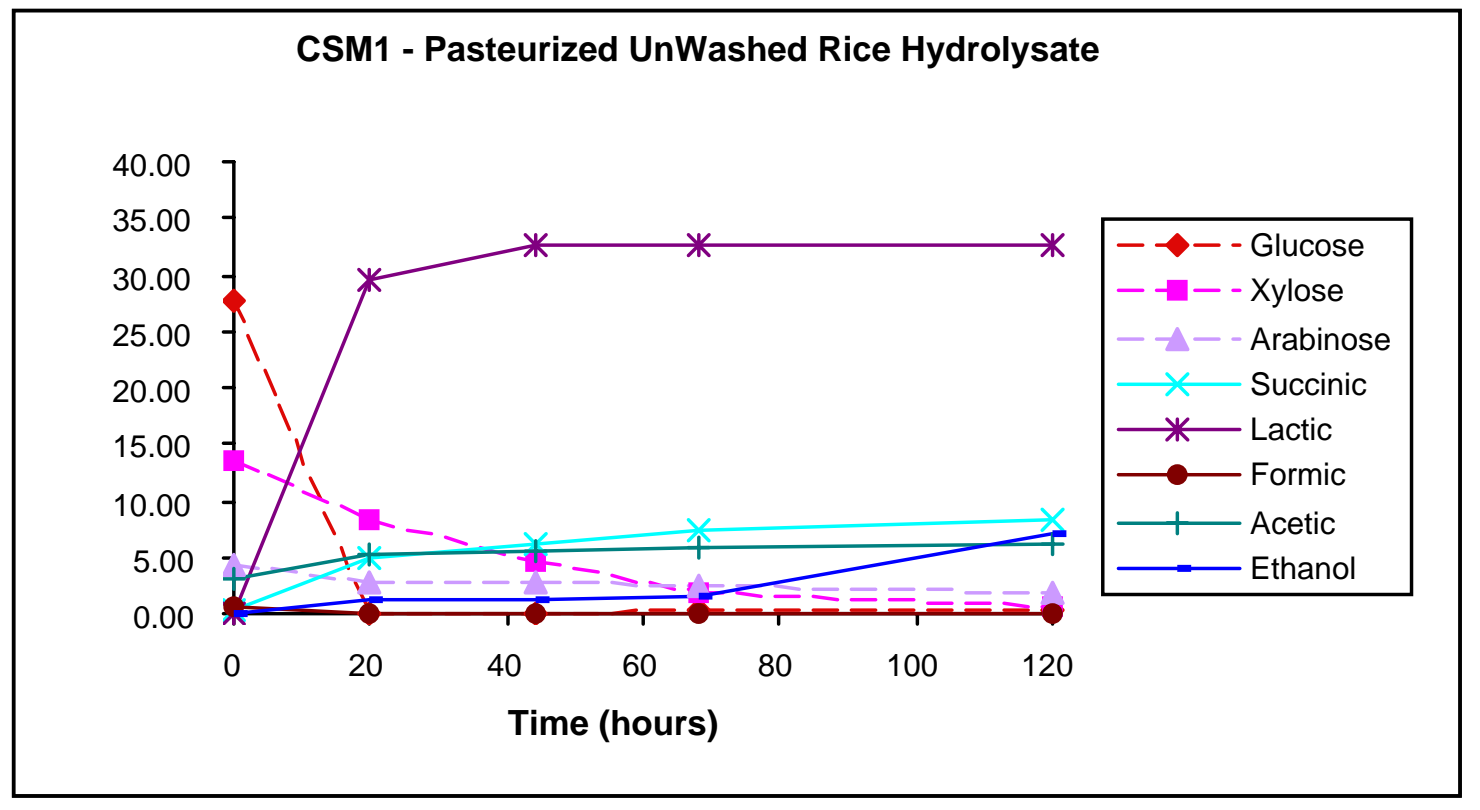


Figure 3.12. Production of lactic acid in minimal medium by CSM2.

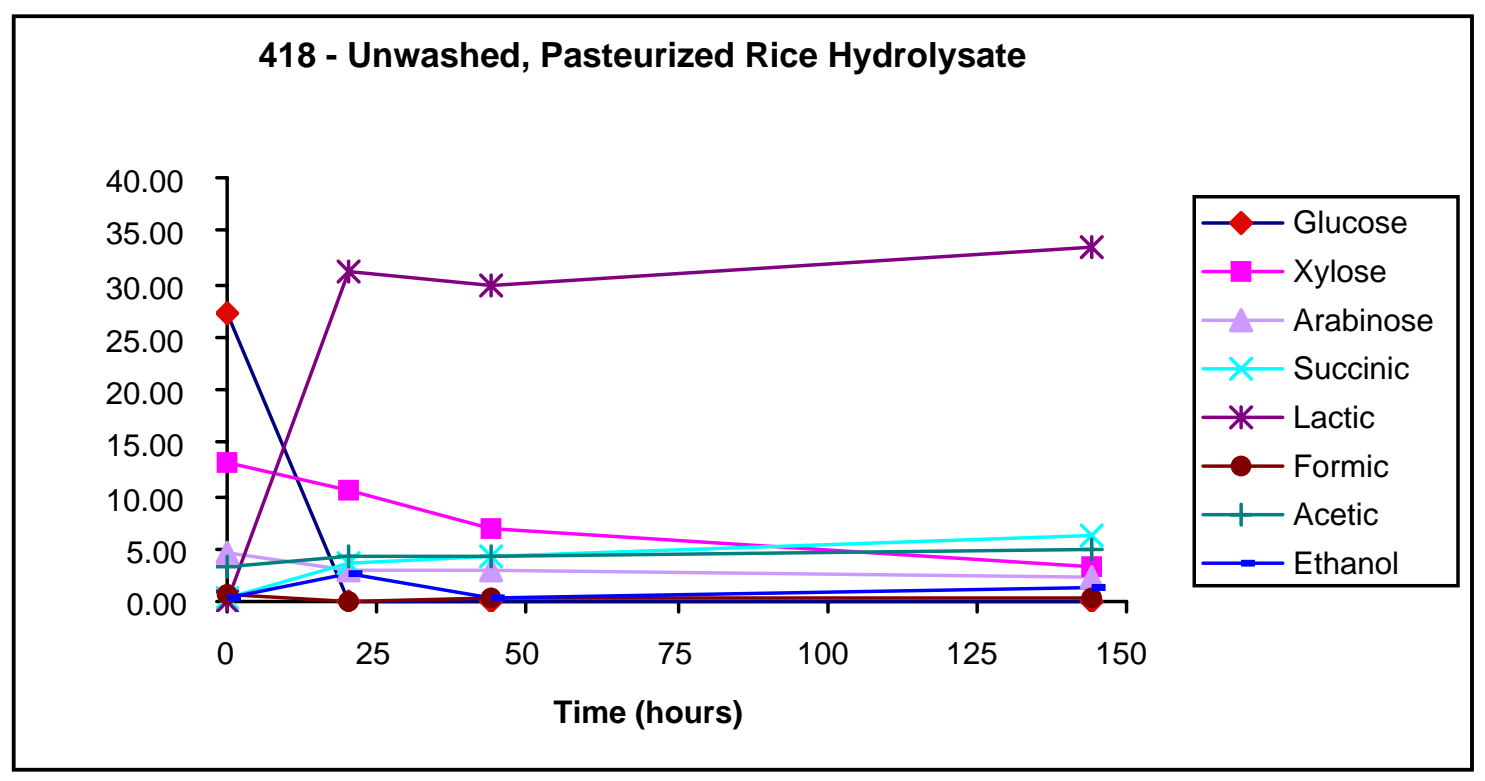

Table 3.8. Products formed from glucose in minimal medium by CSM2.

\begin{tabular}{|l|c|c|}
\hline \multicolumn{1}{|c|}{ Product } & mol/mol glucose & $\mathrm{g} / \mathrm{L}$ \\
\hline Glucose & 0.01 & 0.5 \\
\hline Lactic acid & 1.90 & 92.4 \\
\hline Succinic acid & 0.01 & 0.75 \\
\hline Formic acid & 0.00 & 0 \\
\hline Acetic acid & 0.01 & 0.21 \\
\hline Ethanol & 0.03 & 0.81 \\
\hline
\end{tabular}

E. coli strain CSM2 rapidly produces high yields of lactic acid from glucose in rich media or minimal medium, and strain CSM5 produced lactic acid in high yield from lignocellulosic hydrolysates. It should be noted that the funding allocation for the microbiology research was largely consumed before strain optimization could be completed.

An important property of a production strain is its ability to sustain productivity through without requiring re-initiation of the production process. Most lactic acid producing strains are used in batch processes, which are terminated after a single cycle of production and begun again with fresh inoculum cultures; cells in the final stage of production are not able to initiate another production cycle efficiently. We have demonstrated that CSM5, in contrast, is quite amenable to serial production cycles, suggesting the strain could be used in a continuous process. A culture of 
CSM5 was grown on lignocellulosic hydrolysates and, when production neared completion, subcultured into another tube containing fresh medium. The dilution factor was 10-fold, and four cycles of production were carried out. Under these conditions, CSM5 produced lactic acid as effectively on serial cultures, generating consistent yields, titers and productivities (Figure 3.13). These results indicate the strain should be effective in a simple feed-and-draw continuous process in which $90 \%$ of a culture is harvested and replaced by fresh medium.

\section{Figure 3.13. Continuous production of lactic acid in serial cultures of CSM5}

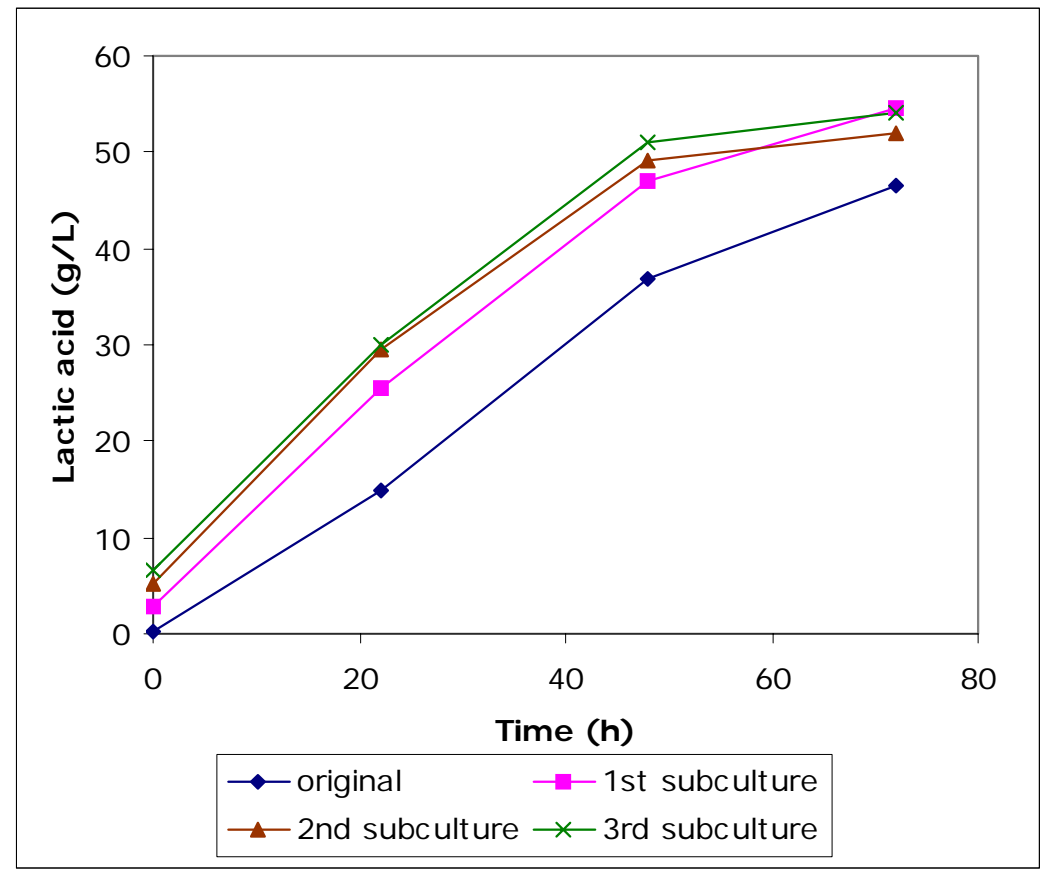

A summary of characteristics of the three best strains that were developed from our studies is given in Table 3.9. 
Table 3.9. Comparison of candidate strains $E$. coli, Lb .brevis and Lb. pentosus

\begin{tabular}{|c|c|c|c|}
\hline $\begin{array}{c}\text { Candidate } \\
\text { strains }\end{array}$ & E. coli & Lb. brevis & Lb. pentosus JH5XP5 \\
\hline Characteristics & $\begin{array}{l}\text { •Recombinant strain } \\
\text { •Well known } \\
\text { microorganism } \\
\text { •Genetics understood }\end{array}$ & $\begin{array}{l}\cdot \text { Wild type strain } \\
\text { •Full genome sequence } \\
\text { available } \\
\text { •Obligately } \\
\text { heterofermentative }\end{array}$ & $\begin{array}{l}\text { •Naturally selected non- } \\
\text { CCR* strain } \\
\text { •complete genome } \\
\text { sequence is not available } \\
\text { •Homofermentative and } \\
\text { heterofermentative }\end{array}$ \\
\hline $\begin{array}{l}\text { Lactic acid } \\
\text { yield from } \\
\text { glucose }\end{array}$ & $\begin{array}{l}\cdot \text { Homofermentative } \\
\text { pathway } \\
\cdot \text { High lactic acid yield at } \\
\text { theoretical maximum of } \\
2.0 \text { (mM lac/mM glc) }\end{array}$ & $\begin{array}{l}\cdot \text { Low yield compare to } \\
\text { E.coli } \\
\cdot 1.0 \text { (mM lac/mM glc) of } \\
\text { lactic acid yield from } \\
\text { glucose }\end{array}$ & $\begin{array}{l}\cdot 2.0 \text { (mM lac/mM glc) of } \\
\text { lactic acid yield from } \\
\text { glucose }\end{array}$ \\
\hline $\begin{array}{l}\text { Pentose and } \\
\text { hexose } \\
\text { utilization } \\
\end{array}$ & $\begin{array}{l}\text {-Utilization is not complete } \\
\text { and sequential }\end{array}$ & $\begin{array}{l}\text {-Simultaneous and } \\
\text { complete utilization of } \\
\text { pentoses and hexoses }\end{array}$ & $\begin{array}{l}\text {-Simultaneous and } \\
\text { complete utilization of } \\
\text { pentoses and hexoses }\end{array}$ \\
\hline $\begin{array}{l}\text { Characteristics } \\
\text { of lag phase } \\
\text { and } \\
\text { fermentation } \\
\text { profile }\end{array}$ & $\begin{array}{l}\text {-Long lag phase } \\
\text { •Un-optimized inoculation } \\
\text { culture / Inhibition by rice } \\
\text { straw hydrolysates is } \\
\text { unknown }\end{array}$ & $\begin{array}{l}\text {-No lag phase } \\
\text { •Complete carbon } \\
\text { utilization } \\
\text { •No inhibition by rice } \\
\text { straw hydrolysate or lactic } \\
\text { acid acid }\end{array}$ & $\begin{array}{l}\text { •No lag phase } \\
\text { •Complete carbon } \\
\text { utilization } \\
\text { - No inhibition by rice } \\
\text { straw hydrolysate or lactic } \\
\text { acid }\end{array}$ \\
\hline $\begin{array}{l}\text { Nitrogen } \\
\text { sources }\end{array}$ & $\begin{array}{l}\text { - Can use a minimal culture } \\
\text { medium }\end{array}$ & $\begin{array}{l}\text {-Effect of minimal or } \\
\text { industrial nitrogen source } \\
\text { is unknown }\end{array}$ & $\begin{array}{l}\text { • Effect of minimal or } \\
\text { industrial nitrogen source } \\
\text { is unknown }\end{array}$ \\
\hline Co-products & $\begin{array}{l}\text {-Small amount of acetate } \\
\text { produced } \\
\text {-Acetate/ethanol from } \\
\text { xylose }\end{array}$ & $\begin{array}{l}\text { •Acetate/ethanol from } \\
\text { xylose and glucose }\end{array}$ & $\begin{array}{l}\text {-Acetate is negligible in the } \\
\text { presence of glucose } \\
\text {-Conversion of two carbon } \\
\text { intermediate to ethanol } \\
\text { instead of acetate }\end{array}$ \\
\hline $\begin{array}{l}\text { Enzyme } \\
\text { stability for the } \\
\text { SSF }\end{array}$ & •Unknown & $\begin{array}{l}\text {-Cellulase and cellobiase } \\
\text { activities are stable during } \\
\text { the fermentation in the rich } \\
\text { media }\end{array}$ & $\begin{array}{l}\text {-Cellulase and cellobiase } \\
\text { activities are stable during } \\
\text { the fermentation in the rich } \\
\text { media }\end{array}$ \\
\hline $\begin{array}{l}\text { Fermentation } \\
\text { mode with } \\
\text { mixed sugar }\end{array}$ & & $\begin{array}{l}\text { •Batch, fed-batch, } \\
\text { SSMSF** }\end{array}$ & $\begin{array}{l}\text { •Batch, fed-batch, } \\
\text { SSMSF** }^{* *}\end{array}$ \\
\hline
\end{tabular}

*CCR is carbon catabolite repression

**SSMSF is simultaneous saccharification mixed sugar fermentation 


\section{Task 4. Fermentation process development.}

The need for better control of fermentation parameters on fermentors in our laboratory prompted the retrofit of two old New Brunswick benchtop fermentors. Benefits of such a retrofit are better overall control and greater flexibility in the fermentation process, computerized data logging for easy data analysis and integration, and a closer resemblance to pilot-scale and full-scale production environment.

Various control alternatives were explored, ranging from Industrial PLCs to embedded controllers. A PC-based system was found to be the best compromise between ease of use, expandability, and dependability.

The hardware solution consisted of using a Compaq Pentium computer with a ComputerBoards Interface PCI board, along with an Ingold Dissolved Oxygen Probe and Transmitter, an Ingold pH Probe and Cole-Parmer Transmitter, and a Cole-Parmer Mass Flow Controller for airflow control. Temperature is monitored by a National Semiconductor LM35 IC and the system can be expanded to monitor four additional parameters.

The software solution consisted of developing our own proprietary control system in Visual Basic 6.0. The current software release features a parameter profile designer, real-time parameter display and control, automatic data logging and data display, and advanced alarm handling. New features in the pipeline include automatic Biological Oxygen Demand computation and Web-based Monitoring.

\subsection{Lactic acid production by Lactobacillus brevis.}

4.1.a. Simultaneous carbohydrate utilization of $\boldsymbol{L} \boldsymbol{b}$. brevis. Simultaneous utilization of glucose and other sugars was examined. Lb. brevis IFO 3960 can co-metabolise ribose, arabinose, xylose, galactose, and fructose, very rapidly with the glucose but cannot take up galactose and lactose. Any carbohydrate that can be used as single carbon source by Lb. brevis IFO 3960, appears to be co-metabolized with glucose. When a five carbon sugar is consumed with glucose, ethanol production is reduced and acetic acid is increased, as compared to endproducts observed with six carbon sugars.

While glucose and xylose are major carbon source of rice straw hydrolysate, they can be separated when acid pretreated rice straw is washed. Hence, results of fermentations of glucose and xylose as a mix, and as separate sugar fermentations, were compared. Culture media containing glucose, xylose and glucose/xylose mixtures (molar ratios of 1:2, 1:1 and 2:1) were incubated with $L b$. brevis and cell growth rates did not show a difference between each group. The specific glucose consumption rate and specific xylose consumption rate of glucose and xylose mixture were reduced to $45 \%$ and $68 \%$ respectively, however, total carbohydrate consumption rate of sugar was equivalent. There was no difference in specific xylose or glucose consumption rate between the different glucose/xylose mixtures. All sugars gave approximately the same lactic acid production rate and yield but the ratio of acetate and ethanol varied with the presence of xylose. No ethanol production was observed when xylose was used as single carbon source. Growth on glucose resulted in more ethanol (ratios between lactic acid: acetate: ethanol were 1:0,16:1) Molar ratio between acetate and ethanol of glucose-xylose mixture was 
approximately 3:2, which could be explained from specific glucose and xylose consumption rates.

We examined if co-metabolism was a specific trait of $L b$. brevis IFO 3960 or common to more $L b$ brevis strains. Three additional strains of $L b$. brevis were examined to confirm the simultaneous fermentation of glucose/xylose mixtures. All three strains, $L b$. brevis NRRL 4527 (=ATCC 14869, type strain), NRRL 1836, NRRL 1834 were found to use the glucose and xylose at the same time but the consumption rates vary. This suggested that $L b$. brevis does not possess the typical catabolite repression observed with other lactobacilli.

4.1.b. Carbohydrate utilization of $\mathbf{L b}$. brevis strains. Carbohydrate utilization of $L b$. brevis was examined because the carbohydrate utilization patterns were different from previously published data on $L b$. brevis. The IFO3960 and NRRL strains show starkly different utilization patterns (Table 4.1). The NRRL strains were promising candidates for the SSF process because they can utilize the cellobiose. The metabolism of tested carbohydrate was not inhibited by the presence of glucose. When glucose existed with a second carbohydrate in the media, Lb. brevis was able to utilize glucose and second carbon source simultaneously, provided that the second carbon source could be used by $L b$. brevis.

Table 4.1. Carbohydrate Utilization by $L$.brevis.

\begin{tabular}{l|cccccccc}
\hline & Cellobiose & Lactose & Sucrose & Mannose & Galactose & Fructose & Ribose & Arabinose \\
\hline Lb.brevis NRRL 4527 & Yes & Yes & Yes & Yes & Yes & Yes & Yes & Yes \\
Lb.brevis NRRL 1836 & Yes & Yes & Yes & Yes & $\begin{array}{c}\text { Unknown } \\
\text { (Yes) }\end{array}$ & Yes & Yes & Yes \\
Lb.brevis NRRL 1837 & Yes & Yes & Yes & Yes & Yes & Yes & Yes & Yes \\
Lb.brevis IFO 3960 & No & No & No & No & Yes & conversion & Yes & Yes \\
\hline
\end{tabular}

4.1.c. Effects of pH on lactic acid production by $\boldsymbol{L} \boldsymbol{b}$. brevis. The optimum $\mathrm{pH}$ for cell growth and product formation was tested. To see the effect of $[\mathrm{H}+], \mathrm{pH}$ was maintained by $\mathrm{HCl}$ and $\mathrm{pH}$ of the medium was adjusted from 1.5 to 9 . Optimum $\mathrm{pH}$ for cell growth was found to be between 6-7 and cells did grow below $\mathrm{pH} 3$ and above $\mathrm{pH}$ 8. The optimum $\mathrm{pH}$ for product formation was found to be $\mathrm{pH} 6$.

4.1.d. Effects of temperature on Lactobacillus brevis strain. Thermostability and temperature effect of $L b$. brevis strain was studied using the same temperature increments used in the enzyme hydrolysis experiments. Four Lactobacillus strains were cultivated in the MRS media with $20 \mathrm{~g} / \mathrm{L}$ of glucose in a semi-aerobic condition. Fermentation was done in the $250 \mathrm{ml}$ baffled flasks with $100 \mathrm{ml}$ working volume. Initial $\mathrm{pH}$ is set 6.0 but not controlled during fermentation. For the experiment at $40^{\circ} \mathrm{C}$, the cells were initially cultured at $30^{\circ} \mathrm{C}$ in the MRS media with same condition except $30 \mathrm{~g} / \mathrm{L}$ of the initial glucose concentration. After 8hours, the temperature was shifted to $40^{\circ} \mathrm{C}$. Kinetic values for the $30^{\circ} \mathrm{C}$ and $40^{\circ} \mathrm{C}$ fermentations were compared at the same growth phase. To test the thermostability at $50^{\circ} \mathrm{C}$, the cells were cultured at $30^{\circ} \mathrm{C}$ for 12 hours and then shifted to $50^{\circ} \mathrm{C}$. Samples were taken every 3 hours and spread on the MRS-agar plate after serial dilutions. Agar plates were incubated at $30^{\circ} \mathrm{C}$ for 24 hours and colonies were counted. 
Specific cell growth rate of the $L b$. brevis strains between $30^{\circ} \mathrm{C}$ and $40^{\circ} \mathrm{C}$ were not significantly different, except for $L b$. brevis IFO 3960. $L b$. brevis showed a $50 \%$ reduction of specific growth rate at $40^{\circ} \mathrm{C}$ compare to that of $30^{\circ} \mathrm{C}$. At $50^{\circ} \mathrm{C}$, cell growth was completely inhibited for all four Lb. brevis strains. Both specific glucose consumption and lactic acid production rate increased at $40^{\circ} \mathrm{C}$. Product yields indicate that the carbon flux was changed from acetate to ethanol at $40^{\circ} \mathrm{C}$ while lactic acid yields were unchanged. Perhaps the increase of temperature (and lower oxygen solubility) resulted in a different redox state for the cell and a need to regenerate the $\mathrm{NADH}$, thus creating more ethanol.

4.2. Process design considerations. Lactic acid production from rice straw is different from other industrial biotech processes. For example, lactic acid production does not require as much cleanness as other pharmaceutical or food industry processes because the product is a bulk organic chemical and the substrate is not fine or a defined chemical. The substrate is a waste product that is being used both in a waste process and a traditional chemical process. The following are some points that considered when the complete process is designed.

4.2.a. Basic features of rice straw. Rice straw not only comprises hemicellulose and cellulose as its primary carbon but also contains high amount of silica particles and unknown compounds. As a substrate, it forms a low density, highly viscous suspension. The goal is to obtain as high a concentration of the substrate (rice straw hydrolysate) as possible in the fermentor. The "mudlike” suspension of rice straw is of low density and is a problem material in pumping through pipes. A solid suspension is achieved at about 8-10\%. Also, its high viscosity affects mixing in the enzyme hydrolysis bioreactor. Homogeneous mixing can result in the failure of $\mathrm{pH}$ and temperature control and the reduction of enzyme efficiency.

The high concentration of silica particles also affects processing, with precipitation during the enzyme hydrolysis in spite of high speed agitation. Silica particles gave problems during the heat sterilization, where there was a slight increase in precipitated silica particle size. If a mode of simultaneous saccharification and fermentation mode (SSF) or the process of hydrolysis and fermentation in one batch reactor (whether simultaneous or sequential) is used, then the increased size silica particle, like sand, in the reactor can bring on special problems with the equipment and microbial growth.

4.2.b. Product features. Unlike most biotechnology processes, the final product of lactic acid fermentation is a very simple organic acid that influences the product purification method. The three-carbon organic acid needs to be isolated in the mixture of another three carbon organic acid (acetate), two-carbon alcohol, and the five and six carbon carbohydrates. Rather than general chromatographic separation methods, such as HIC (hydrophobic interaction), SEC (Size exclusion), or IEC (Ion exchange), traditional chemical separation methods, such as distillation, will be the preferred separation method. The best method for the product separation and purification, however, is complete consumption and removal of the co-products altogether.

4.2.c. Sterilization. For the fermentation, the culture medium should be sterilized in a proper manner such as heat treatment or filtration. But rice straw hydrolysate required different conditions. First, during the acid hydrolysis, the $\mathrm{pH}$ of the suspension was less than $\mathrm{pH}$ 2.0. Second, after acid hydrolysis, although the $\mathrm{pH}$ rose to 5.0, the temperature for the enzyme 
hydrolysis was $58^{\mathrm{O}} \mathrm{C}$ for at least 12 hours, which is enough to inactivate most microorganisms. Third, the silica particles in the rice straw made aggregates, which can affect cell growth and equipment operation. Fourth, unknown compounds and minor compounds in the rice straw cell wall generated unidentified haze materials during heat sterilization.

\subsection{Fermentation process}

Considering the factors describe above, a combination of fermentation and hydrolysis processing options were examined.

4.3.a. SSF (simultaneous saccharification and fermentation). SSF can increase the productivity by reducing the operational time for hydrolysis and fermentation. The solid material in rice straw and the unknown compound from cell walls was found not to inhibit subsequent fermentation. The features for saccharification and fermentation are not optimal, with the optimum temperature for the enzyme hydrolysis as $58^{\circ} \mathrm{C}, \mathrm{pH} 5.0$ and those for the fermentation as $30^{\circ} \mathrm{C}$, $\mathrm{pH} 6.0$.

Though not an optimal situation, an SSF mode was examined in two experiments. The first experiment addressed the effect of temperature on enzyme hydrolysis. If the temperature was decreased from $40^{\circ} \mathrm{C}$ to $30^{\circ} \mathrm{C}$, the enzyme hydrolysis time was increased two and four times, respectively, compared to with the optimal temperature. At $30^{\circ} \mathrm{C}$ even after two days, the hydrolysis was not complete, compared to complete hydrolysis after 12 hours at $58^{\circ} \mathrm{C}$. The second experiment examined the effect from increasing the cell growth temperature. Although the optimum temperature of $L b$. brevis is $30^{\circ} \mathrm{C}$, cell growth rate and lactic acid production was found not to change significantly at $40^{\circ} \mathrm{C}$. However at $45^{\circ} \mathrm{C}$, most of cells were killed dramatically. Therefore using the current enzyme system, SSF was not considered further.

4.3.b. Batch process of sequential hydrolysis and fermentation in a single bioreactor. In a single bioreactor, sterile $0.5 \mathrm{M}$ sodium acetate buffer ( $\mathrm{pH} 5.0$ ) was added to the acid hydrolyzed rice straw to make $150 \mathrm{~g}$-dry mass/L of suspension. With mixing, the $\mathrm{pH}$ was adjusted from 2.0 (initial pH) to 5.0 using NaOH. 100 unit/ 100g-dry mass substrate of cellulase (Spezyme CP) and cellobiase (Novozyme 188) was added. For 12 hour, temperature was maintained at $58^{\circ} \mathrm{C}$. After cooling to $30^{\circ} \mathrm{C}$, MRS powder (nitrogen source) and 5\% inoculum was added. This experiment had multiple problems and in the end failed. Because of the nature of the "mud-like" viscous substrate with high level of solid particles, it could not be mixed adequately and the $\mathrm{pH}$ could not be controlled. With a loss of $\mathrm{pH}$ control, the enzymes were inactivated and the cellulose was not degraded. Another problem was foaming. The suspension of rice straw hydrolysate contained considerable solid materials, comprising proteins and unknown compounds that contributed to vigorous foam production in spite of a low aeration rate $(0.5 \mathrm{vvm})$. To remove the foam, $10 \mathrm{ml}$ of concentrated silicon oil was added in the 3L of fermentation volume. Still, at the end of the fermentation a thick solid precipitation layer of foam remained on the surface. The poor characteristics of the rice straw fermentation system are not trivial to overcome. Although the hydrolysis failed, $L b$. brevis grew and produced lactic acid using xylose and arabinose originating from acid hydrolysis of hemicellulose and glucose from the MRS media. All three carbohydrates were used simultaneously and cell growth rate and product yields gave the same results as the fermentation using MRS media. 
4.3.c. Challenges to the process. The maximum carbohydrate concentration obtained from enzyme hydrolysis in a single batch process is about $80 \sim 90 \mathrm{~g} / \mathrm{L}$. Lb. brevis did not show substrate inhibition below $100 \mathrm{~g} / \mathrm{L}$ carbohydrates. Therefore, simple batch fermentation is an appropriate operation mode. Fed-batch mode for the lactic acid production requires that the feeding solution have a higher carbohydrate concentration. To increase the final lactic acid concentration and overcome the problems of single batch fermentation, it is necessary to develop the fed-batch enzyme hydrolysis process.

The simultaneous saccharification and fermentation of rice straw hydrolysate to produce lactic acid is one of the best ways to increase the lactic acid productivity. However, there are some problems that make it difficult to integrate the two processes. The first is reaction temperature of enzyme hydrolysis. The optimum reaction temperature for cellulose hydrolysis is $50^{\circ} \mathrm{C}$, in this study, or higher. But the cell growth temperature for the bacterial cells is between $30 \sim 37^{\circ} \mathrm{C}$. The second is $\mathrm{pH}$. The optimum $\mathrm{pH}$ for enzyme hydrolysis is $\mathrm{pH} 5$ but for cell growth is $\mathrm{pH}$. The third is inhibition of enzyme activity by cell growth medium components. Enzyme hydrolysis reaction occurs at $\mathrm{pH} 5.0$ in a buffer of $0.05 \mathrm{M}$ sodium acetate buffer but the culture medium contains some materials that could possibly inhibit cellulase and cellobiase. The fourth is degradation of enzymes by proteases, which may be produced by $L b$. brevis during the fermentation. The cost of enzyme hydrolysis is most significant step in cost of producing lactic acid from lignocellulose. Therefore, maintaining the enzyme activity is a very important factor in the overall production process. To achieve SSF, an integrated process of hydrolysis and fermentation, serial experiments were done using the $L b$. brevis system.

\subsection{Integration of enzyme hydrolysis and fermentation}

To produce the lactic acid from rice straw, both hydrolysis and a fermentation steps are required. In the first step, hemicellulose is hydrolyzed by a mild sulfuric acid, and the cellulase portion is converted to glucose by cellulases. The reaction conditions for this part of the process can have a significant affect on the next part of the process. Also, separation of contaminants in the rice straw, such as silicas which represent up to $50 \%$ of the total dry matter of the hydrolysate, is an important process operation. With these important and other process variables, the operational mode of hydrolysis and fermentation was discussed and developed.

\section{4.a. Effect of temperature on enzyme hydrolysis of the acid pretreated rice straw.} Enzymatic hydrolysis of acid-pretreated rice straw was carried out at $30^{\circ} \mathrm{C}, 40^{\circ} \mathrm{C}$ and $50^{\circ} \mathrm{C}$. 250gdry mass $/ \mathrm{L}$ of $\mathrm{H}_{2} \mathrm{SO}_{4}$ pretreated rice straw which is obtained from BC International, was hydrolyzed by Novozyme 188 (Cellobiose) and Spezyme CP(Cellulose) in $0.05 \mathrm{M}$ acetate buffer at $\mathrm{pH}$ 5.0. Cellobiase and cellulase were added 100CBU/g-substrate and 100FPU/g-substrate respectively. Experiments were done at the $250 \mathrm{ml}$ Erlenmeyer flask with gentle shaking. As shown in Figure 4.1, the final glucose concentration obtained from hydrolysis at $30^{\circ} \mathrm{C}$ and $40^{\circ} \mathrm{C}$ are same $\left(35 \mathrm{~g} / \mathrm{L}\right.$ ) while those of $50^{\circ} \mathrm{C}$ group reach $55 \mathrm{~g} / \mathrm{L}$, (the same value obtained at optimum temperature).

Comparison of hydrolysis rate (production formation per unit time) with reaction temperature, shows that only the initial hydrolysis rates are affected by temperature (Figure 4.2). The initial 
glucose production rate at $50^{\circ} \mathrm{C}$ is twice that of $40^{\circ} \mathrm{C}$, but immediately following, the glucose production rates decreased sharply and converged to the same values of $40^{\circ} \mathrm{C}$ reaction. The hydrolysis profile and rates at $30^{\circ} \mathrm{C}$ were the same as the $40^{\circ} \mathrm{C}$ reaction. These results are consistent with end-product (glucose and cellobiose) inhibition. Hence, a key factor to increase or maintain enzyme activity is not the temperature but the elimination of end-product inhibition. Since the optimum cell growth temperature for $L b$. brevis is between $30^{\circ} \mathrm{C}$ and $40^{\circ} \mathrm{C}$, glucose removal by fermentation may resolve the end product inhibition and therefore SSF may increase the productivity of lactic acid. 
Fig 4.1. Glucose production by enzyme hydrolysis of rice straw at different temperature

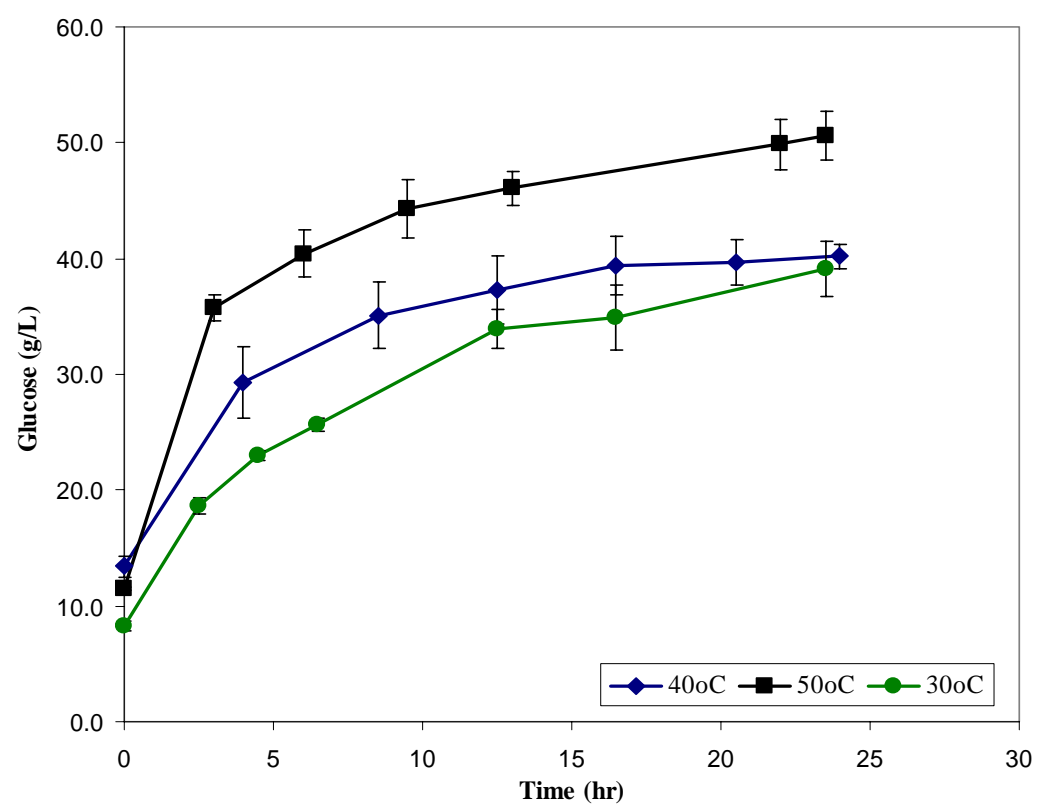

Figure 4.2 Cellulase activities calculated from glucose production rates at different temperature.

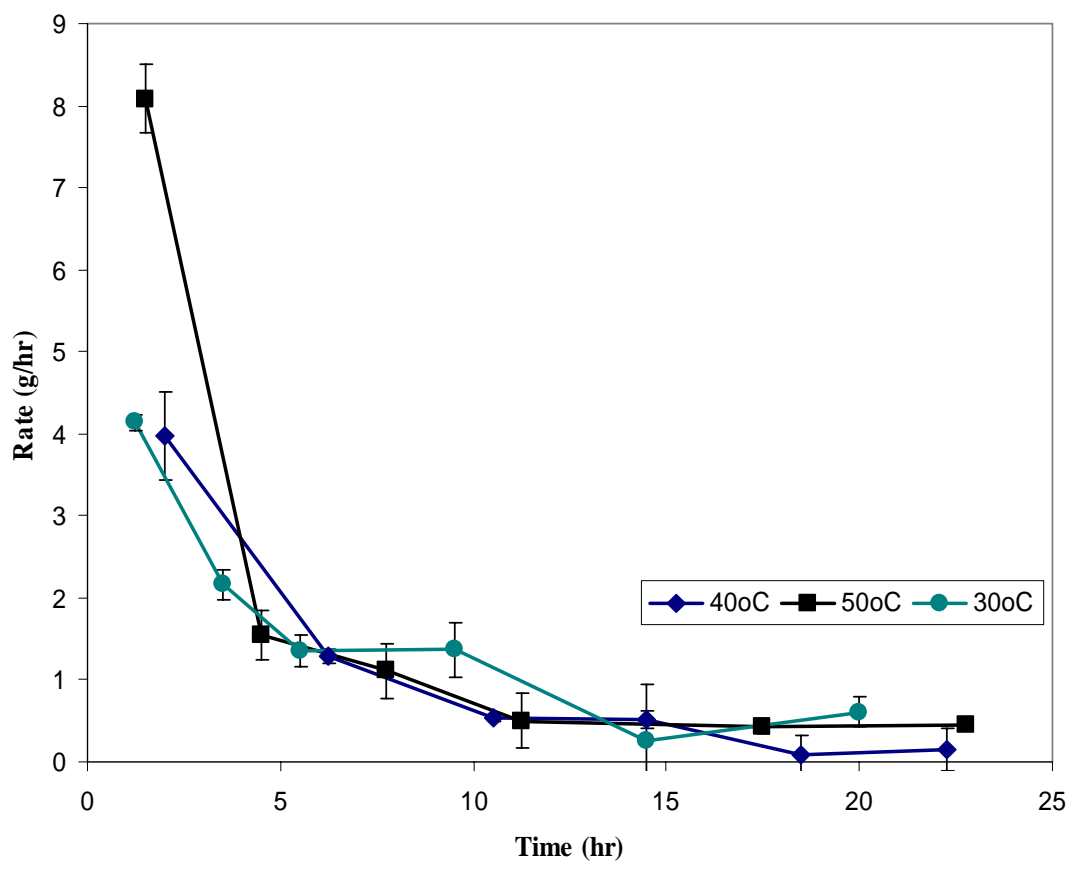


4.4.b. Toxicity test of rice straw hydrolyzates. Cellulosic biomass contains lignin compounds that can act as cell growth inhibitors. In addition, carbohydrate monomers can be converted to furfural compounds under the acidic pretreatment conditions that can act as cell growth inhibitors. Therefore, the acid pretreated rice straw was tested with $L b$. brevis. Rice straw hydrolysate was incubated with $L b$. brevis in lab-scale flask fermentations performed under semi-aerobic conditions at $30^{\circ} \mathrm{C}$. The medium $\mathrm{pH}$ was set at 6.0 initially but not controlled during the fermentation. Four types of media were prepared for the test, MRS (contain 20g/L of glucose) and three other media derived from acid hydrolyzed rice straw were provided by NRRL (washed substrate, unwashed substrate and washed supernatant).

The three media derived from acid hydrolysate were prepared by the following method. 150g dry mass of acid hydrolyzed rice straw was washed the $0.05 \mathrm{M}$ of acetate buffer five times. After the final wash the hydrolyzed rice straw is re-suspended in $1 \mathrm{~L}$ of $0.05 \mathrm{M}$ of acetate buffer $(\mathrm{pH}$ 5.0) and treated via enzyme hydrolysis as obtained in Task 2. The enzyme hydrolysis was carried out at $58^{\circ} \mathrm{C}$ for 48 hours, to give enough time for complete hydrolysis of the cellulosic component of rice straw acid hydrolysate. After centrifugation to remove solids, the supernatant was autoclaved and transferred to $250 \mathrm{ml}$ baffle flask with (33 gm/L) MRS as nitrogen source and designated as "washed" substrate. Unwashed substrate is similar to washed except that no prefiltering of acid hydrolyzed rice straw was performed. During the initial washing steps, first $1 \mathrm{~L}$ of wash buffer was collected separately and autoclaved. This media was designated as 'washed supernatant' and used for toxicity testing.

Figure 4.3 shows that no inhibition was observed by different strains of $L b$. brevis grown in different media (control, washed, unwashed). Final lactic acid concentration of Lb. brevis NRRL 1836 in 'washed' and 'unwashed' media showed some difference at the later stages of the fermentation however during exponential phase, $L b$. brevis NRRL 1836 show the same level of lactic acid production in all three kinds of substrates. Thus, on the basis of flask experiments alone $L b$. brevis NRRL 1836 showed no dramatic differences in lactic acid production. 
Figure 4.3. Lactic acid production in the MRS(A), washed (B), and unwashed(C) media by different Lactobacillus strains
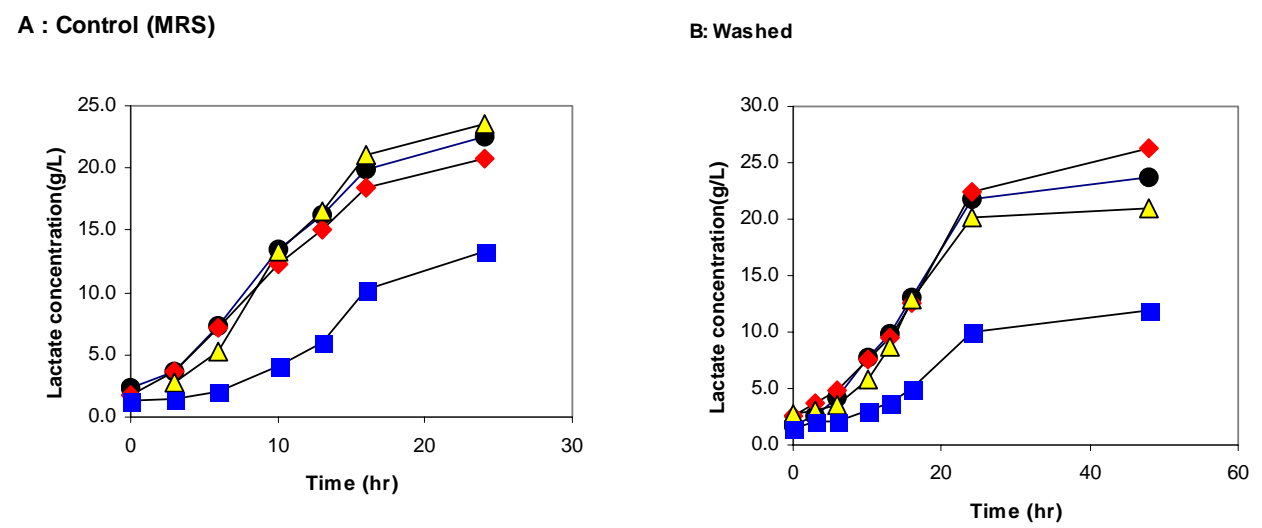

C :Unwashed

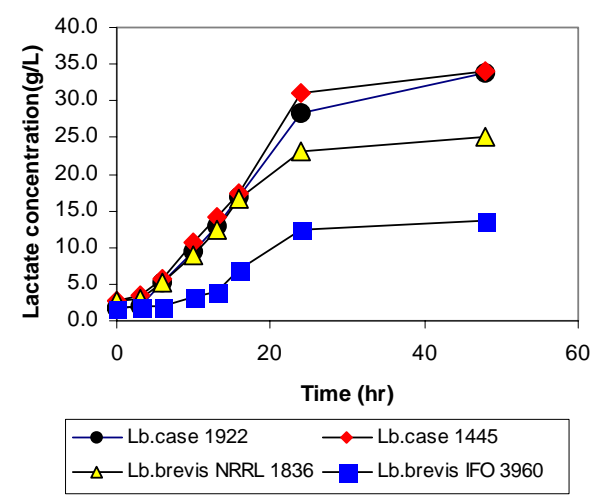

\section{4.c. Further rice straw hydrolysate inhibition studies: Effect of heat sterilization.}

Previous studies used a heat sterilized (autoclaved) rice straw hydrolysate (washed \& unwashed substrate or wash supernatant) prior to use in growth studies. However, acid pre-digested rice straw does not require thermal process for sterilization because of the low $\mathrm{pH}$. Moreover, potential inhibitors in the rice straw hydrolysate such as phenolic or lignin compounds can be converted to polymer compounds through condensation reactions under high pressures and temperatures.

To investigate if the autoclaving step either introduced or removed inhibitors, media was prepared by the same procedure described above with and without autoclaving. Care was taken to ensure no contamination entered the unautoclaved media. Tested strains show the same trends. Autoclaved media was more favorable than unautoclaved media and unwashed media produced more lactic acid than washed media. Autoclaved media, especially, autoclaved-unwashed media shows the same lactic acid production rate as control MRS media. While the unautoclaved media seems to lower lactic acid productivity as compared to the autoclaved media, it appears to be due to the lag time at the early stage of fermentation. At the later stages of fermentation, lactic acid concentrations of unautoclaved media reach those of autoclaved media. Regardless of autoclaving, it is clear that the unwashed media was able to produce more lactic acid than washed substrate media. 


\subsection{Environmental factor optimization for the new integrated process.}

4.5.a. Temperature effects. The effects of temperature on cell growth and lactic acid production and on enzyme hydrolysis were investigated previously using four different $L b$. brevis strains (Lb. brevis NRRL4527, NRRL1834, NRRL1836, IFO3960). Lb. brevis can grow and produce lactic acid up to $40^{\circ} \mathrm{C}$ but are dead within 3 hours at $50^{\circ} \mathrm{C}$. Comparing $30^{\circ} \mathrm{C}$ and $40^{\circ} \mathrm{C}$, lactic acid yields were the same, however, tow carbon product flux move to ethanol from acetate. The specific substrate utilization rate and specific product formation rate at $40^{\circ} \mathrm{C}$ is higher than at $30^{\circ} \mathrm{C}$, though specific cell growth rates showed same values in all tested strains. Table 4.2 gives the overall results.

Table 4.2. The effects of temperature on the specific cell growth, substrate utilization and product formation rates by various Lactobacillus brevis strains.

\begin{tabular}{|c|c|c|c|c|c|c|c|c|c|}
\hline \multirow{2}{*}{ Strains } & \multicolumn{3}{|c|}{$\mu_{s}^{1}$} & \multicolumn{3}{|c|}{$q_{\text {S Glucose }}{ }^{2}$} & \multicolumn{3}{|c|}{$q_{\text {P lactate }}{ }^{3}$} \\
\hline & $30^{\circ} \mathrm{C}$ & $40^{\circ} \mathrm{C}$ & ratio & $30^{\circ} \mathrm{C}$ & $40^{\circ} \mathrm{C}$ & ratio & $30^{\circ} \mathrm{C}$ & $40^{\circ} \mathrm{C}$ & ratio \\
\hline IFO 3960 & 0.34 & 0.22 & 0.65 & $0.28 \pm 0.02$ & $0.44 \pm 0.14$ & 1.57 & $0.28 \pm 0.16$ & $0.28 \pm 0.18$ & 1.11 \\
\hline NRRL 4527 & 0.36 & 0.24 & 0.68 & $0.24 \pm 0.05$ & $0.50 \pm 0.01$ & 2.01 & $0.18 \pm 0.05$ & $0.32 \pm 0.01$ & 1.78 \\
\hline NRRL 1834 & 0.45 & 0.24 & 0.54 & $0.29 \pm 0.06$ & $0.36 \pm 0.12$ & 1.24 & $0.26 \pm 0.08$ & $0.32 \pm 0.15$ & 1.23 \\
\hline NRRL 1836 & 0.44 & 0.29 & 0.65 & $0.32 \pm 0.08$ & $0.83 \pm 0.32$ & 2.59 & $0.29 \pm 0.08$ & $0.75 \pm 0.37$ & 2.58 \\
\hline
\end{tabular}

1: The specific cell growth rates (/hr) were measured by linear regression of time and $\ln ($ optical density) at the exponential phase $\left(\mathrm{r}^{2}<0.9\right)$. Cell growth did not observe at $50^{\circ} \mathrm{C}$. Duplicated results showed the same results within \pm 0.08 range.

2: The specific substrate consumption rates (mM-glucose/OD/hr) were measured at the exponential phase where the specific cell growth rates were measured.

3: The specific product formation rates (mM-lactic acid/OD/hr) were measured at the exponential phase where the specific cell growth rates were measured.

Temperatures of $30^{\circ} \mathrm{C}, 40^{\circ} \mathrm{C}$ and $50^{\circ} \mathrm{C}$ were examined for acid pretreated rice straw hydrolysis by cellulase (Novozyme188) and cellobiose (Spezyme cp) under optimum conditions of $0.05 \mathrm{M}$ sodium acetate buffer at $\mathrm{pH}$ 5.0. Initial hydrolysis rates at 30 and $40^{\circ} \mathrm{C}$ showed same value but half that achieved at $50^{\circ} \mathrm{C}$. However, after very first stage of hydrolysis, hydrolysis rates for all three temperatures were similar. This is likely because of feed back inhibition by glucose. At all three temperatures, the hydrolysis reactions were complete within 12 hours. Since there are no significant differences in the hydrolysis reaction rate between $40^{\circ} \mathrm{C}$ and $50^{\circ} \mathrm{C}$ and cell growth was not affected at $40^{\circ} \mathrm{C}$, then $40^{\circ} \mathrm{C}$ seemed the optimum temperature for the SSF. This temperature was reduced to $37^{\circ} \mathrm{C}$ to provide margin of temperature fluctuations. 


\section{5.b. pH and media component effects}

The effects of $\mathrm{pH}$ and the media component on enzyme hydrolysis were investigated at $37^{\circ} \mathrm{C}$. As a control, $\mathrm{pH}$ 5.0, 0.05M sodium acetate buffer was used with 150g-dry mass/L of rice straw hydrolysate. A pH 5.0 and 6.0 (optimum pH for lactic acid production using MRS media) were used for the experiments with same condition as the control group. As shown in Figure 4.4, there was no difference between the experimental groups. Rice straw hydrolysis reactions, glucose production from cellulose, for each experimental group were saturated within $12 \mathrm{hrs}$ and final glucose concentrations were similar at $50 \mathrm{~g} / \mathrm{L}$. The reaction rates of the three conditions showed no difference as presented in Figure 4.5. Therefore, pH 6.0 of MRS media, rich media with salt for cell growth of Lactobacillus sp., did not show any difference under conditions with the rice straw hydrolysis at $37^{\circ} \mathrm{C}$ compared to optimum enzyme hydrolysis conditions.

\section{5.c. Enzyme stability during fermentation.}

The activity of the enzyme complex (cellulase and cellobiase) were measured during the fermentation of $L b$. brevis at $37^{\circ} \mathrm{C}$ in the rich media that contained an organic nitrogen source such as peptone and yeast extract. For the carbon source, $20 \mathrm{~g} / \mathrm{L}$ of xylose was used to avoid feedback inhibition by glucose when measuring the enzyme activities. Enzyme activities were compared according to how much glucose was produced per unit time.

As shown in Figure 4.6, the enzyme complex activity without inoculation, blue diamond square, was maintained for 24 hours at $37^{\circ} \mathrm{C}$. The black circle refers to cell growth in MRS media using xylose. Lag, exponential cell growth and stationary phase is clearly distinguished in the log optical density vs time curve. The enzyme complex activities with $L b$. brevis inoculation and cell growth (red square) also maintained for 24 hours regardless of the phase of cell growth. Protease production by microorganisms is strongly related to the cell growth conditions and especially related to the nitrogen source. Therefore, the enzyme complex stability with the different nitrogen sources should be followed as a part of media composition optimization, however, SSF looked promising because the enzyme activity was maintained in a medium containing a rich organic nitrogen source.

Through these studies, SSF of acid pretreated rice straw at $37^{\circ} \mathrm{C}$ using $L b$. brevis was shown as possible and, even, most promising as a process condition because it increases the enzyme hydrolysis rates by removing feed back inhibition from glucose. 
Figure 4.4. Acid pretreated rice straw hydrolysis at different conditions. Effects of media component and pH on enzyme hydrolysis. ( $O$ glucose, $\Delta$ xylose, $\square$ arabinose)

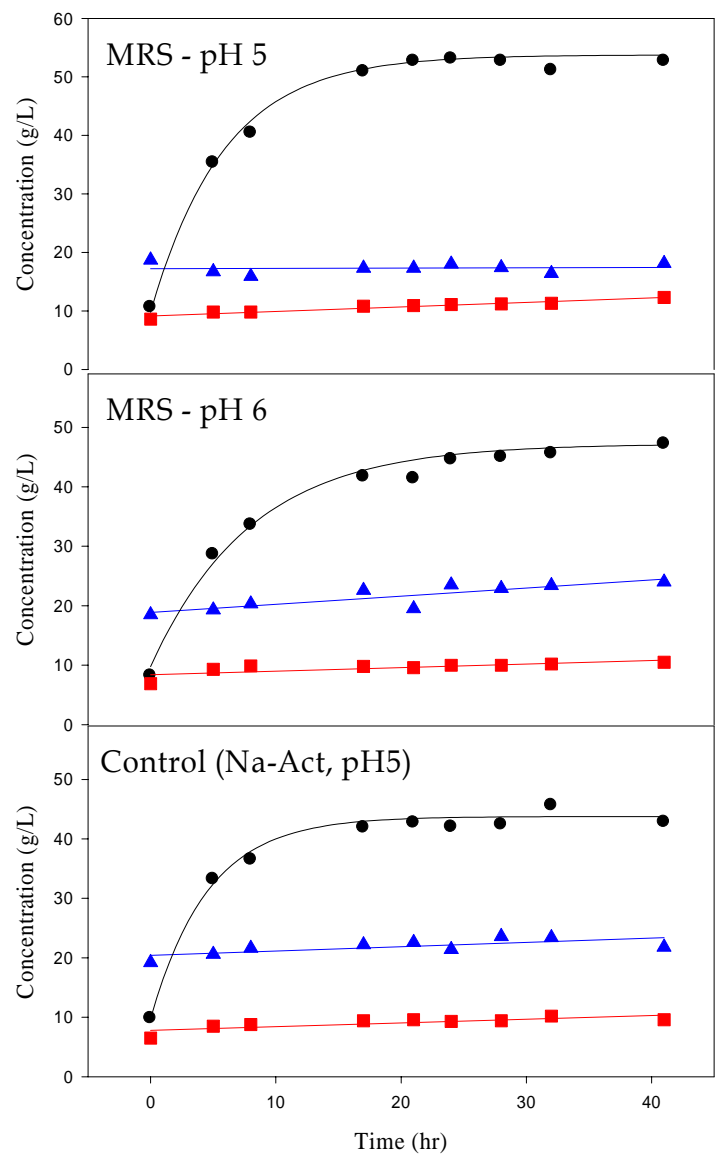

Figure 4.5. Enzyme hydrolysis rates in different conditions. Enzyme hydrolysis rate was calculated from the produced glucose concentration in unit time.

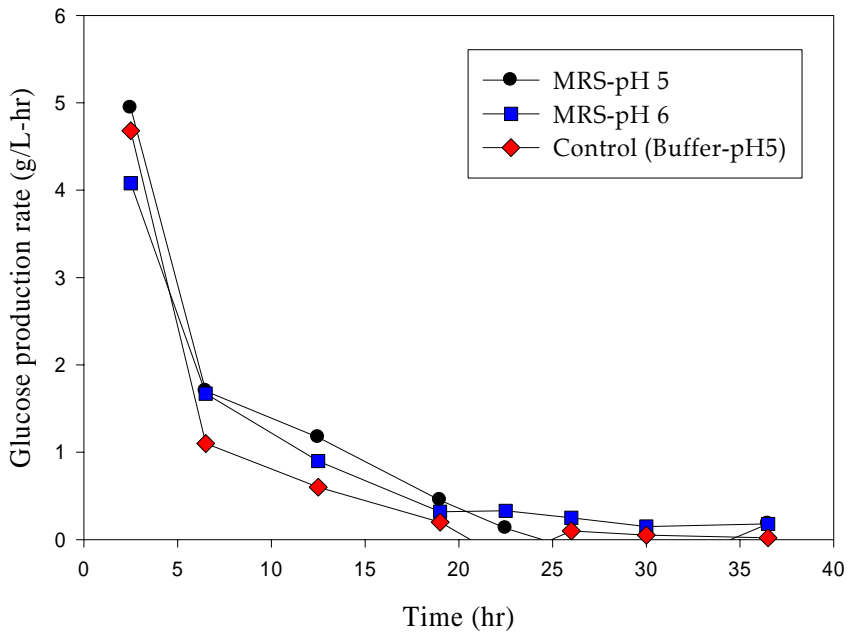


Figure 4.6. Enzyme complex activities for 24 hours with and without inoculation of Lb.brevis.

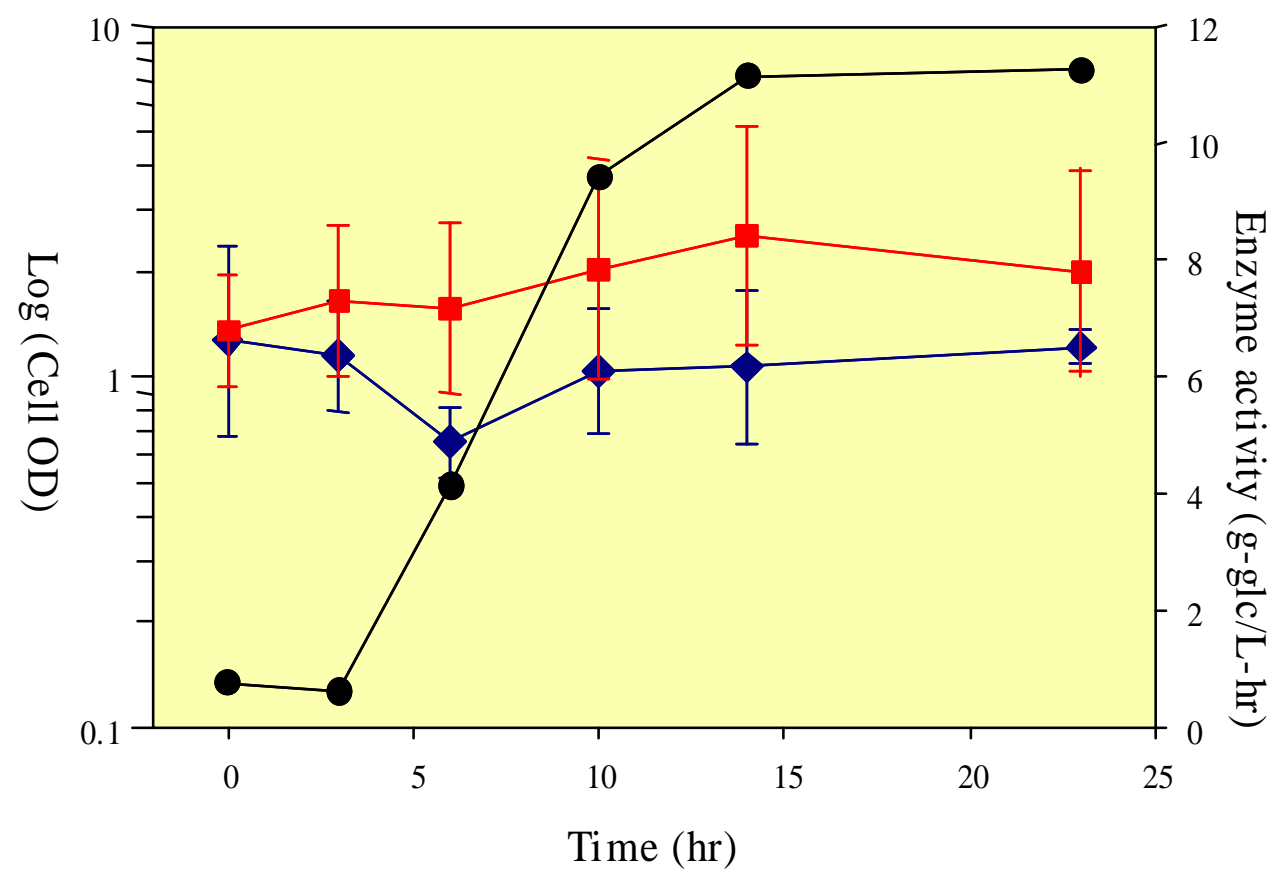

$\begin{array}{ll}- & \text { Cell OD } \\ - & \text { Enzyme activity without inoculation } \\ - & \text { Enzyme activity with inoculation }\end{array}$




\section{5.d. The fed-batch operation of simultaneous saccharification and mixed sugar}

fermentation (SSMSF) of acid pretreated rice straw using $\mathbf{L} \boldsymbol{b}$. brevis. The fed-batch mode of SSMSF was carried out with the 80 g-dry mass/L of initial acid-pretreated rice straw. 15FPU/gsubstrate of cellulase and 15CBU/g-substrate of cellobiase was added upon with inoculation. Initial carbohydrate concentrations are $1.6 \mathrm{~g} / \mathrm{L}$ of glucose, $7.3 \mathrm{~g} / \mathrm{L}$ of xylose and $1.6 \mathrm{~g} / \mathrm{L}$ of arabinose. During the first 16 hours (lag phase), glucose concentration increased up to $4.9 \mathrm{~g} / \mathrm{L}$ and then decreased to an apparent concentration of $0.3 \mathrm{~g} / \mathrm{L}$ after 4 hours. Xylose and arabinose concentration decreased simultaneously. From 33 hours to 38 hours, the apparent sugar concentration in the media was zero and product concentration did not increase. At 38 hours, 80 g-dry mass/L of substrate was fed as a solid powder (Figure 4.7, point A) and after 50 hours, no soluble sugars were detectable but the concentration of products increased gradually. The product concentrations did not change after 62 hours (Figure 4.7, point B), signaling the apparent end of the fermentation. In order to confirm the complete consumption of cellulose, an excessive amount of enzymes were added and the temperature was shifted to $45^{\circ} \mathrm{C}$, the temperature optimum for the enzymes but lethal to $L b$. brevis (Figure 4.7, point C). For 38 hours after this enzyme addition, the concentrations of glucose and the products remained constant, which is consistant with complete utilization of acid-pretreated rice straw. The concentrations of lactic acid, acetic acid, and ethanol at 62 hours were 29.6g/L, 13.3g/L, and 1.6g/L respectively. 
Figure 4.7. Simultaneous saccharification and mixed sugar fermentation (SSMSF) of acid pretreated rice straw by Lactobacillus brevis in the fed-batch mode at $37^{\circ} \mathrm{C}, \mathbf{p H ~ 6 . 0}$. (A) 80 g-dry mass/L of acid pretreated rice straw was added, (B) excessive amount of cellulase and cellobiase were added (C) fermentation and hydrolysis supposed to be completed. Symbols: glucose, $\boldsymbol{\Delta}$ xylose, $\boldsymbol{\nabla}$ arabinose, $\diamond$ lactic acid, $\Delta$ acetate, $\nabla$ ethanol

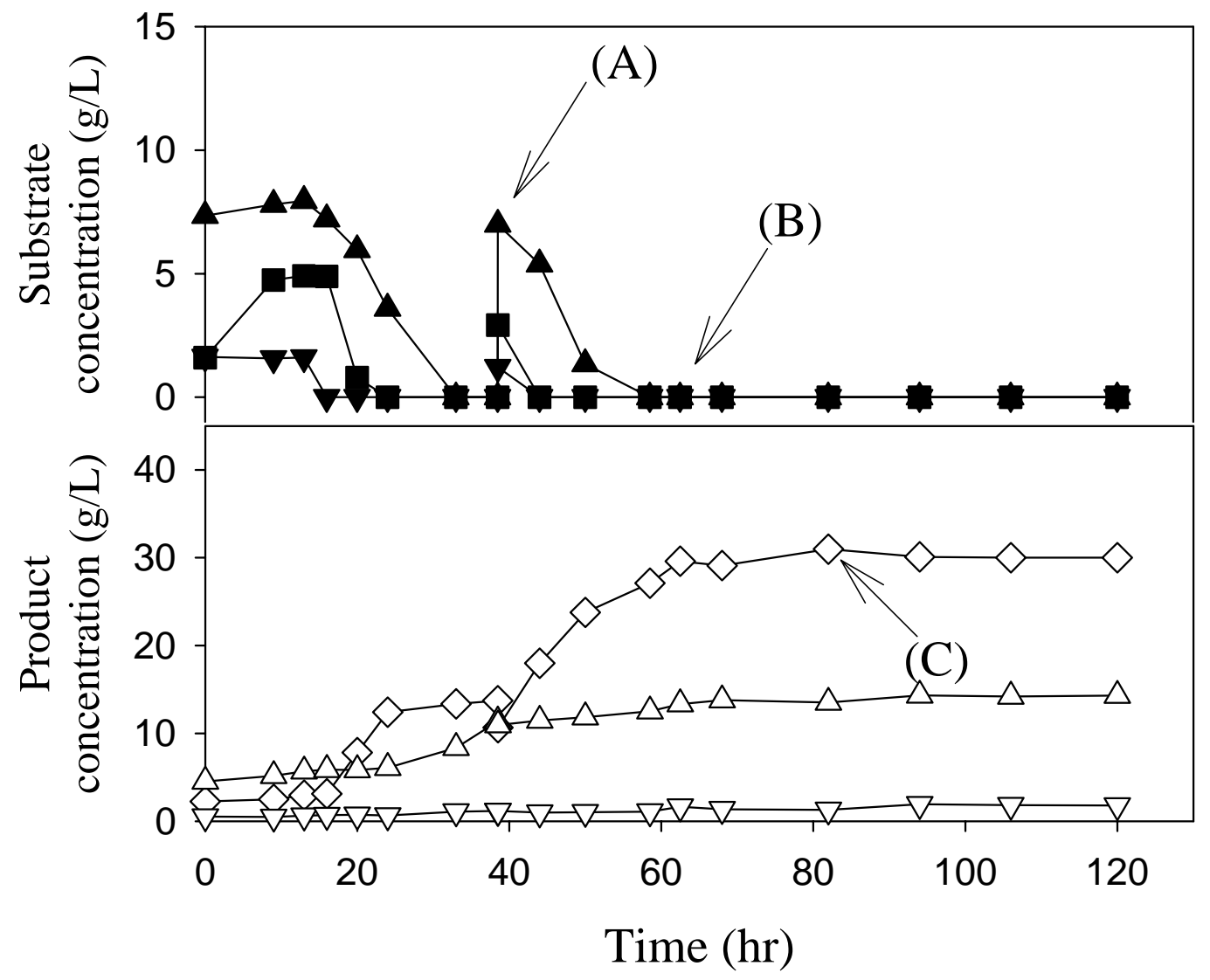




\subsection{Lactic acid production from acid-pretreated rice straw using Lb. pentosus JH5XP5: sequential hydrolysis and fermentation vs simultaneous saccharification and fermentation.}

4.6.a. Sequential hydrolysis and fermentation (SHF). A fermentation study using the rice straw hydrolysate was performed under controlled conditions (Figure 4.8). In the fermentor, 100g-dry mass/L of acid pretreated rice straw was hydrolyzed by enzymes (cellulase and cellobiase) for 24 hours (A), followed by sterilization of the entire contents (B). The total concentration of mixed soluble sugars after enzyme hydrolysis was $36.4 \mathrm{~g} / \mathrm{L}$. The soluble sugars consisted of glucose, xylose and arabinose at $23.0 \mathrm{~g} / \mathrm{L}, 8.9 \mathrm{~g} / \mathrm{L}$ and $4.5 \mathrm{~g} / \mathrm{L}$, respectively). The fermentor was inoculated with $L b$. pentosus and the fermentation proceeded until completion (21 hours) without any apparent inhibition of the strain by the rice straw hydrolysate. The products formed were lactic acid, acetate and ethanol at $25.3 \mathrm{~g} / \mathrm{L}, 14.3 \mathrm{~g} / \mathrm{L}$ of and $3.7 \mathrm{~g} / \mathrm{L}$, respectively. The product yields of lactic acid, acetic acid and ethanol from total carbohydrates were 1.12 $(\mathrm{mM} / \mathrm{mM}), 0.49(\mathrm{mM} / \mathrm{mM})$ and $0.39(\mathrm{mM} / \mathrm{mM})$, respectively.

4.6.b. Simultaneous saccharification and fermentation (SSMSF). Fed-batch operation of SSMSF was performed under controlled environments (Figure 4.9). 100 g-dry mass/L of acid pretreated rice straw was suspended in the DDW the autoclaved. 15-FPU/g-substrate and 15 CBU/g-substrate of cellobiase were added with inoculation. After 24 hours, approximately 65gdry mass/L amount of acid-pretreated rice straw was suspended in the fermentation broth as solid without additional sterilization (point A). Fermentation apparently ended after 48 hours because no additional increase in the concentration of glucose and lactic acid was observed (point B). After an additional 12 hours, an increase of $1 \mathrm{~g} / \mathrm{L}$ glucose was measured. The fermentation contents were then subjected to addition of excessive amount of enzyme (50 FPU/g-substrate of cellulase and $50 \mathrm{CBU} / \mathrm{g}$-cellobiase) and the temperature raised to $45^{\circ} \mathrm{C}$ in order to determine if unhydrolyzed cellulose remained in the medium (point C). After 113 hours at $45^{\circ} \mathrm{C}$, glucose only increased $3.2 \mathrm{~g} / \mathrm{L}$ of glucose and thus, the fermentation seemed to have been completed at 48 hours (point B).

As seen in Figure 4.9, the pentoses and hexoses were consumed simultaneously during the fermentation. Even without detectable sugars in the media, lactic acid production continued with an apparent immediate utilization of soluble sugars generated by the enzyme action by $L b$. pentosus JH5XP5 in a simultaneous saccharification fermentation mode. The final product concentrations of lactic acid, acetic acid (10.7g/L of production) ethanol were $42 \mathrm{~g} / \mathrm{L}, 15.7 \mathrm{~g} / \mathrm{L}$, and $12.1 \mathrm{~g} / \mathrm{L}$, respectively, at 48 hours. At this point, $1.0 \mathrm{~g} / \mathrm{L}$ glucose remained in the medium.

The fed-batch mode of simultaneous saccharification and concurrent mixed sugar fermentation (SSMSF) is recommended process design for bioprocessing lignocellulose to chemicals. The advantages of simultaneous sugar utilization, SSF and fed-batch operation were integrated in one process and are:

- Removes feedback inhibition by glucose and cellobiase, thereby reducing the enzyme requirement;

- Complete consumption of mixed sugars which enhances the product separation efficiency. Higher concentration of final products;

- Increases product yield and productivity by consumption of all available sugars derived from the substrate without inhibition or accumulation; and 
- Reduces the operational time by integration of two processes.

Lb. pentosus JH5XP5 could have additional benefits because it

- Showed resistance to potential inhibitors in the acid hydrolysates of lignocellulosic biomass, eliminating the need for additional pre-separation or clean up steps;

- Does not interfer with enzyme activity through the fermentation, thereby allowing continuous usage of the enzyme during the fed-batch fermentation; and

- Operates under anaerobic conditions, thus minimizing aeration and shear stress, especially important given the presence of silica in rice straw fermentations. .

Because the substrate is acid-pretreated and unfiltered, it can be added as a solid powder without sterilization. The acid-pretreated rice straw has the $\mathrm{pH}$ lower than 2.0 when suspended in water and low water activity. Therefore, it seemed that the heat sterilization of substrate was unnecessary.

Comparison of sequential hydrolysis and mixed sugar fermentation (SHMSF) and simultaneous saccharification and mixed sugar fermentation (SSMSF), showed clearly that SSMSF reduces operational time and as well as enzyme loading. Even with three times higher enzyme loading, SHMSF required 24 hours of additional hydrolysis time. As a result, SSMSF needs half the operational time and 6.6 times less amount of enzyme as SHMSF (Table 4.3).

Table 4.3. Comparison of Fermentation Parameters* for Lb. brevis and Lb. pentosus

\begin{tabular}{|l|c|c|}
\hline Enzyme Dosage & $\begin{array}{c}\text { Sequential hydrolysis } \\
\text { and fermentation }\end{array}$ & $\begin{array}{c}\text { Simultaneous saccharification } \\
\text { and mixed sugar fermentation }\end{array}$ \\
\hline Substrate $* *(\mathrm{~g} / \mathrm{L})$ & 100 & 180 \\
\hline Cellulase $* * *(\mathrm{FPU})$ & $50 / \mathrm{g}$ & $15 / \mathrm{g}$ \\
\hline Cellobiose $* * *(\mathrm{CBU})$ & $50 / \mathrm{g}$ & $15 / \mathrm{g}$ \\
\hline Hydrolysis time $(\mathrm{h})$ & 24 & $\mathrm{Na}$ \\
\hline Fermentation time $(\mathrm{h})$ & 24 & $\mathrm{Na}$ \\
\hline Hydrolysis and fermentation time & $\mathrm{Na}$ & 48 \\
\hline
\end{tabular}

*Submerged stirred-tank fermentation of acid-pretreated rice straw. Initial working volume is $3 \mathrm{~L}$ and after feeding volume is 4.3L.

**Substrate is acid-pretreated straw, g are on a dry basis (e.g. $100 \mathrm{~g}$ dry equals $350 \mathrm{~g}$ wet)

***Enzyme units/g of acid-treated rice straw (dry basis) 
Figure 4.8. Sequential hydrolysis and fermentation of acid pretreated rice straw by Lactobacillus pentosus JH5XP5. A: hydrolysis of rice straw by cellulose and cellobiase mixture, B: heat sterilization and cooling, C: fermentation of rice straw hydrolysate, symbols: glucose, $\boldsymbol{\Delta}$ xylose, $\nabla$ arabinose, $\diamond$ lactic acid, $\Delta$ acetate, $\nabla$ ethanol.

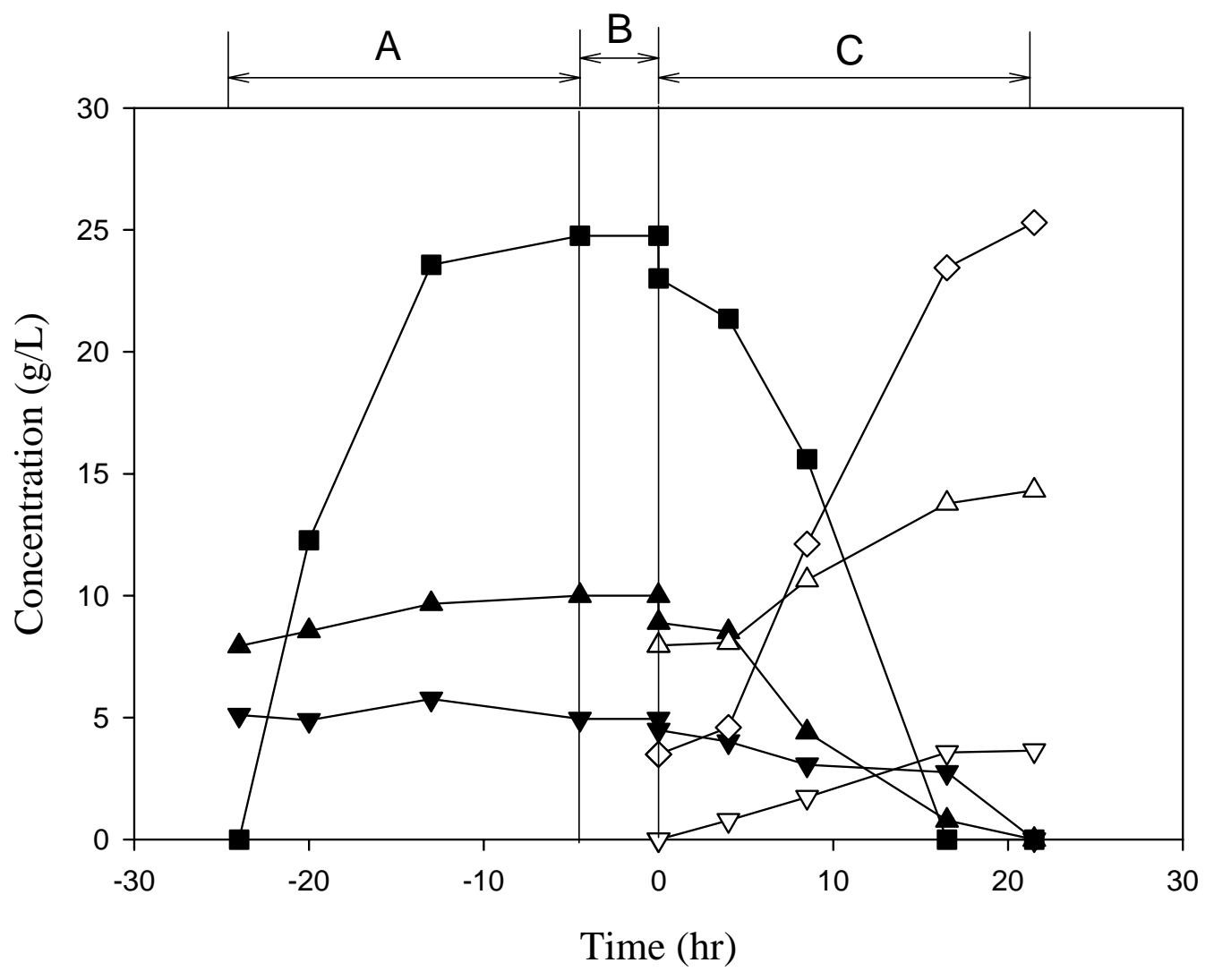


Figure 4.9. Fed-batch operation of simultaneous saccharification and mixed sugar fermentation (SSMSF) of acid pretreated rice straw by Lactobacillus pentosus JH5XP5 at $37^{\mathbf{0}} \mathbf{C}$, pH6.0. A: addition of 100 g-dry mass/L of acid-pretreated rice straw, B: completion of hydrolysis and fermentation, $\mathrm{C}$ : addition of excessive amount of cellulose and cellobiase and temperature shift to $45^{\circ} \mathrm{C}$. Symbols: $\mathbf{\square}$ glucose, $\boldsymbol{\Delta}$ xylose, $\boldsymbol{\nabla}$ arabinose, $\diamond$ lactic acid, $\triangle$ acetate, $\nabla$ ethanol.

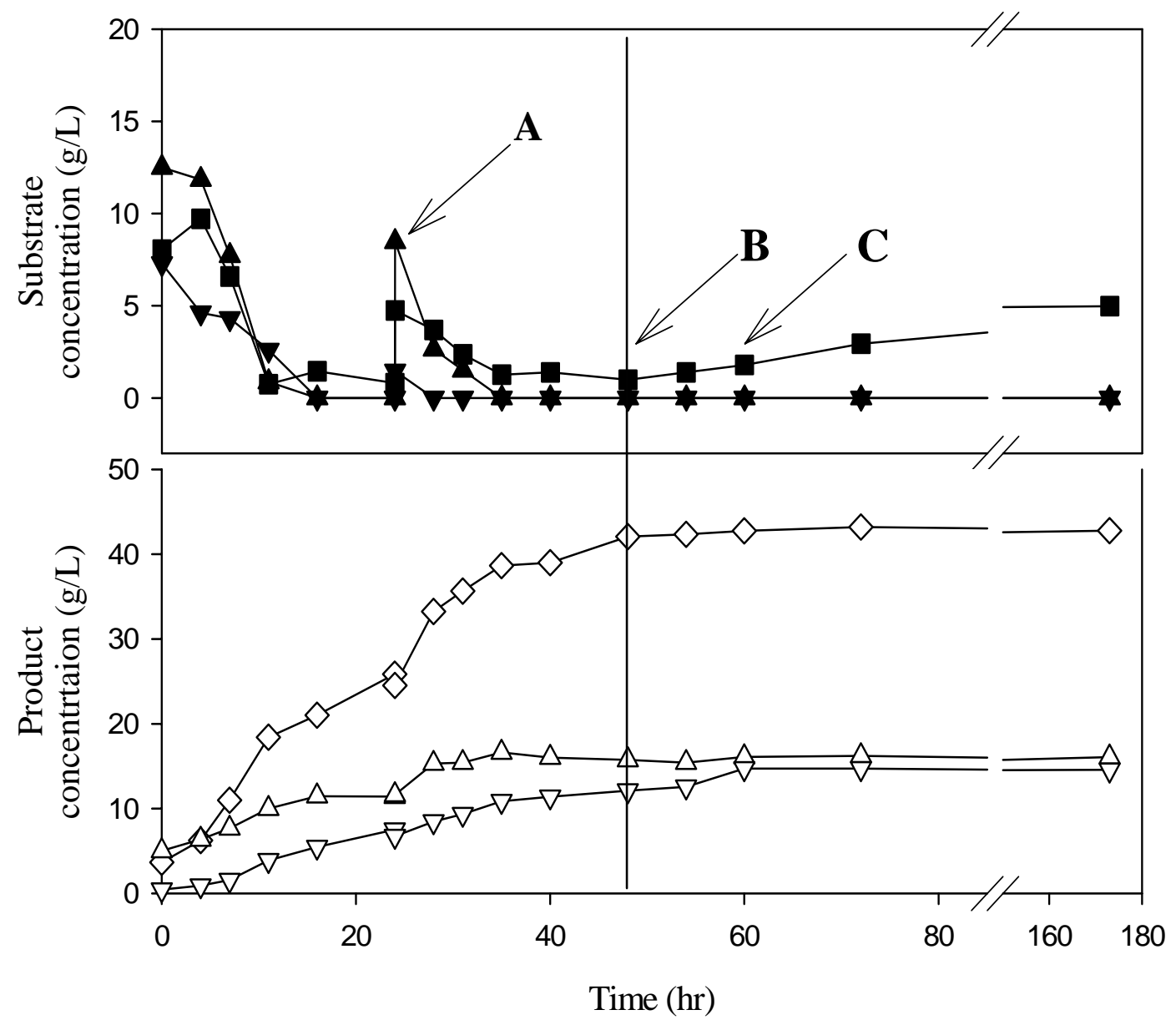




\section{Task 5. Technical interface with project teams \& protocol definition for analytical testing.}

Team members from UC Davis and Argonne National Laboratory met formally twice a year throughout the project, once for an annual project review that also included DOE staff and industrial partners, and once amongst the technical project team. These later meetings were scheduled in conjunction with the Symposium on Biotechnology for Fuels and Chemicals and American Chemical Society National Meetings.

\section{Task 6. Develop new applications for ethyl lactate across all industrial sectors.}

Table 6.1 Product Development of Lactate Esters (Ethyl Lactate)

\begin{tabular}{|c|c|c|c|}
\hline Product Name & Description & Area of Application & Comments \\
\hline VertecBio EL ${ }^{\mathrm{TM}}$ & $\begin{array}{l}\text { Ethyl lactate (ethyl alpha- } \\
\text { hydroxy propionate) } \\
\text { solvent. It is the ester of } \\
\text { natural }(\mathrm{L}+\text { ) produced by } \\
\text { fermentation from corn- } \\
\text { derived feedstock. } \\
\text { A clear and colorless liquid } \\
\text { of low volatility with a } \\
\text { natural distinctive odor. }\end{array}$ & $\begin{array}{l}\text { Lactate esters have found } \\
\text { industrial applications in } \\
\text { specialty coatings, inks, } \\
\text { pigments, dyes, cleaners and } \\
\text { straight use cleaning because } \\
\text { of their high performance and } \\
\text { versatility. Use in soil } \\
\text { remediation (extraction of } \\
\text { trapped chlorinated solvents). } \\
\text { Use as an inert in pest control } \\
\text { products. }\end{array}$ & $\begin{array}{l}\text { They have an excellent safety } \\
\text { and environmental record due to } \\
\text { their organic origin, have very } \\
\text { low toxicities and are readily } \\
\text { biodegradable. Can replace toxic } \\
\text { N-methyl Pyrrolidone (NMP) in } \\
\text { many existing formulations. }\end{array}$ \\
\hline $\begin{array}{l}\text { VertecBio } \\
\text { Gold }\end{array}$ & $\begin{array}{l}\text { A patented blend of ethyl } \\
\text { lactate } \\
\text { (derived from corn) and } \\
\text { fatty acid methyl esters } \\
\text { (soy methyl ester derived } \\
\text { from soybean oil in the } \\
\text { U.S. }\end{array}$ & $\begin{array}{l}\text { Industrial applications in } \\
\text { specialty coatings, inks, } \\
\text { cleaners (machinery parts } \\
\text { and printing ink cleaners) } \\
\text { and straight use cleaning } \\
\text { because of their high } \\
\text { performance and versatility. } \\
\text { Use as an inert in pest control } \\
\text { products. }\end{array}$ & $\begin{array}{l}\text { They each have excellent safety } \\
\text { and environmental records due } \\
\text { to their organic origins. Can } \\
\text { replace toxic N-methyl } \\
\text { pyrrolidone (NMP) in many } \\
\text { existing formulations }\end{array}$ \\
\hline $\begin{array}{l}\text { VertecBio } \\
\text { Citrus }^{\mathrm{TM}}\end{array}$ & $\begin{array}{l}\text { A blend (patent pending) } \\
\text { of lactate esters and d- } \\
\text { limonene, which is derived } \\
\text { from citrus peels. }\end{array}$ & $\begin{array}{l}\text { Industrial applications in } \\
\text { paint line flushing, paint } \\
\text { strippers, and a variety of } \\
\text { cleaning formulations. Use as } \\
\text { an inert in pest control } \\
\text { products. }\end{array}$ & $\begin{array}{l}\text { Excellent safety and } \\
\text { environmental records due to } \\
\text { their organic origins. Can } \\
\text { replace toxic N-methyl } \\
\text { pyrrolidone (NMP) in many } \\
\text { existing formulations }\end{array}$ \\
\hline Ink Zapper ${ }^{\mathrm{TM}}$ & $\begin{array}{l}\text { A patented blend of } \\
\text { biodegradable solvents. }\end{array}$ & $\begin{array}{l}\text { Used to clean UV, textile, } \\
\text { newspaper, screen-printing, } \\
\text { and offset printing inks. Use } \\
\text { as an inert in pest control } \\
\text { products. }\end{array}$ & $\begin{array}{l}\text { Can replace toxic N-methyl } \\
\text { pyrrolidone (NMP) in many } \\
\text { existing formulations. }\end{array}$ \\
\hline
\end{tabular}


Task 7. Purification and esterification process development and validation.

Lactic acid was separated from fermentations of rice straw hydrolysates with both $E$. coli strain and $L b$. brevis strains using the laboratory scale electrodialysis unit. Samples were runs for about 5 hours resulting in a capture of about $75 \%$ of the lactic acid and final product concentrations above $13 \mathrm{~g} / \mathrm{L}$.

In work on cost shared funding, Argonne has demonstrated efficient production of ethyl lactate from synthetic batches of ammonium lactate. In this work, EL was produced by esterification of the ammonium lactate by ethanol. The thermal cracking was driven by pervaporation to remove both the water and ammonia byproducts of the reactions. Argonne and Vertec used commercially available polymeric membranes purchased from Sulzer Chemtech. These runs have been conducted at the laboratory scale (hundreds of grams) and the pilot scale (a few kilograms).

Task 8. Process integration from biomass to ethyl lactate.

\subsection{Evaluation of enzyme system for saccharification of dilute-acid pretreated lignocellulosic feedstocks.}

Larger quantities (several pound lots) of acid-treated and washed (Stage I) rice straw were prepared by BC International and shipped to UC Davis for use as substrates for hydrolysis. Two Trichoderma reesei cellulase preparations (Spezyme CP and TW-1) and Penicillium verruculosum B-1 cellulase preparation were compared for enzymatic hydrolysis of acidpretreated lignocellulosic materials. Enzymes were either used alone or supplemented with Novozym 188 cellobiase. Spezyme CP (Lot \#301-97338-001) was obtained from Genencor International, USA. Cellulase preparation (Lot \# 2-322.1) derived from new T. reesei strain TW1 was provided by Fermtech (Russia). Solid preparation (\#3-12/1) derived from $P$. verruculosum B1 was provided by Fermtech (Russia). Novozym 188 was obtained from Novo Nordisk (Denmark).

Filter-paper activity of cellulases was measured according to the standard procedure recommended by the Commission on Biotechnology, IUPAC (Ghose, 1987) and expressed in Filter Paper Units (FPU). Cellobiase activity was determined as the initial rate of hydrolysis of 2 $\mathrm{mM}$ cellobiose to glucose at $\mathrm{pH} 5.0,50^{\circ} \mathrm{C}$. One unit of cellobiase activity (CBU) corresponded to 1 mol of -1,4-glycosidic bonds of cellobiose hydrolyzed in one minute during the initial stage of hydrolysis. Protein content in enzyme preparations was determined by the Folin-Lowry method (Lowry, 1951). The data for four enzyme preparations are shown in Table 8.1. In the case of the solid enzyme preparation ( $P$. verruculosum B1), we suspended the solids at $50 \mathrm{~g} / \mathrm{L}$ in $0.05 \mathrm{M}$ sodium acetate buffer, $\mathrm{pH}$ 5.0, with stirring, then removed precipitate by centrifugation. 
Table 8.1 Activities and protein content of cellulase preparations

\begin{tabular}{cccccc}
\hline $\begin{array}{c}\text { Cellulase } \\
\text { preparation }\end{array}$ & $\begin{array}{c}\text { Protein } \\
(\mathbf{m g} / \mathbf{m l})\end{array}$ & \multicolumn{2}{c}{ Filter paper activity } & \multicolumn{2}{c}{ Cellobiase activity } \\
& & FPU/ml & $\begin{array}{c}\text { FPU/mg } \\
\text { protein }\end{array}$ & CBU/ml & $\begin{array}{c}\text { CBU/mg } \\
\text { protein }\end{array}$ \\
\hline Spezyme CP & 164 & 119.0 & 0.73 & 13.5 & 0.08 \\
TW-1 & 213 & 115.1 & 0.54 & 8.1 & 0.04 \\
B-1 (50 g/L) & 25 & 9.9 & 0.40 & 6.6 & 0.27 \\
Novozym 188 & 193 & 0.51 & 0.003 & 515.8 & 2.73 \\
\hline
\end{tabular}

Enzymatic hydrolysis was carried out at pH 5.0 (0.05 M sodium acetate buffer) and $50^{\circ} \mathrm{C}$ for 99 hours. The results of saccharification experiments are presented in Table 8.2

Table 8.2 Glucose yield (\%) after 99-h hydrolysis of acid-pretreated lignocellulosic materials with cellulase preparations

\begin{tabular}{ccccccc}
\hline Substrate & $\begin{array}{c}\text { Spezyme } \\
\text { CP }\end{array}$ & TW-1 & B-1 & $\begin{array}{c}\text { Spezyme CP } \\
\text { \& Novozym } \\
188\end{array}$ & $\begin{array}{c}\text { TW-1 \& } \\
\text { Novozym } \\
188\end{array}$ & $\begin{array}{c}\text { B-1 \& } \\
\text { Novozym } \\
188\end{array}$ \\
\hline $\begin{array}{c}\text { Wood } \\
(\text { BCI) }\end{array}$ & 19 & 19 & 19 & 24 & 20 & 20 \\
$\begin{array}{c}\text { Rice Straw } \\
\text { (BCI) }\end{array}$ & 74 & 74 & 65 & 74 & 75 & 66 \\
$\begin{array}{c}\text { Rice Straw } \\
(\text { NREL })\end{array}$ & 79 & 81 & 78 & 93 & 96 & 80 \\
$\begin{array}{c}\text { MSW } \\
(\text { NREL })\end{array}$ & 74 & 65 & 71 & 89 & 74 & 76 \\
\hline
\end{tabular}

With the cellulose and cellobiase, most of cellulose was degraded with in 4 hours. 99\% of cellulose was converted to glucose and cellobiose in 4 hours. However, without cellobiase, $65 \sim 85 \%$ of cellulose was degraded to glucose.

\subsection{Lactic acid production from rice straw hydrolyzate by $L$ b. brevis and $E$. coli}

8.2.a. Hydrolysis. Two batches of $3 \mathrm{~L}$ hydrolysate were prepared for E. coli and Lb. brevis fermentations. 100g-dry mass/L (= 250g wet rice straw acid hydrolysate/L) was suspended in the $\mathrm{pH} 5.0$ of $0.05 \mathrm{M}$ sodium acetate buffer with 50FPU/g-dry mass of cellulase (Spezyme CP) and 50CBU/g-dry mass of cellobiase (Novozyme 188). After 24 hours the carbohydrate concentrations were as follows;

- For E.coli fermentation: 33.8g/L of glucose, $10.1 \mathrm{~g} / \mathrm{L}$ of xylose and $8.5 \mathrm{~g} / \mathrm{L}$ of arabinose. 
- For $L b$. brevis fermentation: $25.4 \mathrm{~g} / \mathrm{L}$ of glucose, $10.1 \mathrm{~g} / \mathrm{L}$ of xylose and $8.3 \mathrm{~g} / \mathrm{L}$ of arabinose.

The differences in glucose concentration are due to a lack of homogeneity of acid pretreated rice straw.

8.2.b. Media preparation. After filtration, hydrolysates were transferred to the fermentor vessel and autoclaved. Ammonium sulfate and other salts (same as the instruction which ANL sent) and MRS media without carbohydrate were added as solid for E.coli and Lb.brevis fermentation, respectively.

8.2.c. Fermentation. $5 \%(\mathrm{w} / \mathrm{w})$ inoculate was added, and fermentation conditions were 100rpmof agitation, $0.5 \mathrm{vvm}$ of aeration and $\mathrm{pH} 6.0$, which was controlled by $\mathrm{NaOH}$. Fermentation profiles are described in Figures 8.1 and 8.2 and results are summarized in Table 8.3. Lactic acid yields were calculated based on the total carbohydrate utilized.

Table 8.3. Summary of fermentation results

\begin{tabular}{|c|c|c|c|c|c|c|c|c|}
\hline & & \multicolumn{3}{|c|}{ Substrate (g/L) } & \multicolumn{3}{|c|}{ Product $(\mathrm{g} / \mathrm{L})$} & \multirow{2}{*}{$\begin{array}{c}\text { Yield } \\
(\mathrm{mM} / \mathrm{mM}\end{array}$} \\
\hline & & Glucose & Xylose & Arabinose & Lactate & Acetate & Ethanol & \\
\hline \multirow{2}{*}{ E.coli } & Initial & 38.8 & 10.1 & 8.5 & \multirow{2}{*}{21.4} & \multirow{2}{*}{11.8} & \multirow{2}{*}{9.3} & \multirow{2}{*}{0.91} \\
\hline & Remain & 6.3 & 6.9 & 5.8 & & & & \\
\hline \multirow{2}{*}{ L.brevis } & Initial & 25.4 & 10.0 & 8.3 & \multirow{2}{*}{28.0} & \multirow{2}{*}{3.0} & \multirow{2}{*}{0.0} & \multirow{2}{*}{1.57} \\
\hline & Remain & 0.0 & 0.0 & 0.0 & & & & \\
\hline
\end{tabular}

8.2.d. Fermentation broth separation. After fermentation, the culture medium was sterilized, centrifuged and filtrated to remove fine solid particles.

8.2.e. Electrodialysis. ANL performed the electrodialysis of lactic acid from fermentation broth. $1 \mathrm{~L}$ of fermentation broth was processed. Conductivity and $\mathrm{pH}$ of feed and concentrate were monitored as control parameters. There were unknown peaks in both runs. Some of the unknown was captured on the concentrate side. Neither sample was run to completion. E. coli broth was filtered twice to partially clarify before running but the $L b$. brevis broth was used as provided without filtration.

Table 8.4 and 8.5 give the separation efficiency and the amount of lactic acid removed with time. 
Table 8.4 Separation of lactic acid in $E$. coli fermentation broth

\begin{tabular}{c|ccc}
\hline \multirow{2}{*}{ Time (min) } & \multicolumn{2}{|c}{ Lactic acid } & $\begin{array}{c}\text { Separation efficiency } \\
\text { (electric current) }\end{array}$ \\
\cline { 2 - 3 } & Feed side (g/L) & $\begin{array}{c}\text { Amount removed } \\
(\mathrm{g} / \mathrm{L})\end{array}$ & \\
\hline \hline Initial feed & 22.5 & 0 & $29 \%$ \\
115 & & 2 & $26 \%$ \\
232 & & 9.6 & $28 \%$ \\
292 & & 15.1 & $31 \%$ \\
Final feed & 5.85 & 16.65 & \\
\hline
\end{tabular}

Table 8.5 Separation of lactic acid in $L b$. brevis broth

\begin{tabular}{c|ccc}
\hline \multirow{2}{*}{ Time (min) } & \multicolumn{2}{|c}{ Lactic Acid } & Separation efficiency \\
& Feed side (g/L) & $\begin{array}{c}\text { Amount removed } \\
\text { (g/L) }\end{array}$ & \\
\cline { 2 - 3 } & 18.5 & 0 & $19 \%$ \\
\hline \hline Initial feed & & 2.64 & $23 \%$ \\
89 & & 7.45 & $24 \%$ \\
162 & & 13.27 & $24 \%$ \\
277 & 5.1 & 13.4 & \\
Final feed & & & \\
\hline
\end{tabular}


Figure 8.1. Fermentation profile of $L b$. brevis

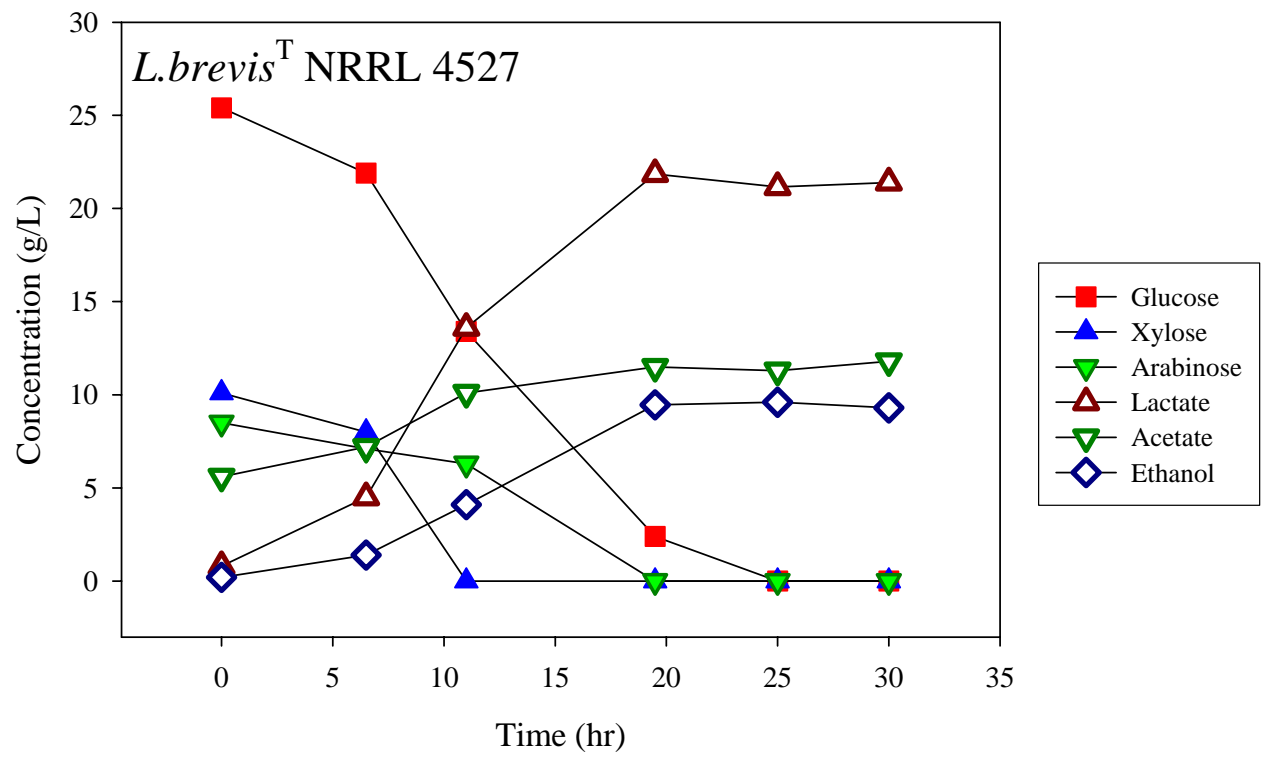

Figure 8.2 Fermentation profile of $E$. coli

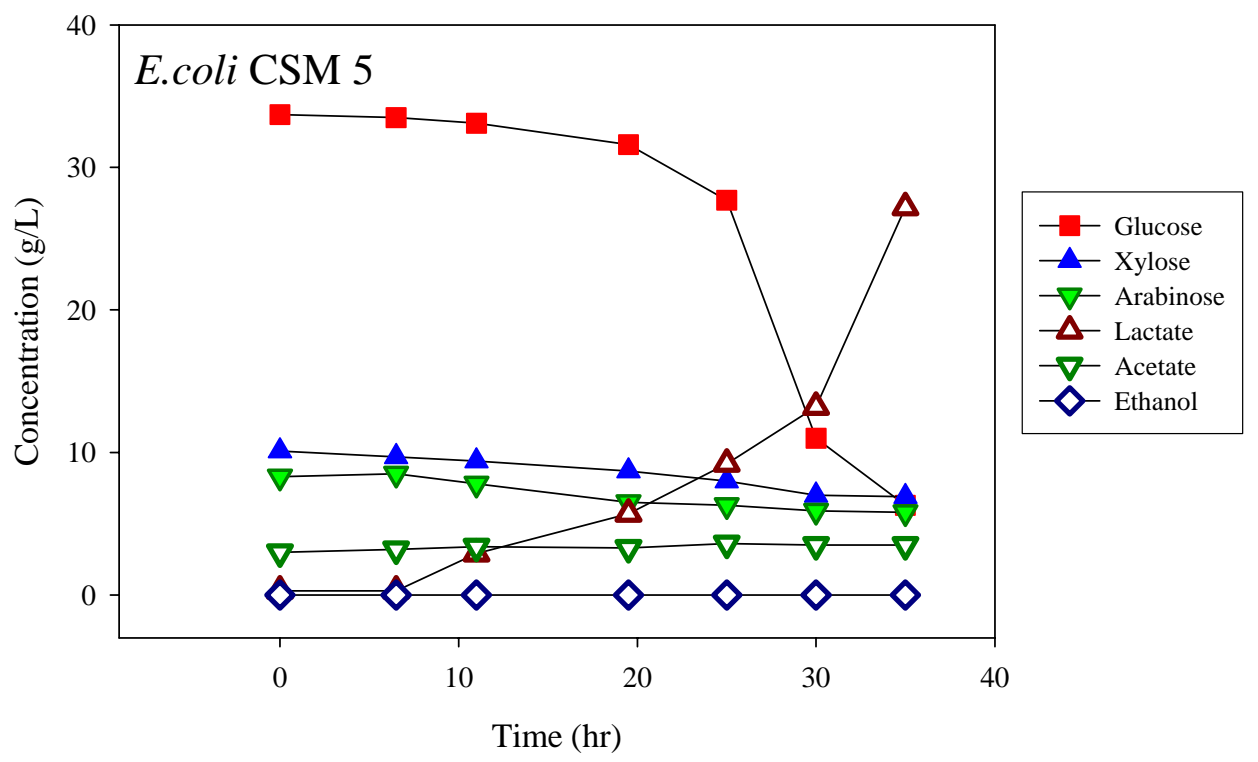




\section{Task 9. Process design and economic evaluations.}

The following summarizes a life-cycle analysis performed by TSS Consultants. The full report is in Appendix A.

This study evaluated the potential energy, economic and environmental (3E) benefits of producing ethyl lactate (ETLA) from rice straw using a process jointly developed by the Argonne National Laboratory and Vertec Biosolvents, Inc. called the "Direct Process." The rice straw process was compared to the fossil fuel-derived, conventional chlorinated cleaning solvent, trichloroethylene. In addition the 3E analysis is to evaluate the potential benefits of producing ETLA from rice straw via the Direct Process and comparing to it to the "Conventional Process" corn to ETLA process.

The energy benefits also compared corn to rice straw. Corn is $8 \%$ more efficient at producing fermentables, and requires one-tenth the amount of enzymes than rice straw. The higher energy requirements for growing corn may offset that somewhat. The Direct Process requires only 88.6 percent of the fermentables that are required by the conventional process to produce the same quantity of ETLA. Besides the fermentables, the Conventional Process requires about three times the quantity of process inputs as the Direct Process. Energy requirements for the Direct Process are only 71.5 percent that of the Conventional Process.

The economic analysis revealed that rice straw has the potential to cost $13 \%$ less than corn when converting agricultural products to ETLA. Rice straw raw material costs $\$ 0.02 / \mathrm{kg}$ less than corn. The corn to dextrose yield is $65 \%$ and the rice straw yield is estimated to be $60 \%$. The analysis did not attempt to reconcile the optimization of the recovery of silica and lignin for the rice straw plant. After adjusting for moisture content and yields, rice straw costs $\$ 0.036 / \mathrm{kg}$ or $31 \%$ less than corn. The conversion of corn to dextrose costs are about 37\% less than rice straw. This number can vary depending on enzyme cost.

Environmental benefits were compared between the conventional and direct processes. $\mathrm{CO}_{2}$ emissions from the corn were considered whereas $\mathrm{CO}_{2}$ from the straw was presumed to be zero. The difference was 27 times more $\mathrm{CO}_{2}$ emissions when using corn versus rice straw. $\mathrm{CO}_{2}$ emissions from the production of fermentables is about ten times less for rice straw. Once the fermentables are acquired from either corn or rice straw, the ETLA production process is the same for the fermentables in the Direct Process, so the emissions would be the same.

The rice straw process produces much more solid waste and aqueous waste than corn. The combined rice straw waste generated during this process is a factor of 2100 times that of corn. The wastewater treatment required for the conventional process is significantly higher than that of the Direct Process. The conventional process aqueous waste is about double that of the Direct Process. The conventional process solid waste produced is over three times the quantity of the product itself (ETLA). The Direct Process in contrast requires no solid waste treatment. Cooling water and process water requirements are also significantly lower for the Direct Process than the conventional process. 


\section{Technology Transfer Activities}

\section{A. Publications}

Datta, R. and M. Henry. 2002. “Green” solvents-emerging markets, applications, and membrane based manufacturing technologies. Proceedings of the BCC $20^{\text {th }}$ Membrane/Separations Planning Conference (Newton MA).

Kim, J-H, Shoemaker, S.P. and D. A. Mills. Atypical sugar consumption in Lactobacillus brevis simultaneous utilization of sugars derived from rice straw lignocellulose. (submitted)

\section{B. Presentations}

Frank, Jim. December 1999. Overview of biobased chemicals. $12^{\text {th }}$ CIFAR Conference-New Processing Technologies for Utilization of Agricultural “Wastes,” Davis, California.

Shoemaker, Sharon. P. 2000. Overview of bioenergy. Bioenergy Workshop, University of California, Davis, California.

de la Salle, Olivier and Sharon P. Shoemaker. May 2000. Upgrading benchtop New Brunswick fermenters to in-house PC-based computer control. $22^{\text {nd }}$ Symposium on Biotechnology for Fuels and Chemicals, Gatlinburg, Tennessee (Abstract No. 3-52).

Kim, J-H., Y-W Ryu, J-H Seo and S.P. Shoemaker. May 2000. Process optimization for xylose bioconversion to xylitol by C. tropicalis. In Proceedings of 22nd Symposium on Biotechnology for Fuels and Chemicals. (Abstract No. 3-53).

Shoemaker, S.P. ${ }^{1}$, E.Y. Vlasenko ${ }^{1}$, and J. Glas ${ }^{2}$. 2000. Development of California's Lignocellulosic Feedstocks and Depolymerase Systems for Conversion to Chemicals. ${ }^{1}$ California Institute of Food and Agricultural Research, University of California, Davis, CA 95616; ${ }^{2} \mathrm{BC}$ International, 990 Washington St. Suite 104, Dedham, MA 02026. In Proceedings of $219^{\text {th }}$ ACS National Meeting, San Francisco, CA.

Shoemaker, Sharon P., Elena Y. Vlasenko, Jatal Mannapperuma and Hanshu Ding. Oct. 2000. Bioconversion of food and agricultural "wastes" to chemicals and energy. $4^{\text {th }}$ International Conference of Food Science and Technology, Wuxi, China.

Shoemaker, S.P., E. Y. Vlasenko. 2001. Cellulase technology. In proceedings of Society of Industrial Microbiology.

Shoemaker, S.P. 2001. Cleaning your plate: Biotech for fuels and renewables. Workshop: Biotechnology Communications in Food and Agriculture, University of California, Davis, California.

Shoemaker, S.P. 2001. Biomass education and outreach: University programs. USDA-DOE Workshop, Kansas City, Kansas. 
Frank, Jame R. and Michael P. Henry. May 2001. Lactate esters and bio-solvents technology development and commercialization, $23^{\text {rd }}$ Symposium on Biotechnology for Fuel and Chemicals, Breckenridge, CO.

Shoemaker, S.P.and E.Y. Vlasenko. July 2001. Cellulase technology. Session 9: Lignocellulose hydrolysis and fermentation. Society of Industrial Microbiology Annual Meeting, St. Louis, Missouri.

Shoemaker, S.P. Aug. 2001. New uses of rice straw. Rice Utilization Workshop, New Orleans, Louisiana.

Snyder, S.W., E. St. Martin, M. Donnelly, C.S. Millard, M.B. Arora, J.A.Hestekin, Y. J. Lin. Production of Lactic Acid in a $\mathrm{pH}$-Controlled Separative Bioreactor. $25^{\text {th }}$ Symposium on Biotechnology for Fuels and Chemicals, Gatlinburg, Tennessee.

St. Martin, E., C.S. Millard, J. Frank, and M. Donnelly. April 2002. Production of lactic acid from lignocellulosic hydrolysates by Escherichia coli mutants. $24^{\text {th }}$ Symposium on Biotechnology for Fuels and Chemicals, Gatlinburg, Tennessee (Poster Presentation No. 2-24).

Kim, Jae-Han, David A Mills, David E. Block, Sharon P. Shoemaker. April-May 2002. Simultaneous conversion of hexose and pentose sugars to lactic acid by Lactobacillus brevis. $24^{\text {th }}$ Symposium on Biotechnology for Fuels and Chemicals, Gatlinburg, Tennessee.

Kim, Jae-Han, David A Mills, David E. Block, Sharon P. Shoemaker. May 2001. Simultaneous conversion of hexose and pentose sugars to lactic acid by Lactobacillus brevis. Eleventh Annual UC Davis Biotechnology Retreat. Napa, California.

Kim, Jae-Han, S. P. Shoemaker, and D. A. Mills. May 2002. Atypical carbohydrate utilization by Lactobacillus brevis. General Meeting of the American Society for Microbiology, Salt Lake City, Utah.

Kim, Jae-Han, David A.; Block, David E.; Shoemaker, Sharon P. March 2003. Lack of catabolite repression in a lactic acid bacterium: A new opportunity for maximizing efficiency of biomass utilization. $225^{\text {th }}$ ACS National Meeting, New Orleans, Louisiana.

Kim, Jae-Han, David A. Mills, David, E. Block, Sharon P. Shoemaker. May 2003. Strain development for the complete utilization of mixed carbohydrates in lignocellulosic biomass. $25^{\text {th }}$ Symposium on Biotechnology for Fuel and Chemicals, Breckenridge, CO. 


\section{References}

Barre, P., Identification of Thermobacteria and Homofermentative Thermophilic, Pentose Utilizing Lactobacilli from High-Temperature Fermenting Grape Musts, J. Appl. Bacteriol. 44:125-129 (1978).

Datta, R., et al., Technological and Economic Potential of Poly(Lactic Acid) and Lactic Acid Derivatives, in FEMS Microbiology Reviews 16:221-231 (1995).

Datta, R., and S.P. Tsai, U.S. Patent 5,723,639, assigned to Argonne National Laboratory (March 3, 1998).

Hamilton, I.R. and E. J. St.Martin, Evidence for the Involvement of Proton Motive Force in the Transport of Glucose by a Mutant of Streptococcus Mutans Strain DR0001 Defective in Glucose-Phosphoenolpyruvate Phosphotransferase Activity, Infect. Immun., 36:567-575. (1982).

Lynd, L.R., P.J. Weimer, W.H. van Zyl, and I.S. Pretorius, Microbial Cellulose Utilization:

Fundamentals and Biotechnology. Microbiol. and Molec. Biol. Reviews. 66:506-577 (2002).

Mills, D. A. 2004. The lactic acid bacteria genome project. Journal of Food Science, 69 FMS2830.

Saier, M.H., Mechanisms of Regulation of Carbohydrate Transport in Bacteria, Academic Press, Orlando, FL, USA, (1985).

Shane Gold, R., et al., Ethanol Tolerance and Carbohydrate Metabolism in Lactobacilli, J. Industrial. Microbiol., 10:45-54 (1992).

Sheehan, J., and M. Himmel, Enzymes, Energy, and the Environment: A Strategic Perspective on the U.S. Department of Energy's Research and Development Activities for Bioethanol. Biotechnol. Prog., 15, 817-827 (1999)

Tsai, S.P. and S.-H. Moon, An Integrated Bioconversion Process for the Production of L Lactic Acid from Starchy Potato Feedstocks, Applied Biochemistry and Biotechnology, 70 72:417-428 (1998).

Wood, A. with A. Scott, Bioprocessing: Reaping the Benefits of Renewable Resources. Chem. Week, 15-17 (February 11, 2004) 


\section{Glossary}

ANL, Argonne National Laboratory

BCI, BC International

ETLA, Ethyl lactate

3 E, energy, economic and environmental

NREL, National Renewable Energy Laboratory

SHF, Sequential hydrolysis and fermentation

SHMSF, Sequential hydrolysis and mixed sugar fermentation

SSF, Simultaneous saccharification and fermentation

SSMSF, Simultaneous saccharification and mixed sugar fermentation

\section{Appendix A.}

